\title{
SUPPORTING IMFORMATION
}

\section{One-pot Synthesis of 3-Fluoro-4-(trifluoromethyl)- quinolines from Pentafluoropropen-2-ol and}

\section{Their Molecular Modification}

Tsuyoshi Hosokawa, Akemi Matsumura, Toshimasa Katagiri, Kenji Uneyama*

Department of Applied Chemistry, Faculty of Engineering, Okayama University,

3-1-1 Tsushimanaka, Okayama 700-8530, Japan

Page

General

S2-S2

References

S2-S2

X-ray Crystallographic Data

S3-S3

Copies of IR, ${ }^{1} \mathrm{H},{ }^{19} \mathrm{~F}$ and ${ }^{13} \mathrm{C}$ NMR spectra

S4-S78 
General. ${ }^{1} \mathrm{H},{ }^{19} \mathrm{~F}$, and ${ }^{13} \mathrm{C}$ NMR spectra were recorded at 600,564 , and $151 \mathrm{MHz}$ by a Varian Unity INOVA AS600 instrument, respectively. The chemical shifts are reported in $\delta(\mathrm{ppm})$ relative to $\mathrm{CHCl}_{3}$ $\left(\delta 7.26\right.$ ppm for ${ }^{1} \mathrm{H}$ NMR in $\left.\mathrm{CDCl}_{3}\right), \mathrm{C}_{6} \mathrm{~F}_{6}\left(\delta 0.00 \mathrm{ppm}\right.$ for ${ }^{19} \mathrm{~F} \mathrm{NMR}$ in $\left.\mathrm{CDCl}_{3}\right)$ and $\mathrm{CHCl}_{3}(\delta 77.0 \mathrm{ppm}$ for ${ }^{13} \mathrm{C} \mathrm{NMR}$ in $\mathrm{CDCl}_{3}$ ) as internal standards. Coupling constants $(J)$ are reported in hertz $(\mathrm{Hz})$. IR spectra were recorded in $\mathrm{cm}^{-1}$ on a Hitachi Model 270-30 Infrared Spectrometer. For elemental analyses, a Perkin-Elmer series II CHNS/O Analyzer 2400 was employed. GC/MS analyses were performed on a Shimadzu GCMS-QP5050A. Single crystal X-ray diffraction data were collected on a Rigaku R-AXIS IV imaging plate diffractometer using graphite-monochromated Mo-K $\alpha$ radiation $[\lambda=0.71073 \AA]$. The structures were solved by direct methods $\left[\operatorname{SIR} 97^{1}\right]$ and were refined by full-matrix least-squares calculations on $F$ using teXsan package program ${ }^{2}$. Melting points were analyzed by a Yanako MP-S3 melting point measurement apparatus and uncorrected.

All air or moisture sensitive reactions were carried out under argon atmospheres with dry, freshly distilled solvents using a standard syringe-septa technique. DMF, NMP and toluene were distilled from $\mathrm{CaH}_{2}$. After separation of silyl enol ether 2 from DMF solution by distillation, DMF was distilled in the presence of $\mathrm{P}_{2} \mathrm{O}_{5}$ and $\mathrm{NaOH}$ and reused for the preparation of 2. EtOH was distilled from $\mathrm{Mg}$ activated by $\mathrm{I}_{2}$. DCM was distilled from $\mathrm{P}_{2} \mathrm{O}_{5}$. TMSCl and TFA were distilled prior to use.

\section{References}

1. SIR97, Altomare, A.; Burla, M. C.; Camalli, M.; Cascarano, G. L.; Giacovazzo, C.; Guagliardi, A.; Moliterni, A. G. G.; Polidori, G.; Spagna, R. J. Appl. Cryst., 1999, 32, 115-119.

2. teXsan, Single Crystal Structure Analysis Software. Version 1.11, Molecular Structure Corporation, Rigaku Corporation, 2000. 
cis-3,3-Difluoro-6-methoxy-2-phenyl-4-(trifluoromethyl)-1,2,3,4-tetrahydroquinolin-4-ol (8a)

X-ray for $\mathrm{C}_{17} \mathrm{H}_{14} \mathrm{~F}_{5} \mathrm{NO}_{2}$ (CCDC 660771), $M=359.30$, monoclinic, $\mathrm{P} 2{ }_{1} / \mathrm{n}(\# 14), a=10.455(1), b=$ 14.183(3), $c=11.467(3) \AA, \beta=107.785(8)^{\circ}, Z=4, D_{\text {calc }}=1.474 \mathrm{~g} / \mathrm{cm}^{3}, 3432$ unique reflections, 2816 with $I>2 \sigma(I), R_{I}=0.067, R_{w}=0.126,240$ parameters.

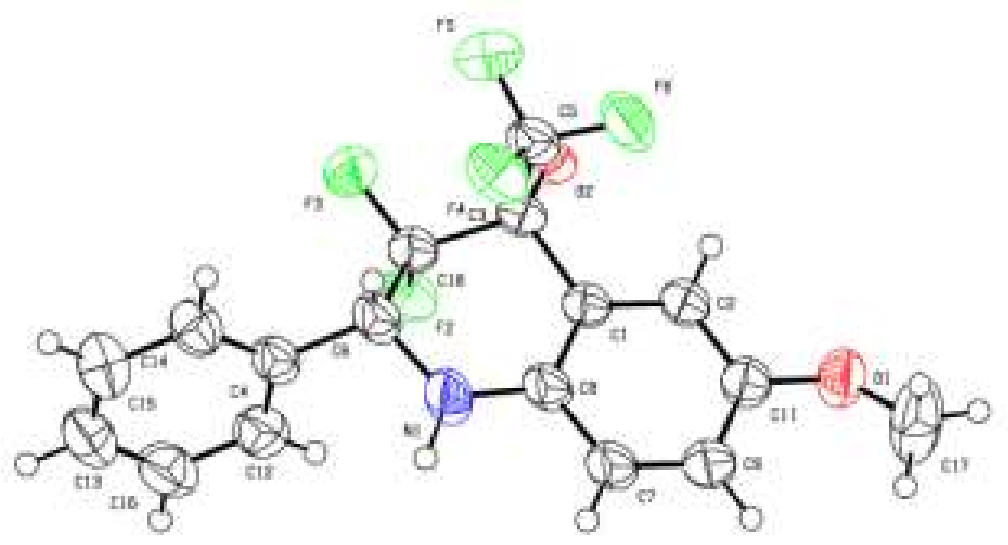

\section{3-Fluoro-6-methoxy-2-phenyl-4-(trifluoromethyl)quinoline (5a)}

X-ray for $\mathrm{C}_{17} \mathrm{H}_{11} \mathrm{~F}_{4} \mathrm{NO}$ (CCDC 660770), $\mathrm{M}=321.27$, monoclinic, $\mathrm{P} 2_{1} / \mathrm{a}$ (\#14), $a=7.4092(6), b=$ 18.552(2), $c=10.841(1) \AA, \beta=107.867(8)^{\circ}, Z=4, \mathrm{D}_{\text {calc }}=1.505 \mathrm{~g} / \mathrm{cm}^{3}, 3056$ unique reflections, 2118 with $\mathrm{I}>5 \sigma(\mathrm{I}), \mathrm{R}_{1}=0.079, \mathrm{R}_{\mathrm{w}}=0.119,219$ parameters.

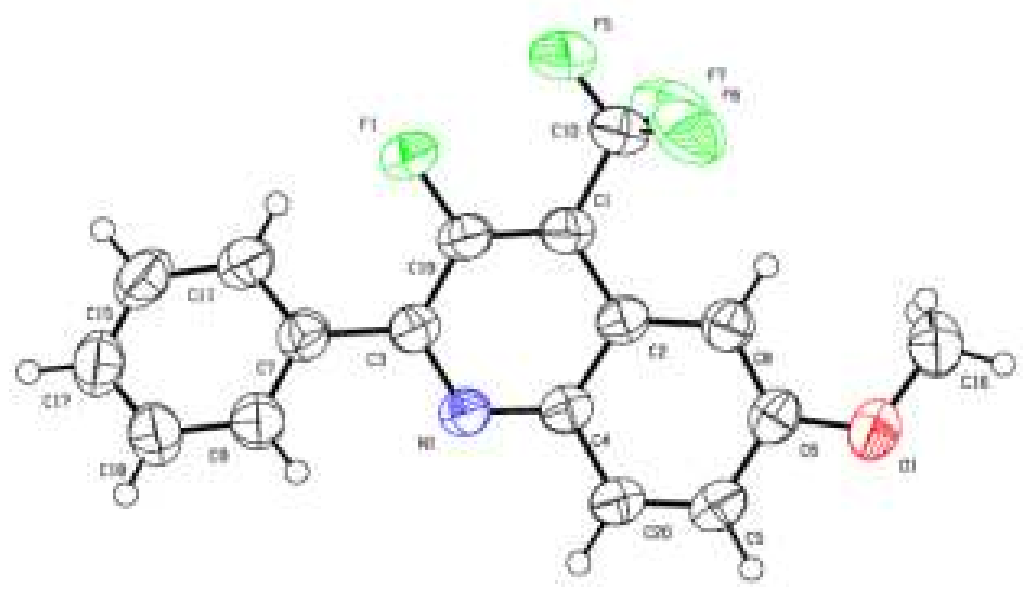



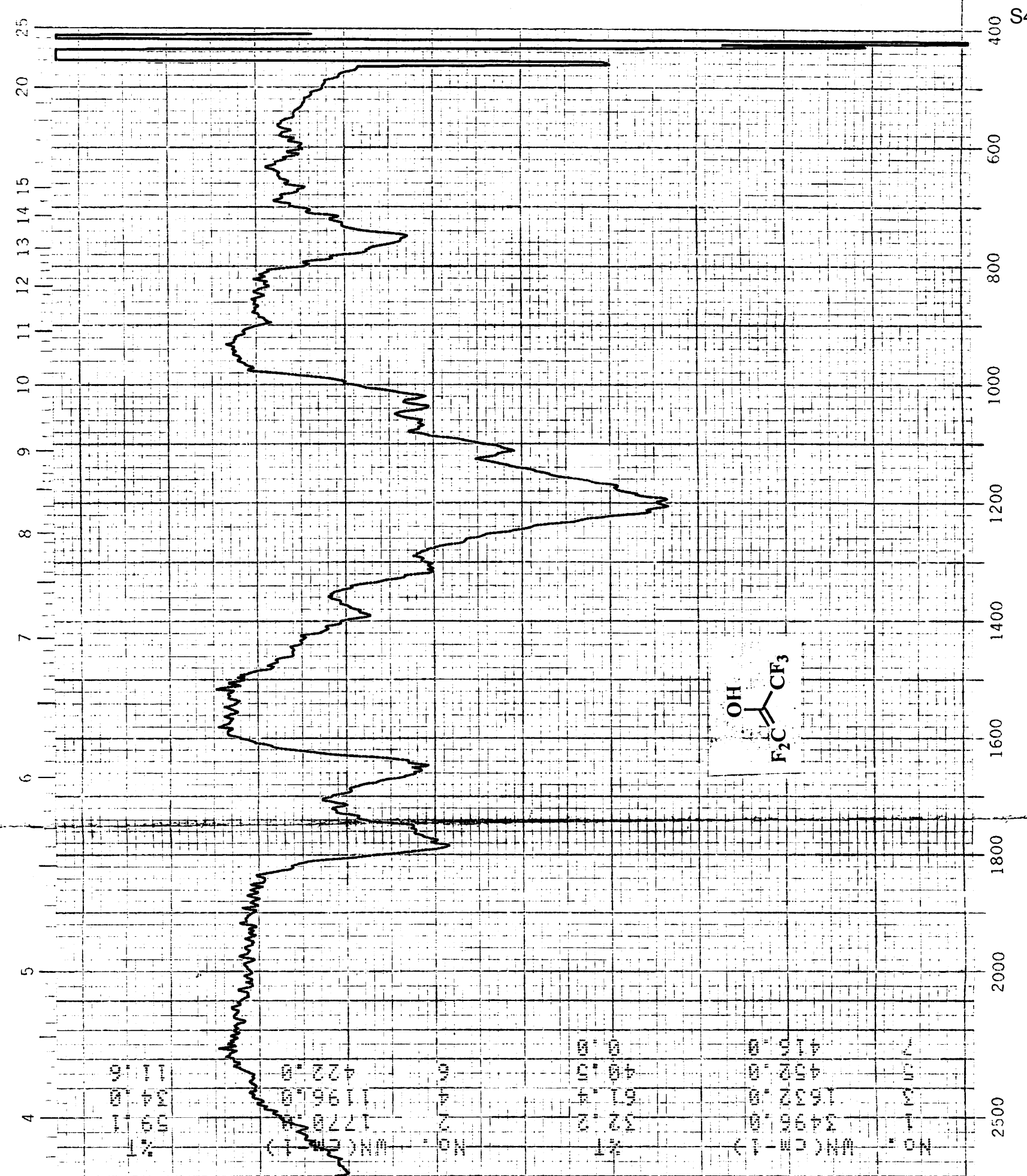

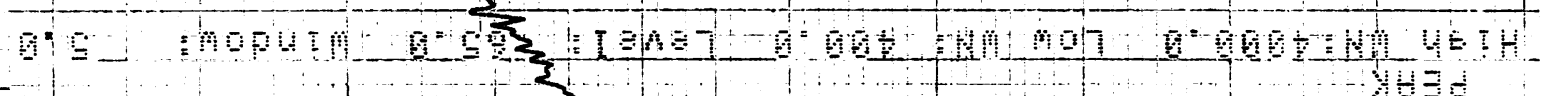

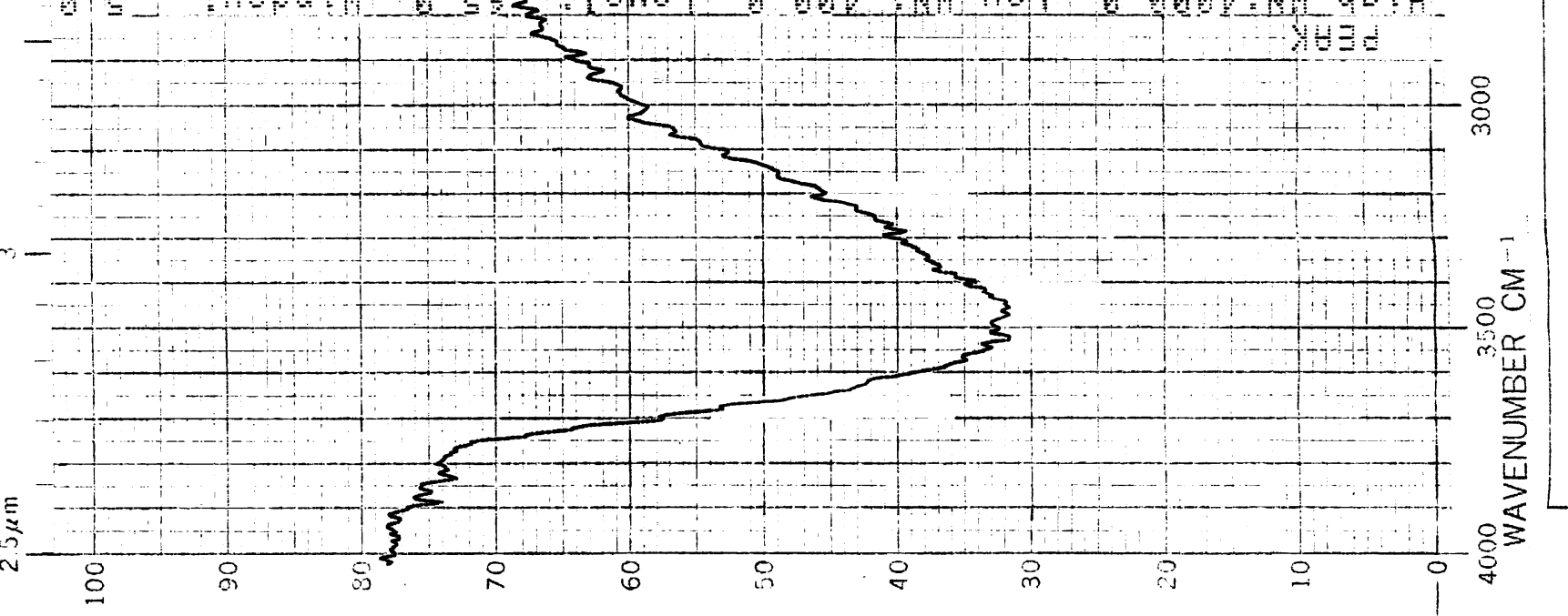




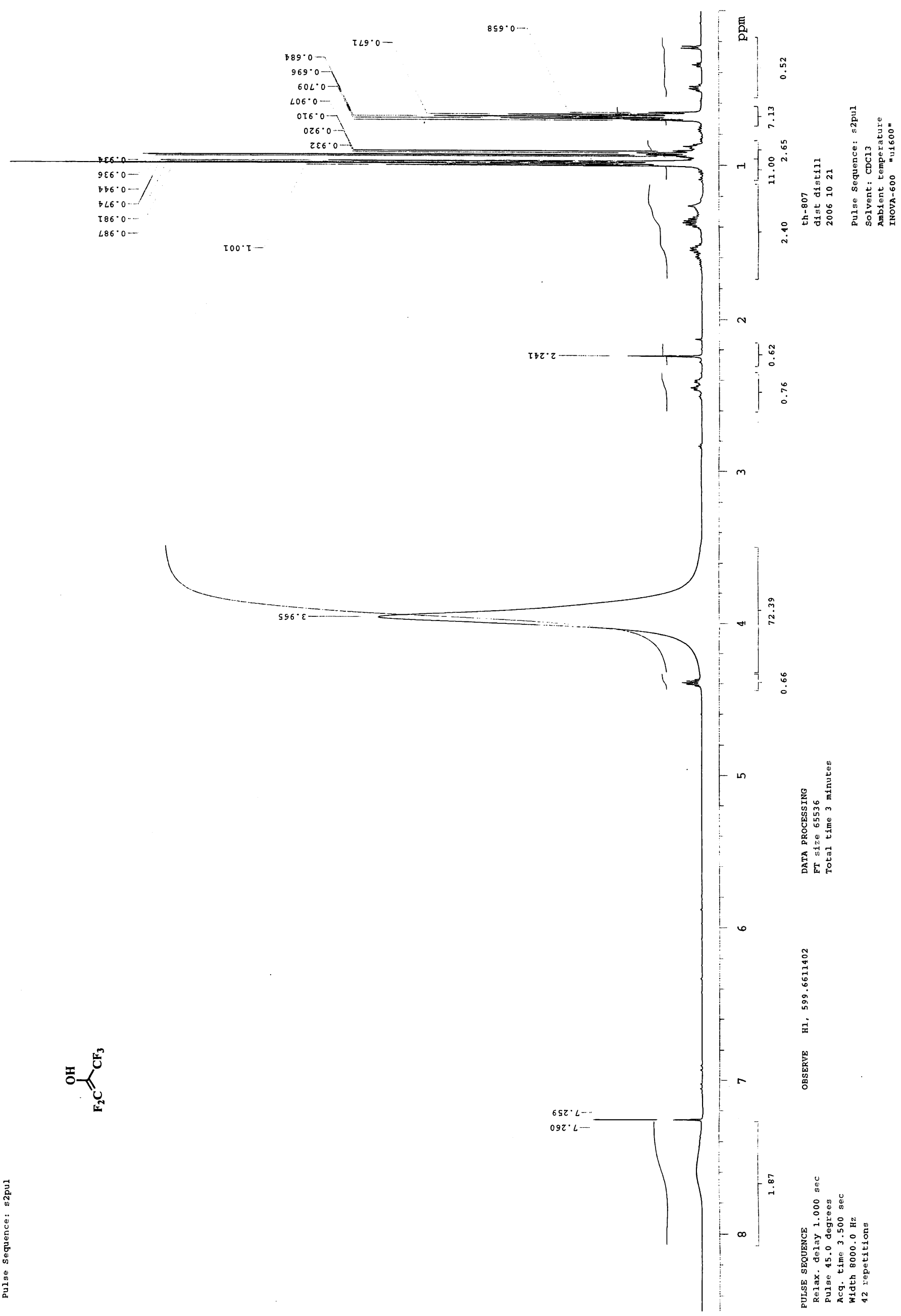




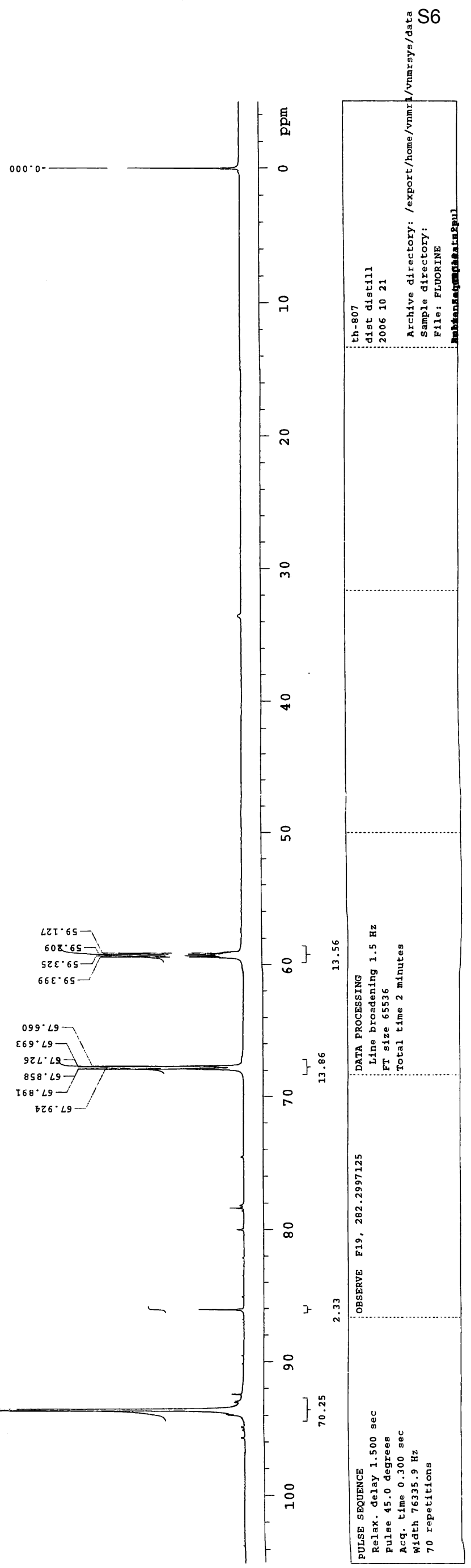




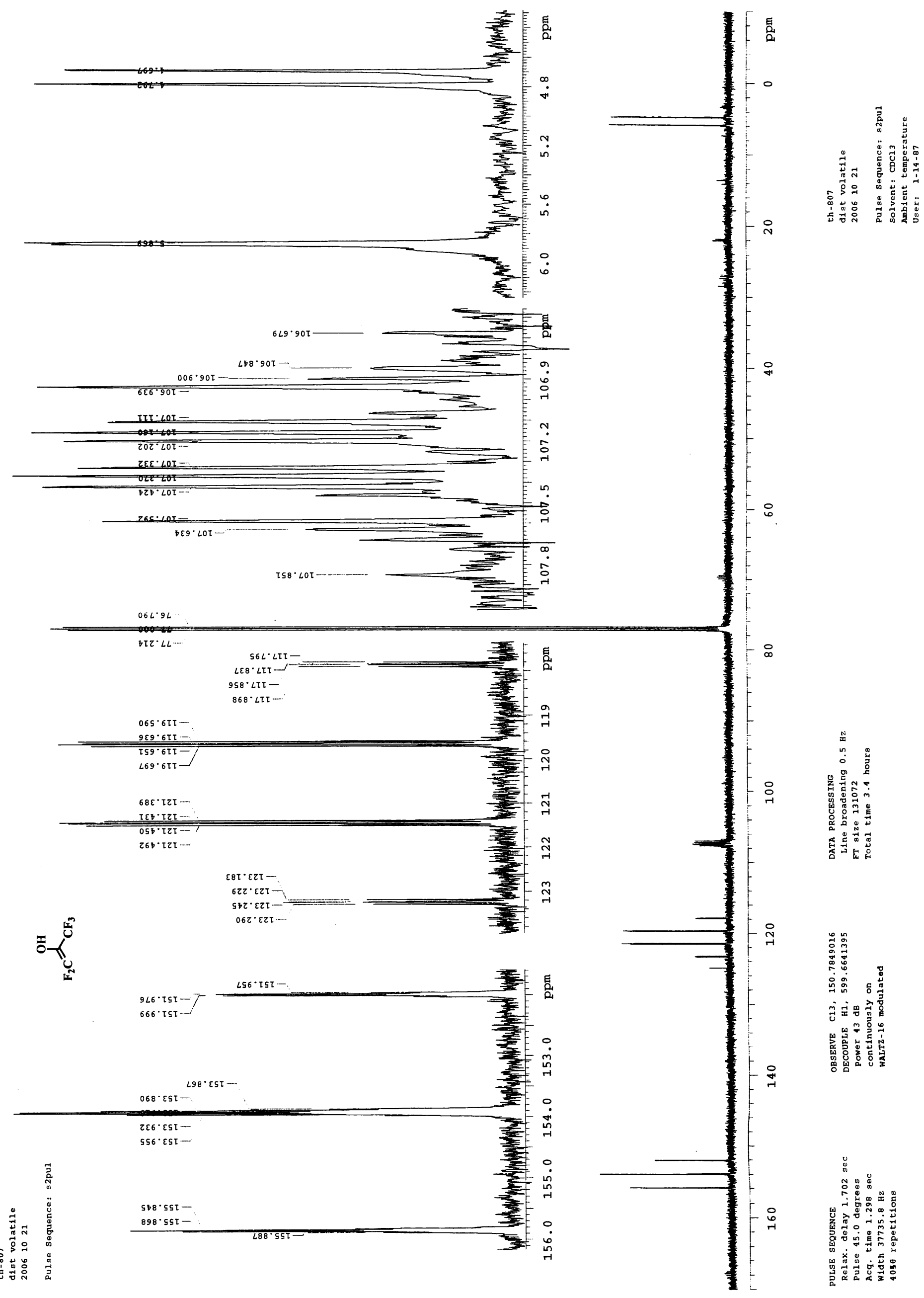



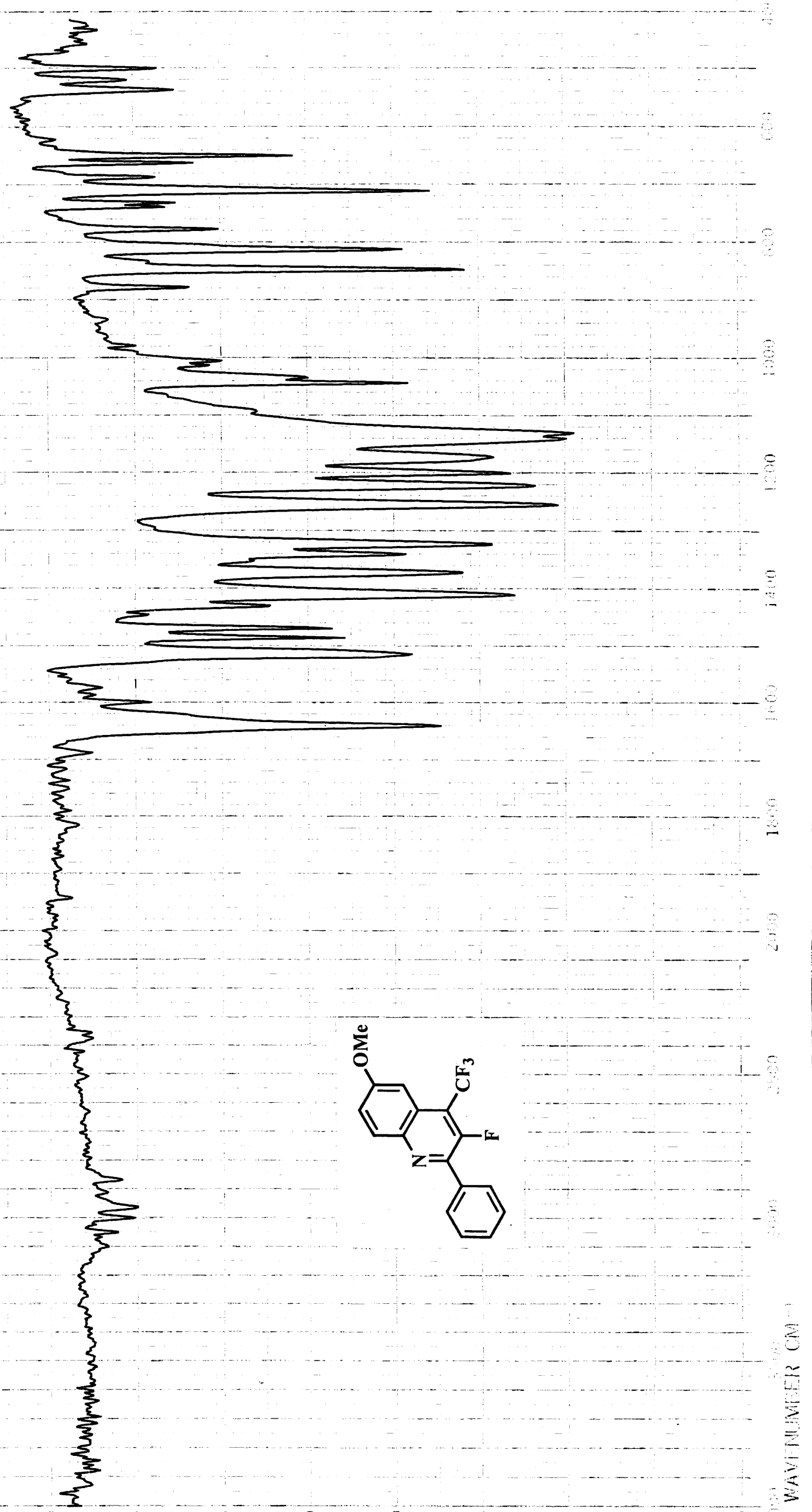


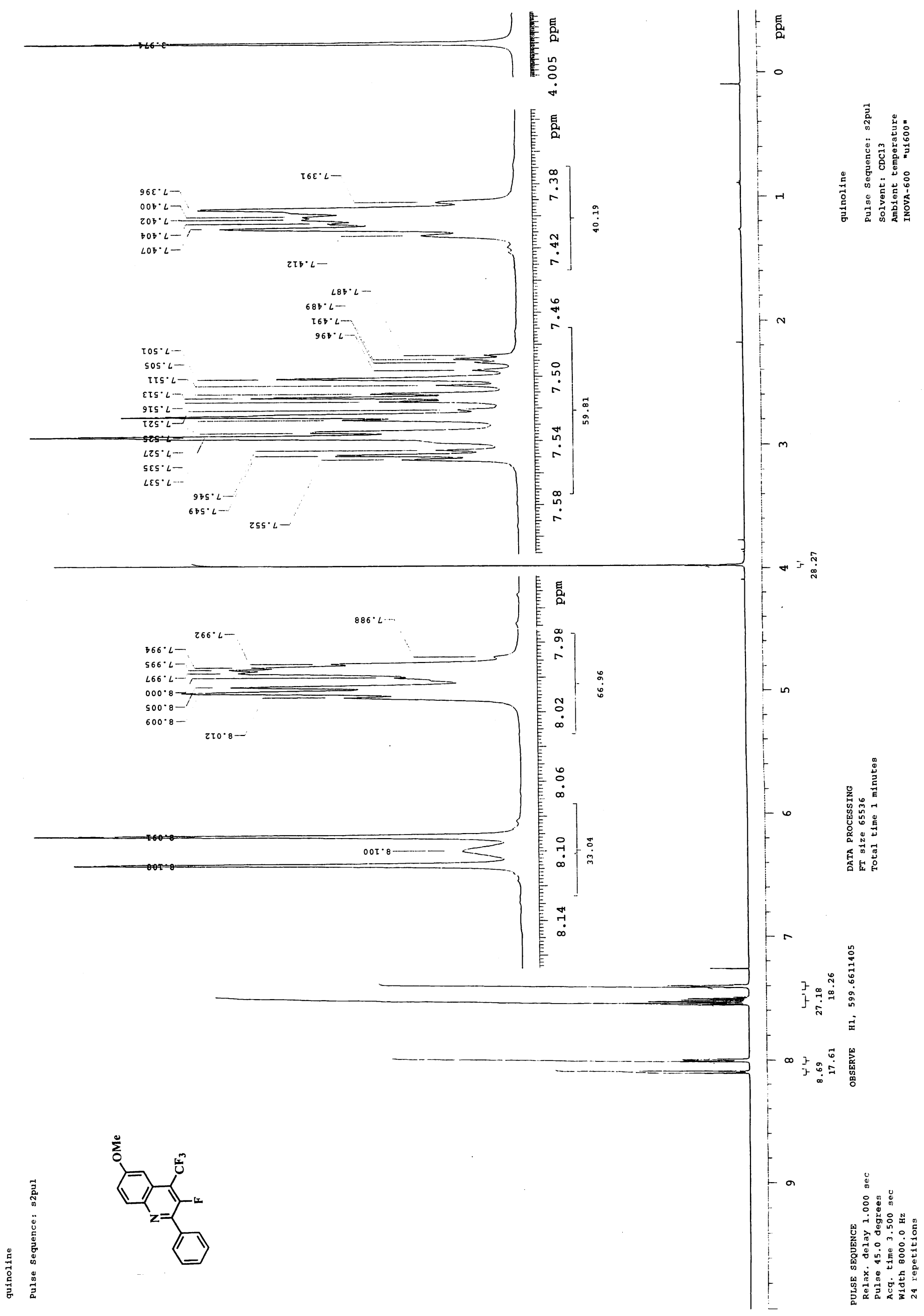




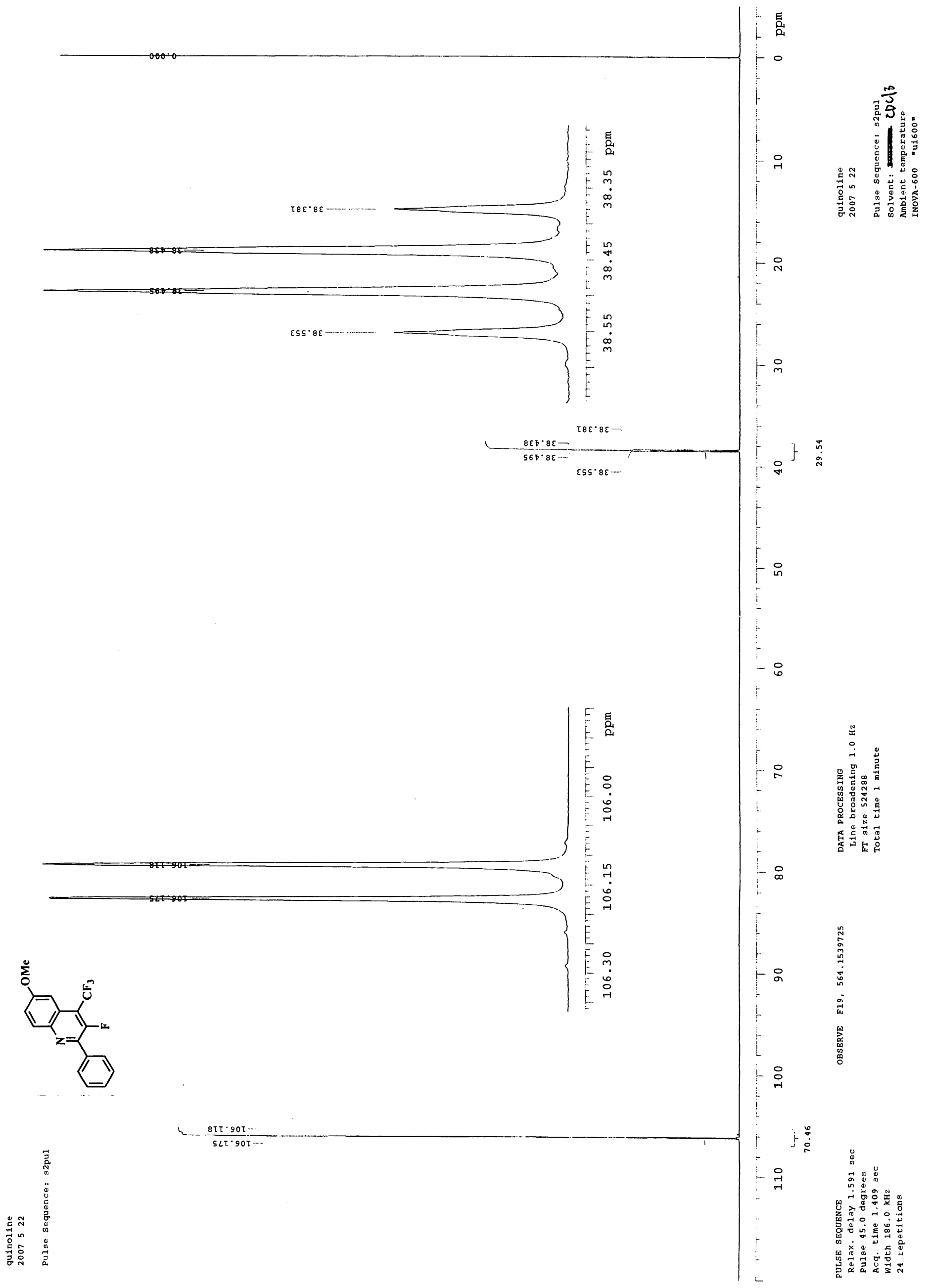




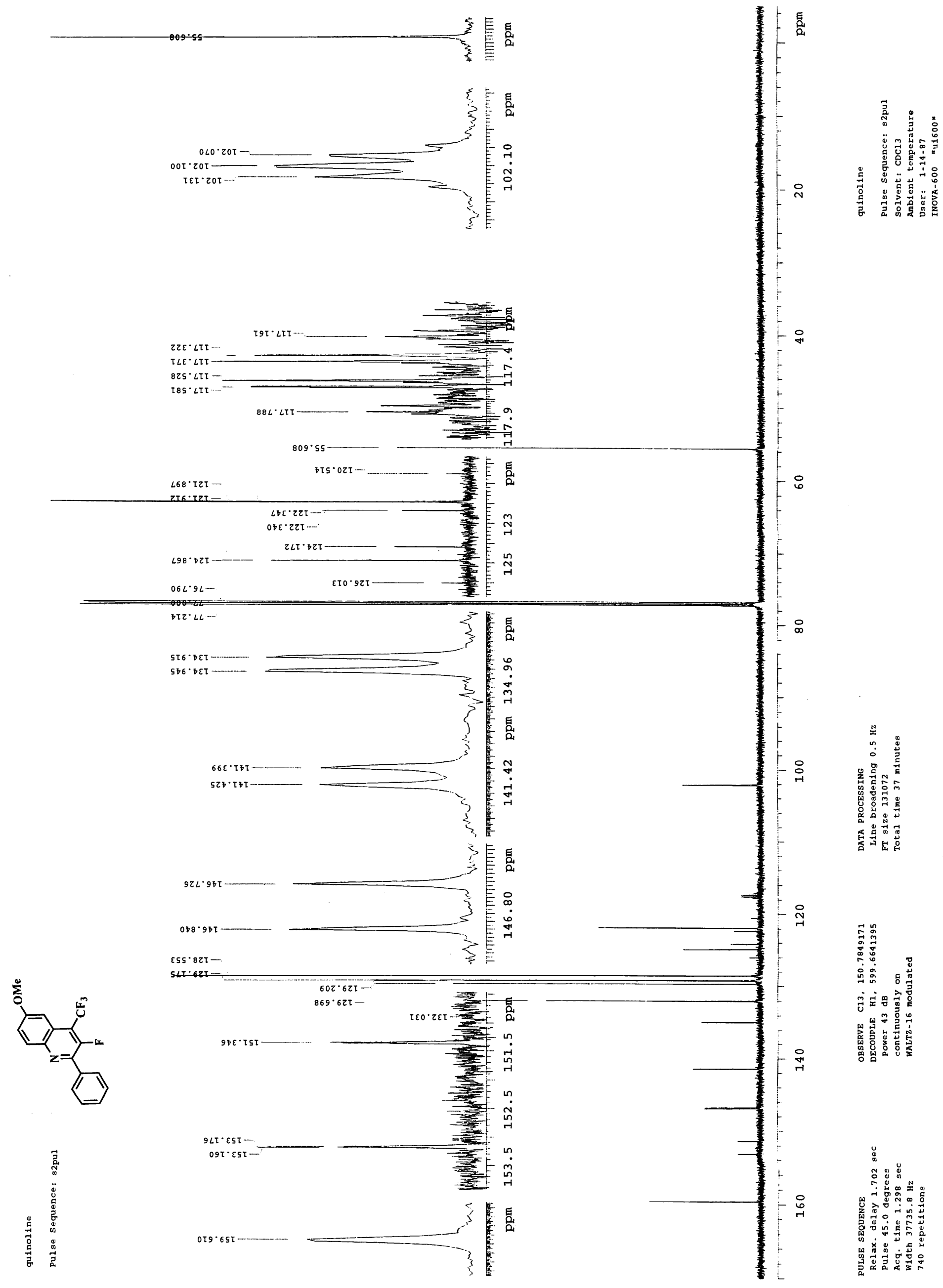


$5 b$

S12 


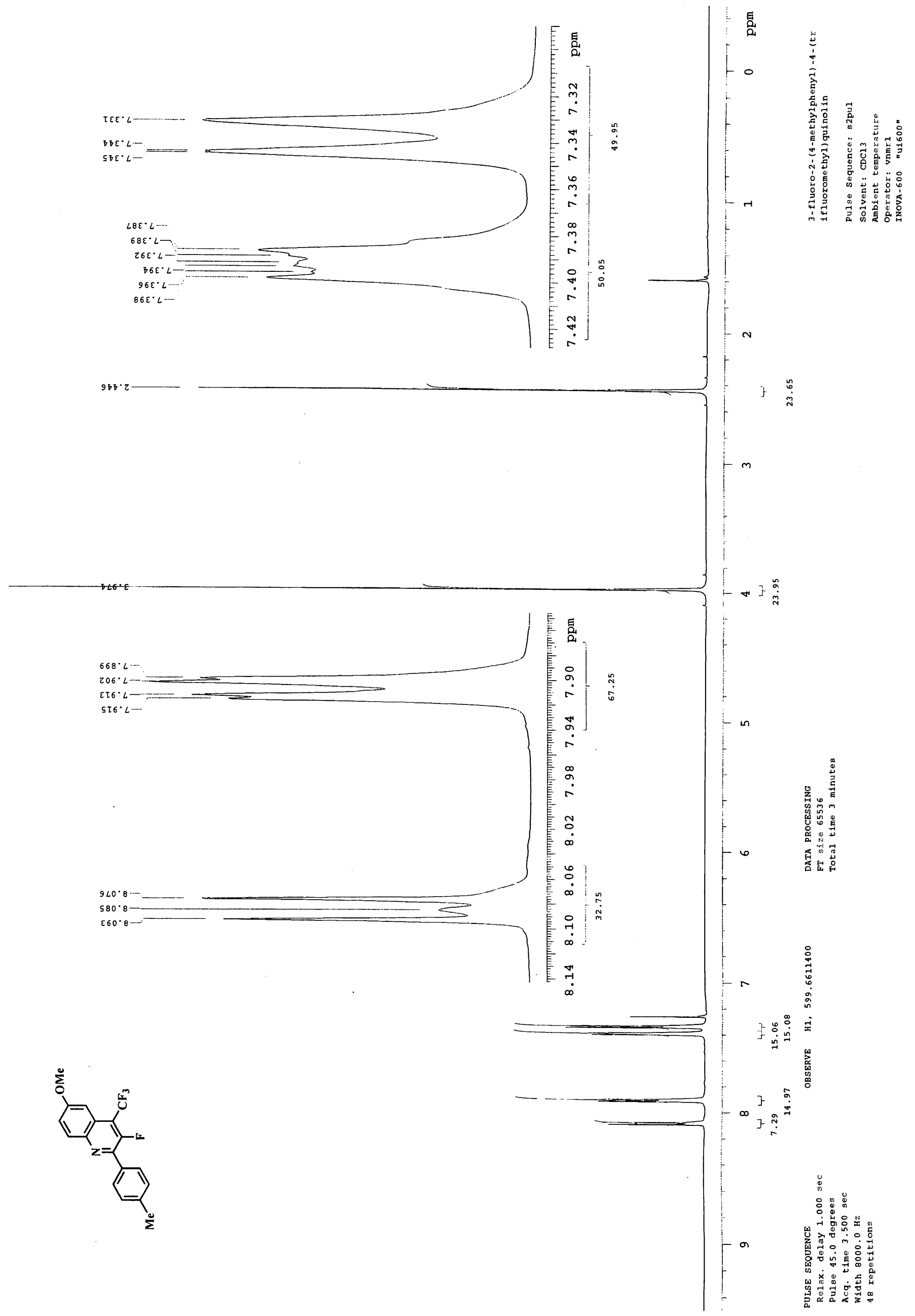




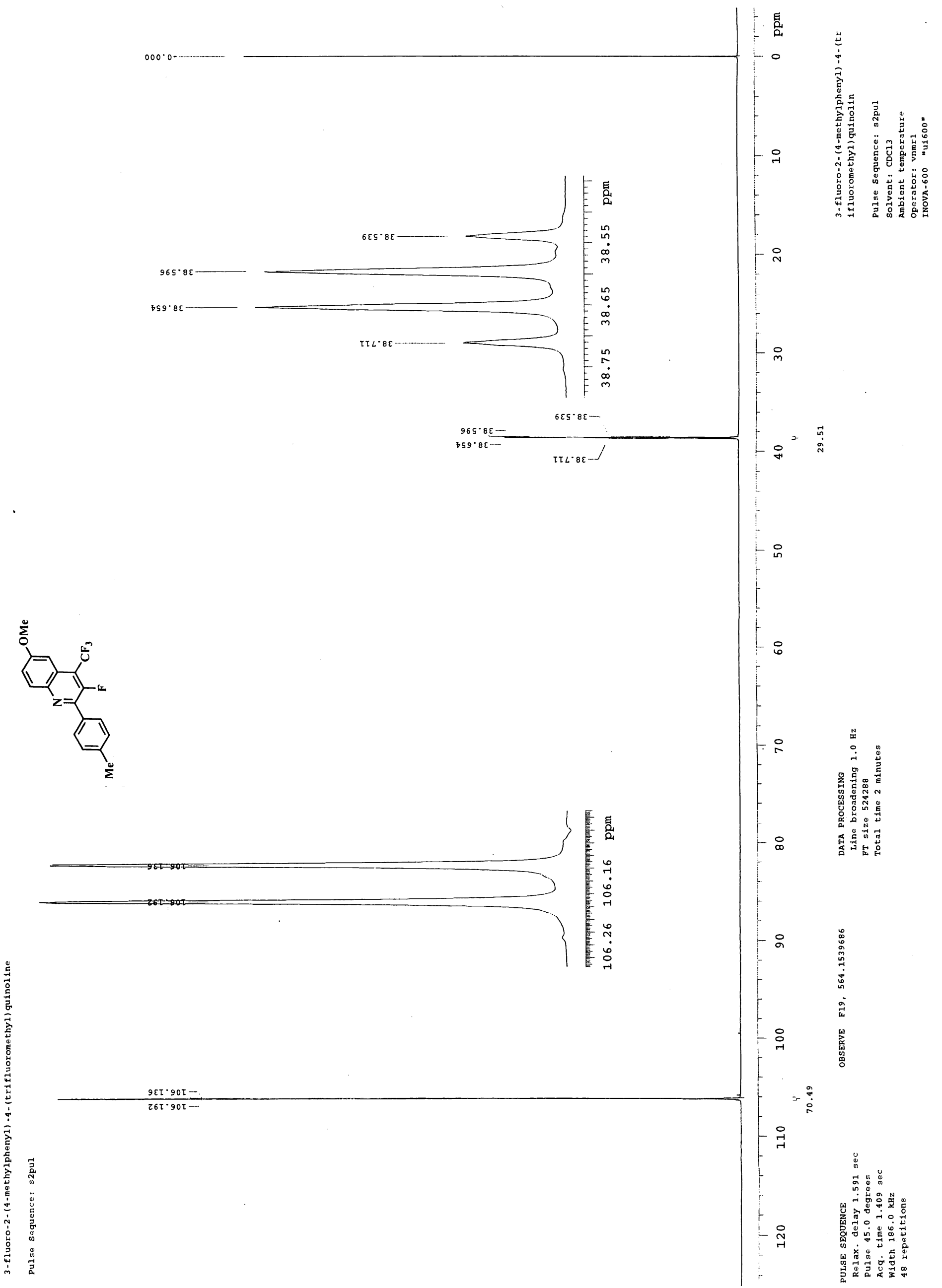



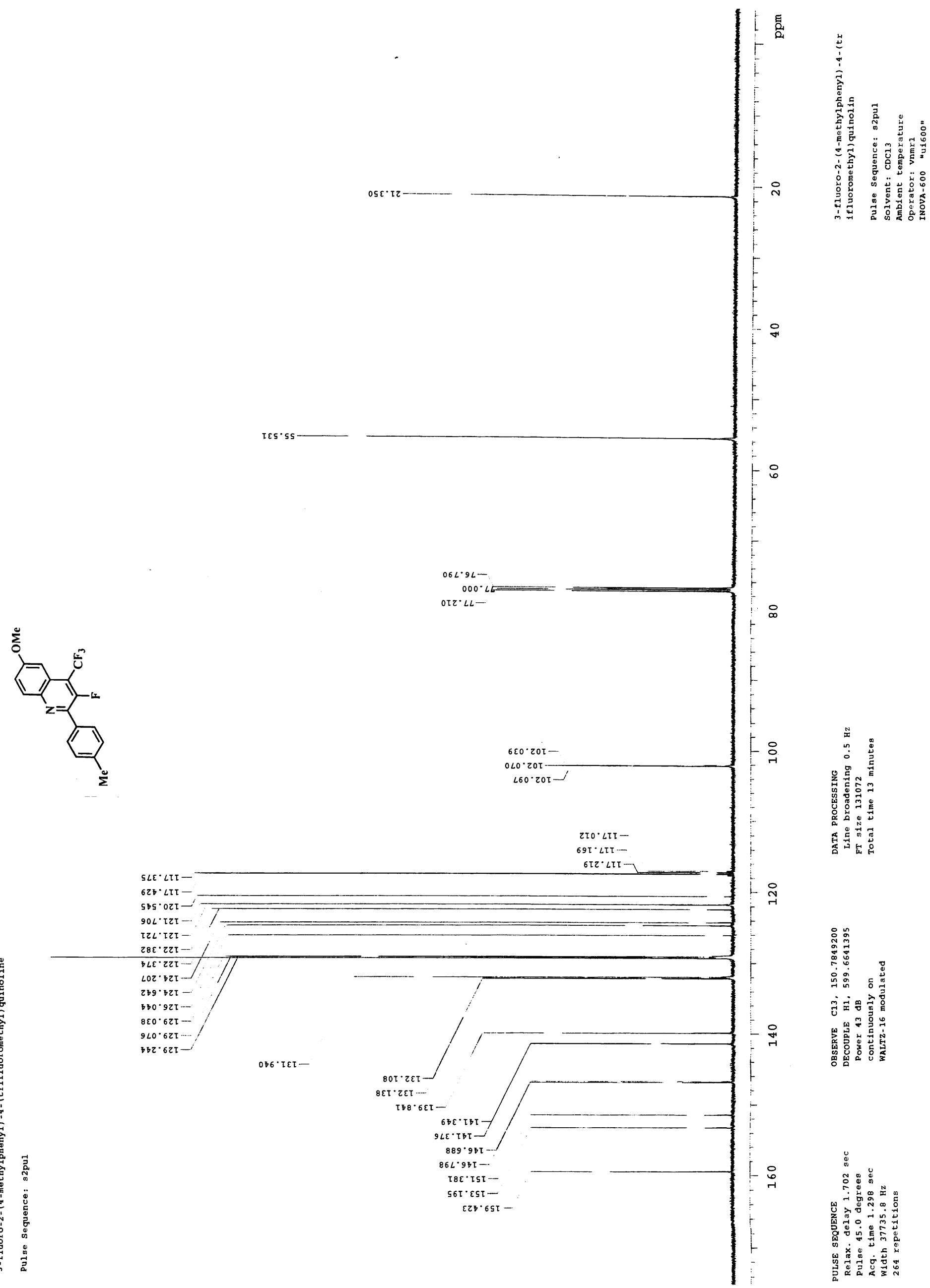

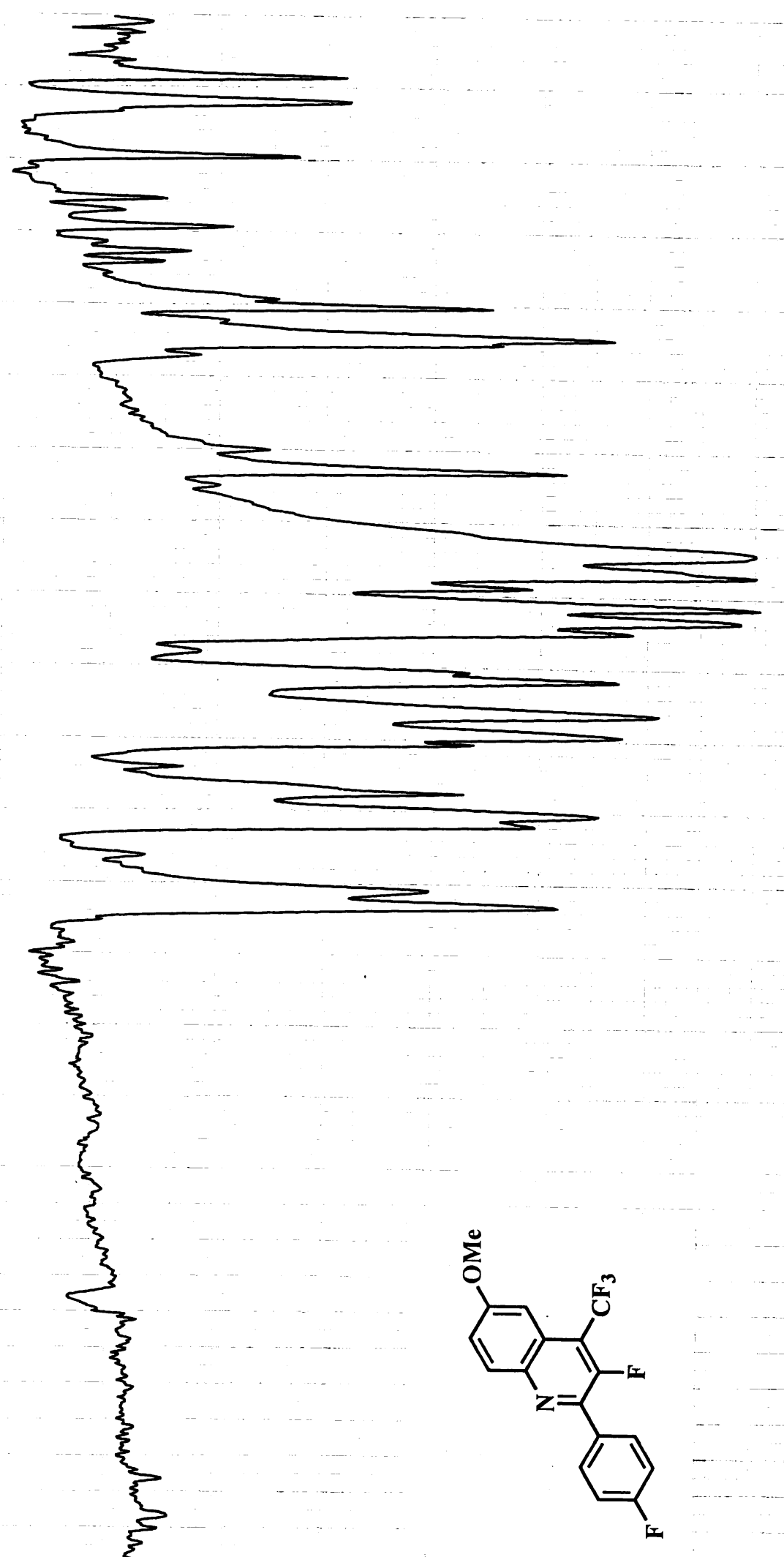


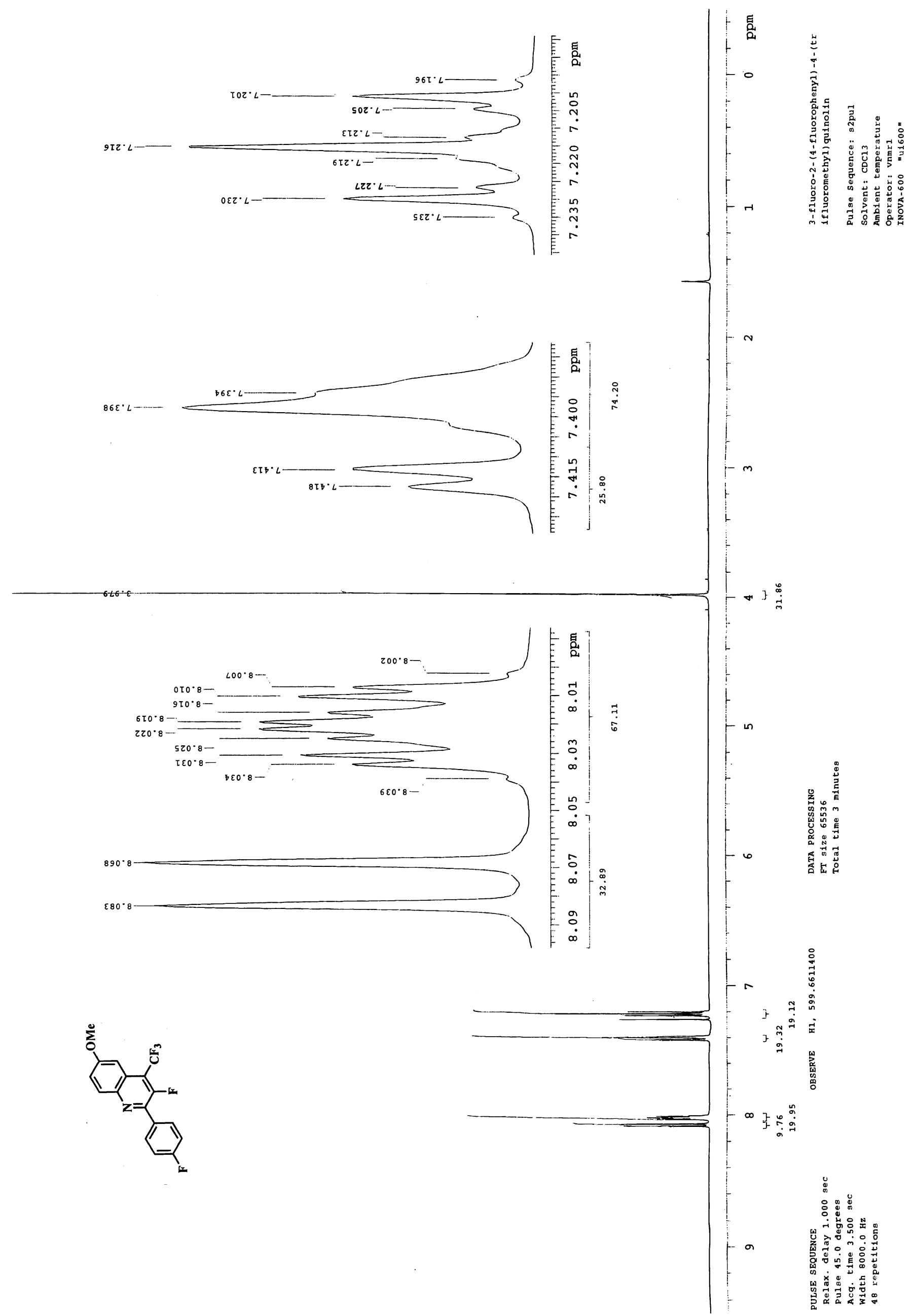




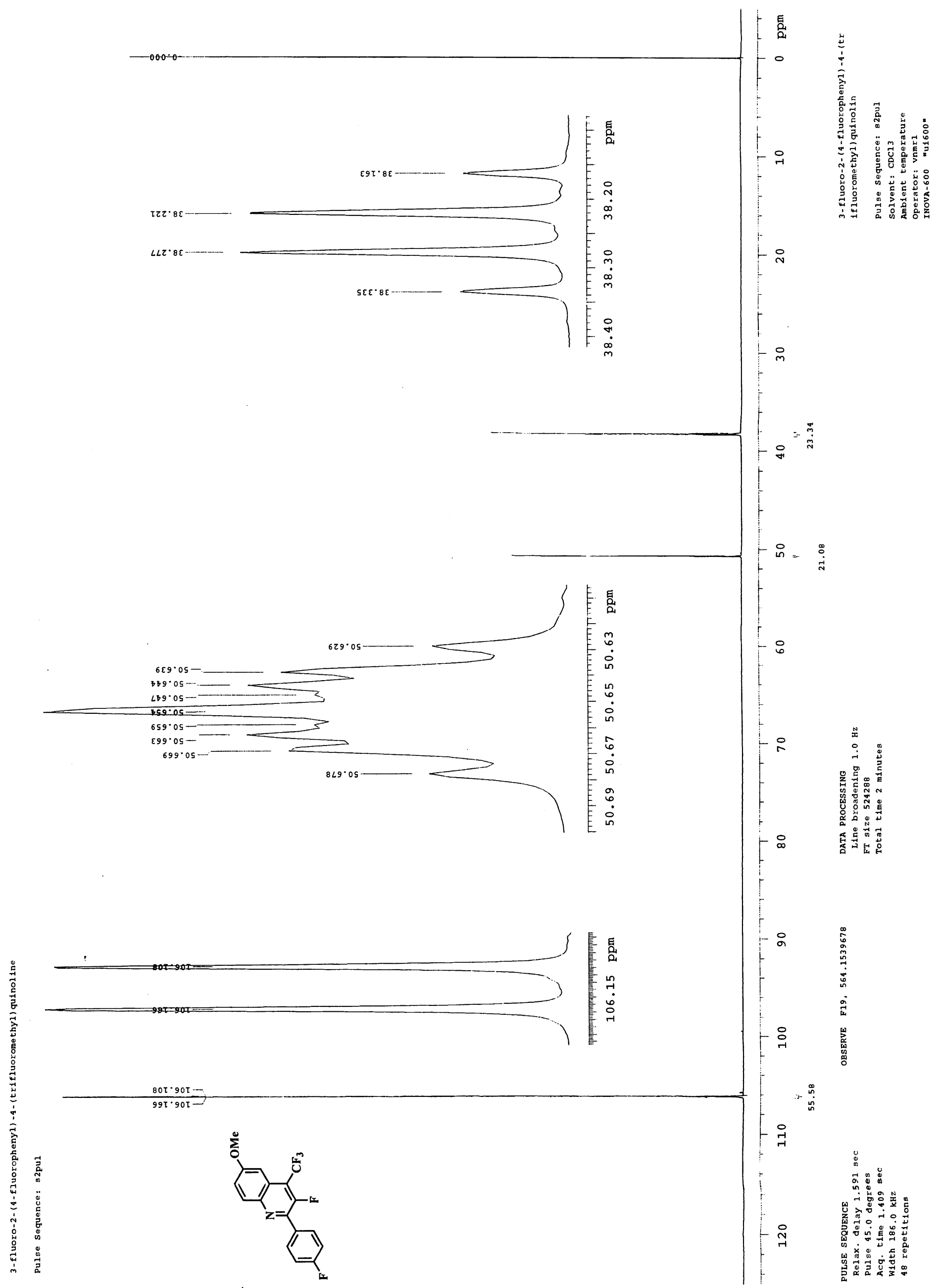




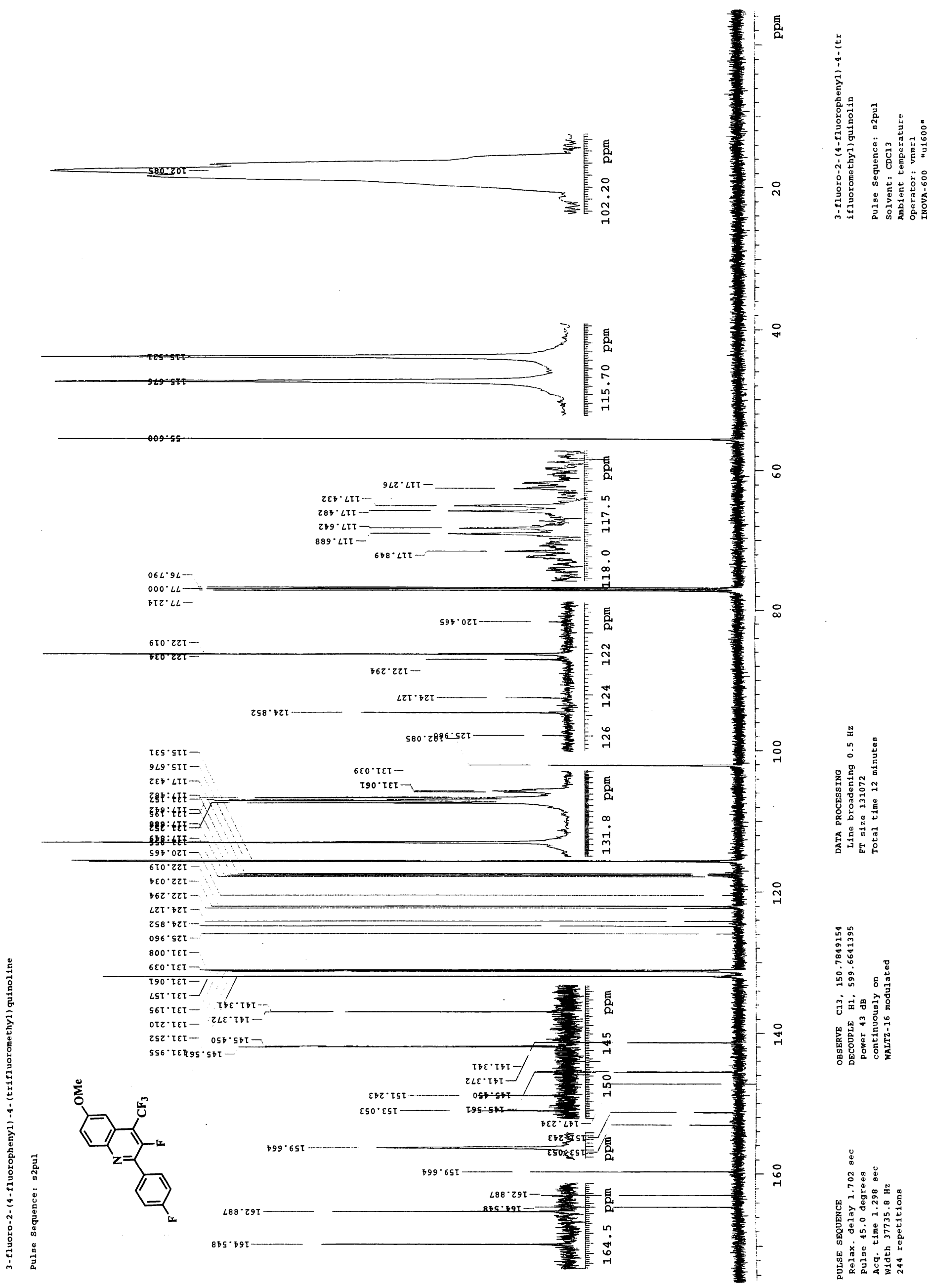



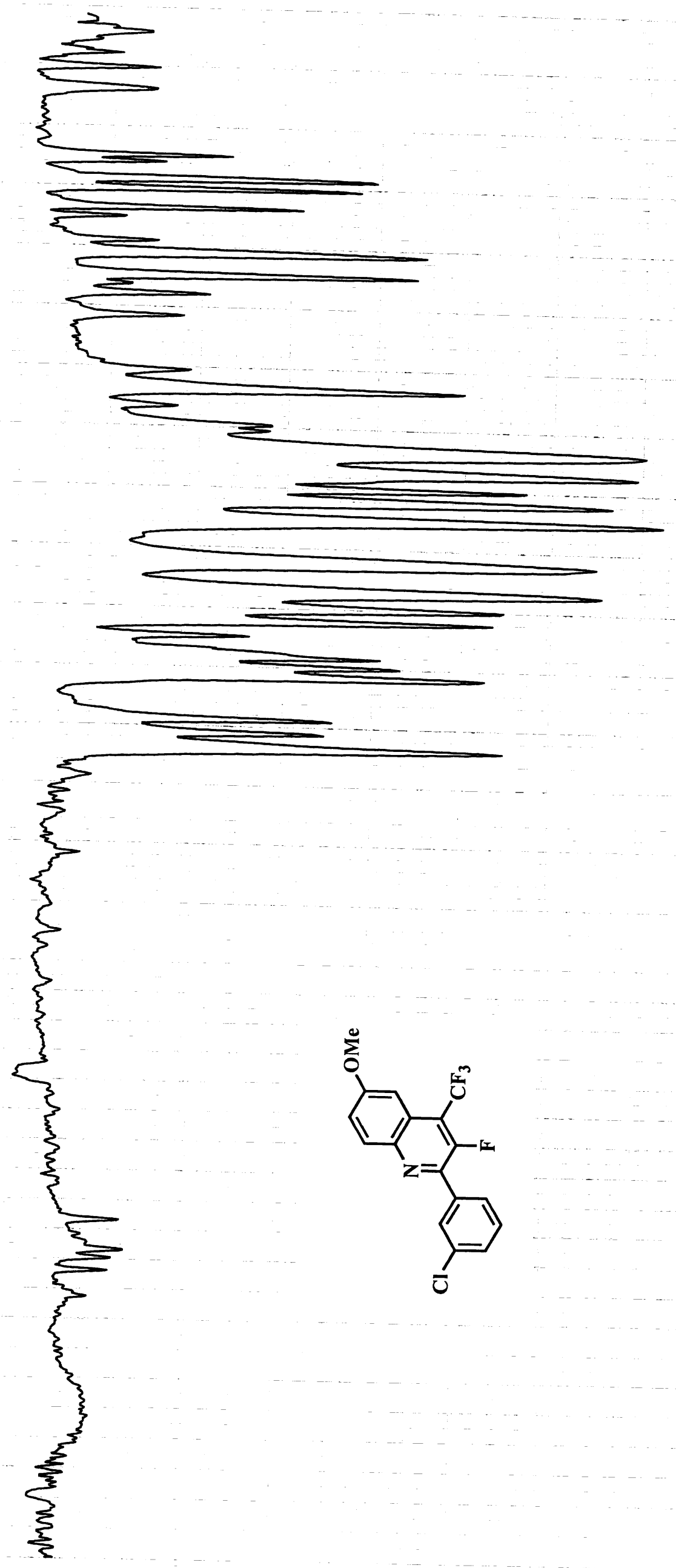


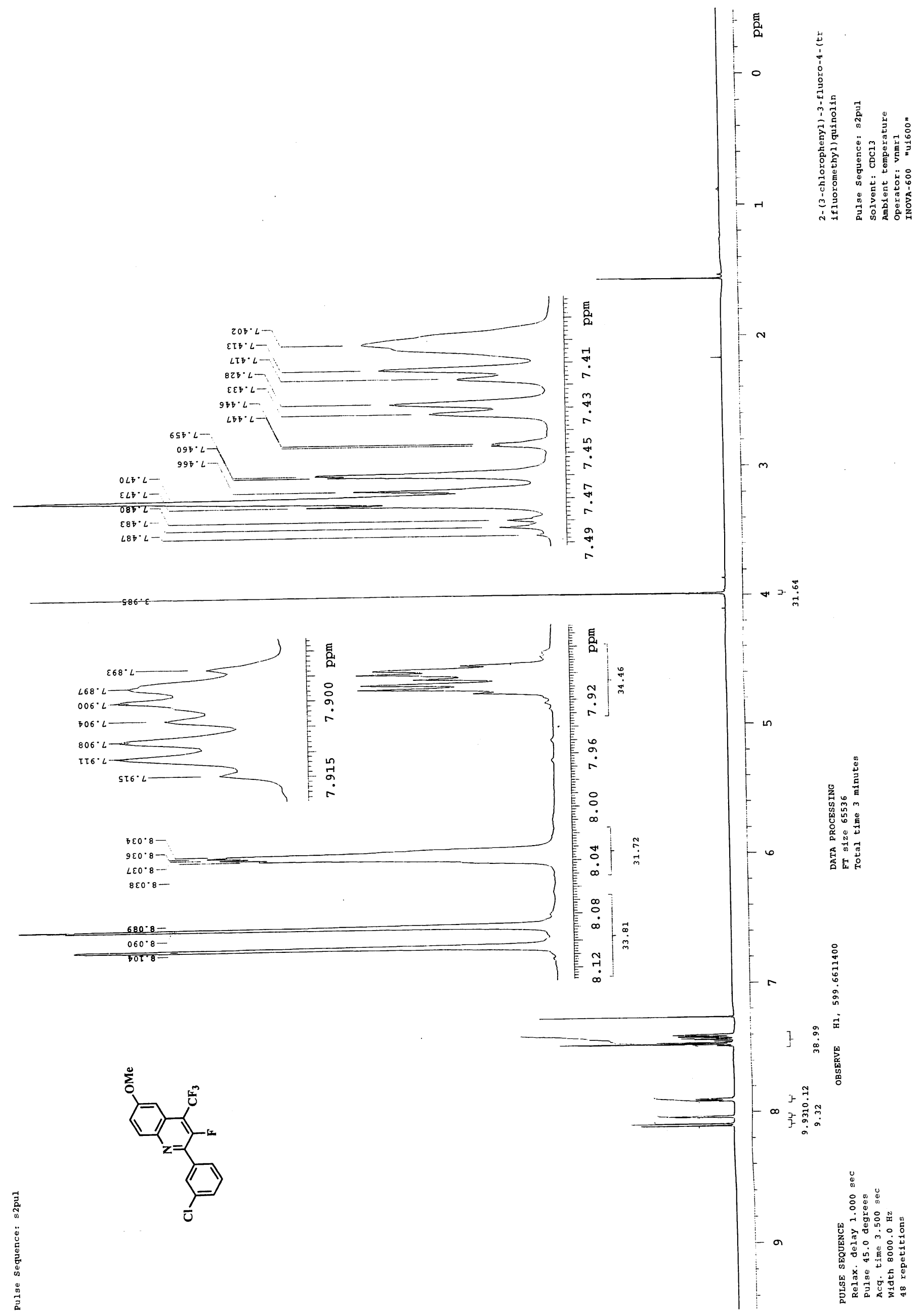




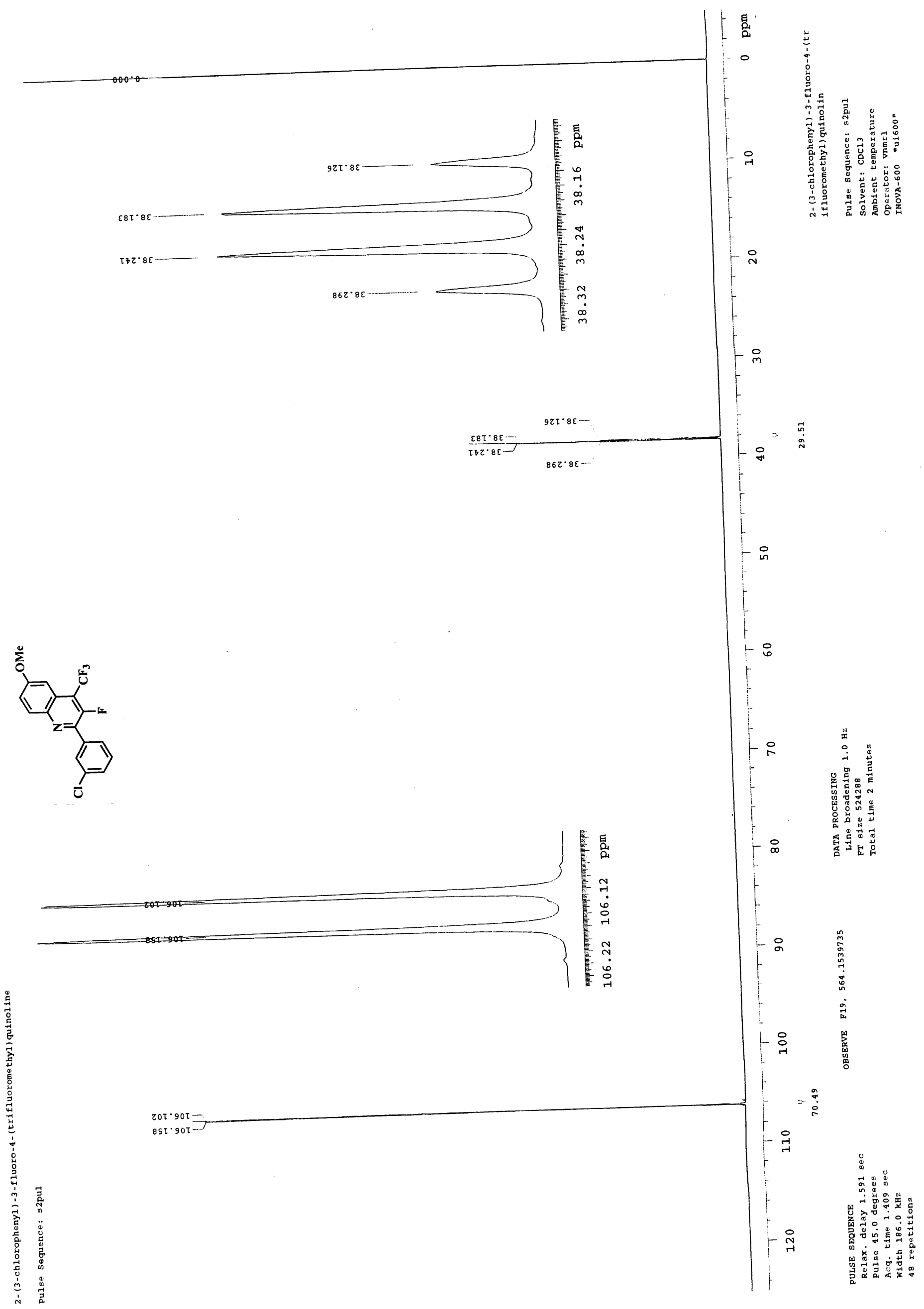




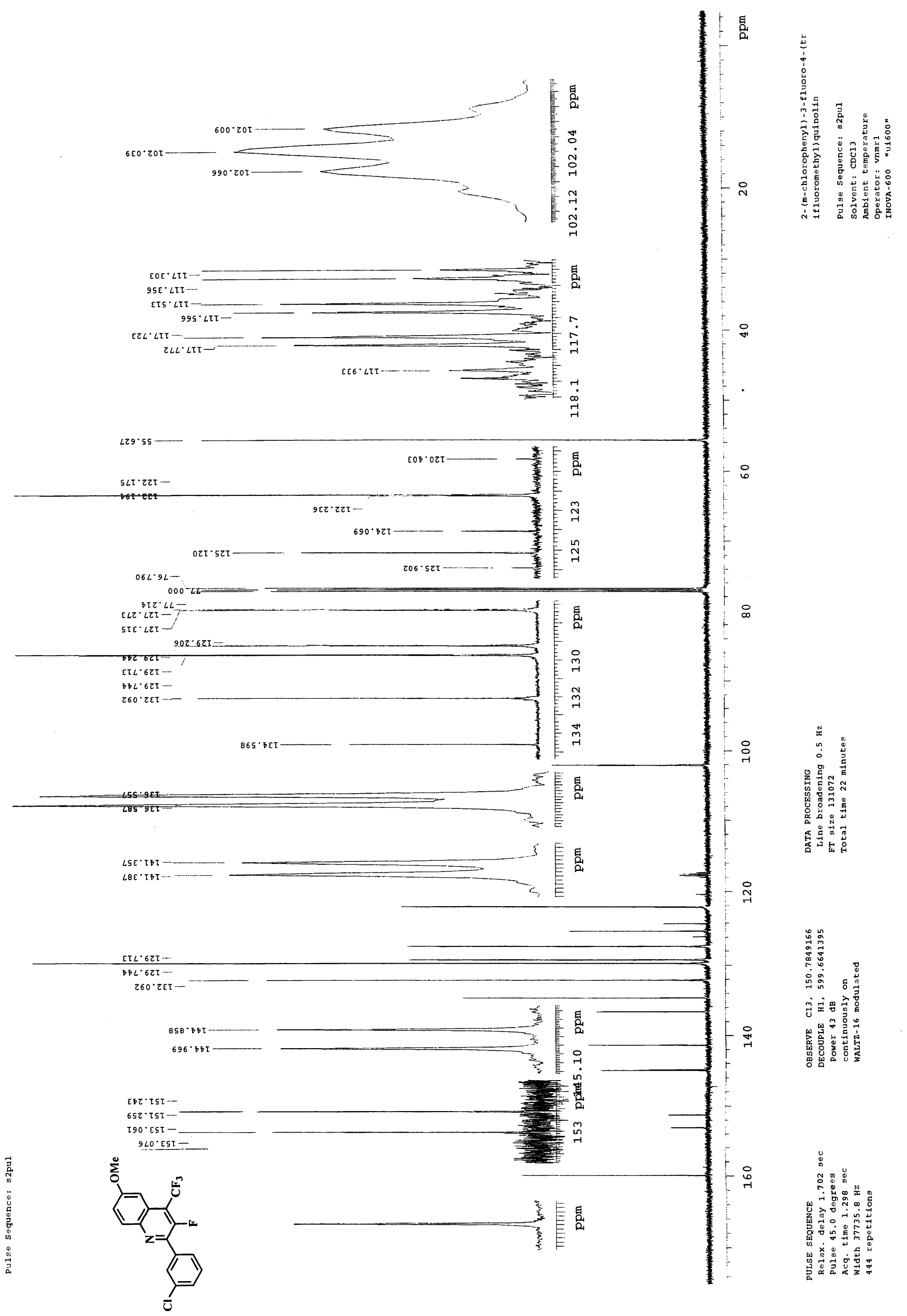



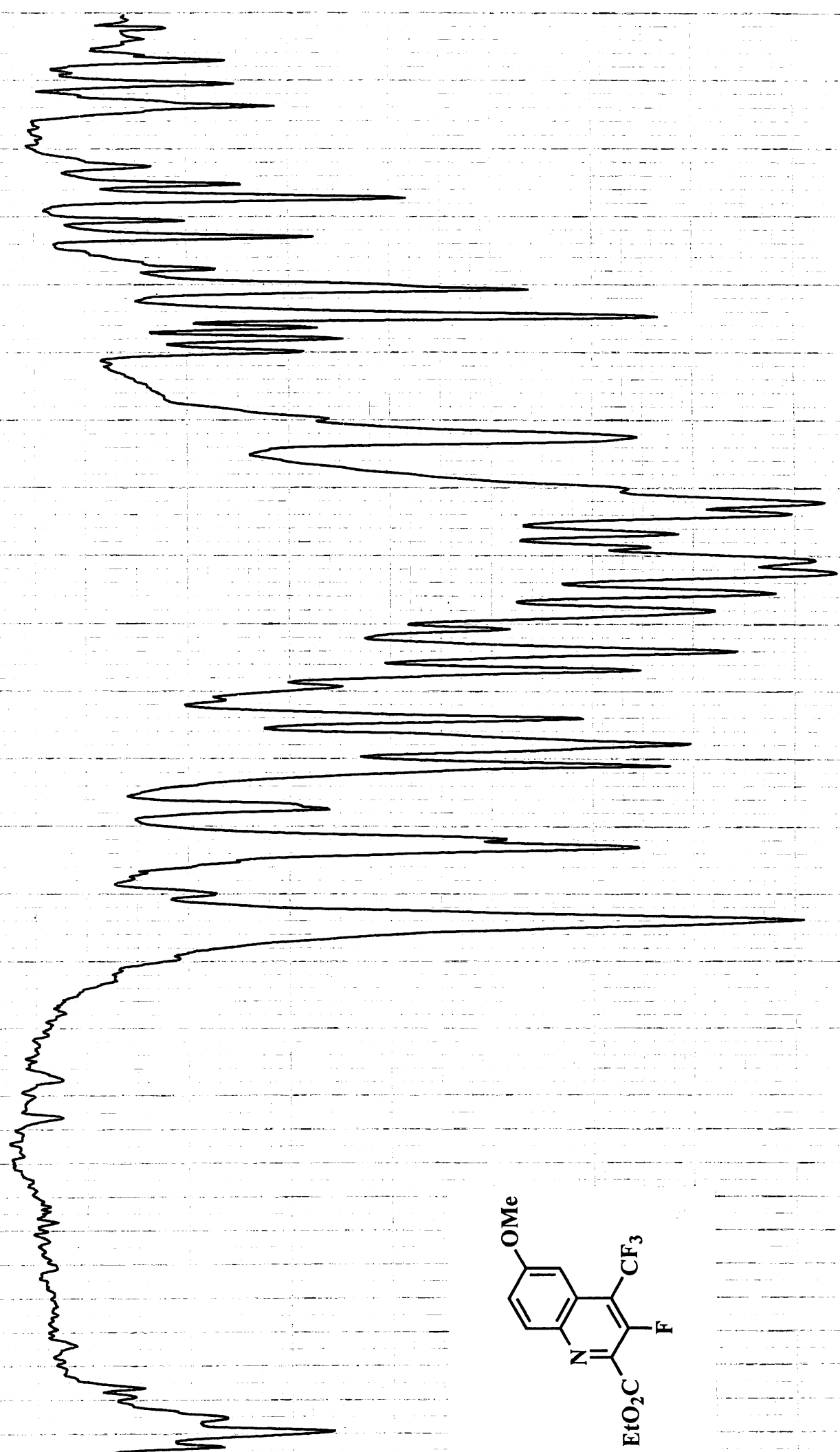


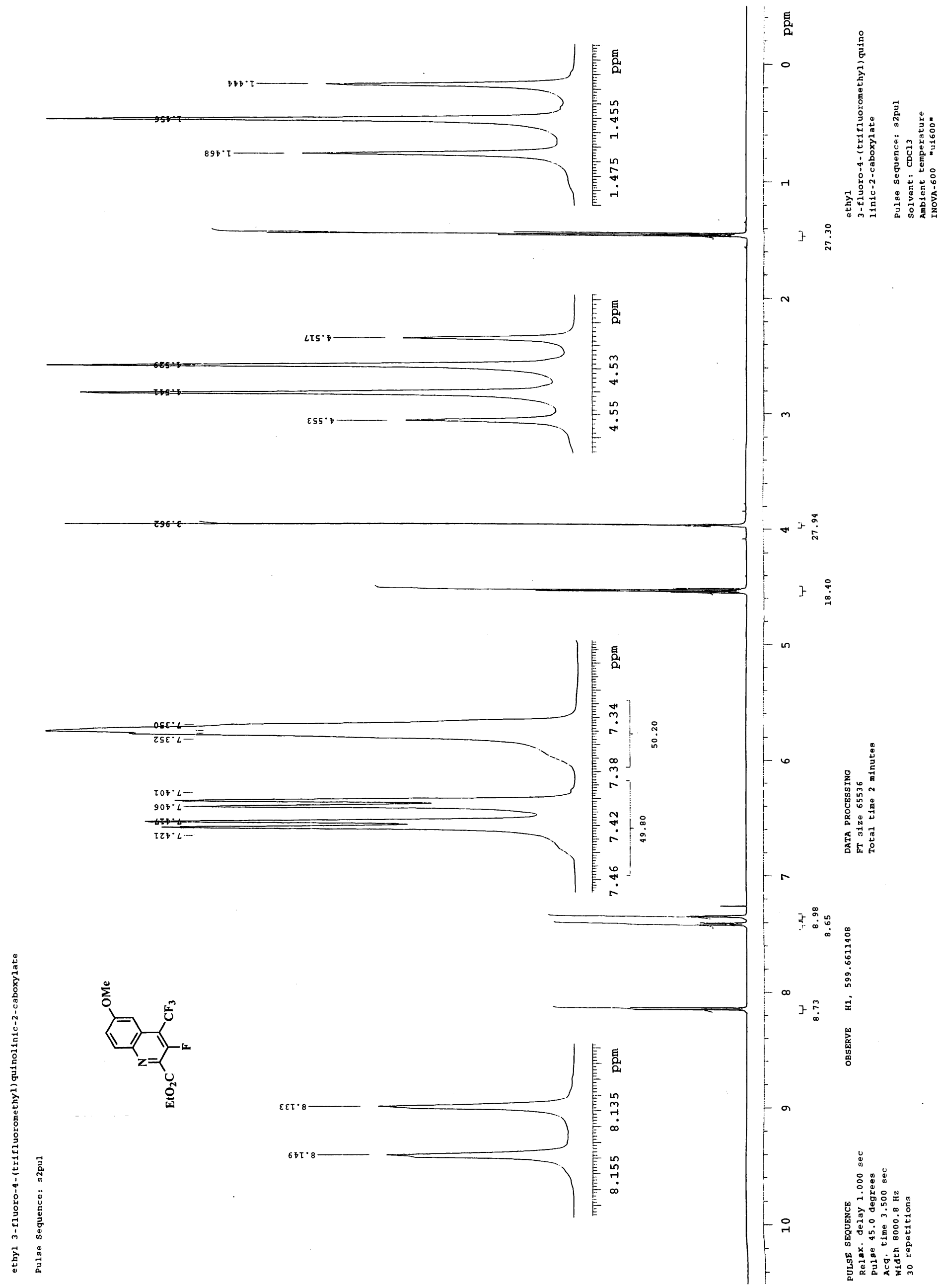




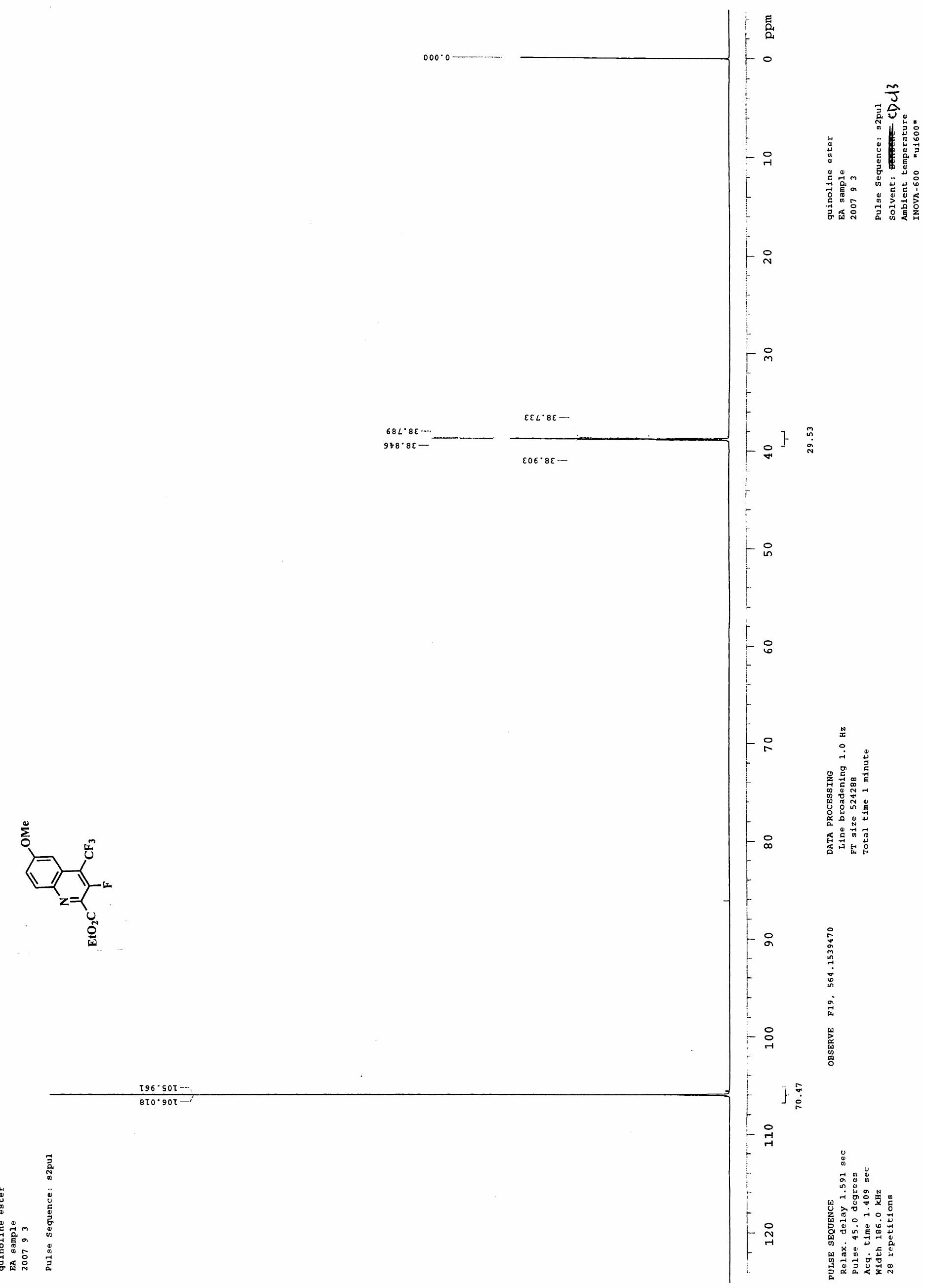




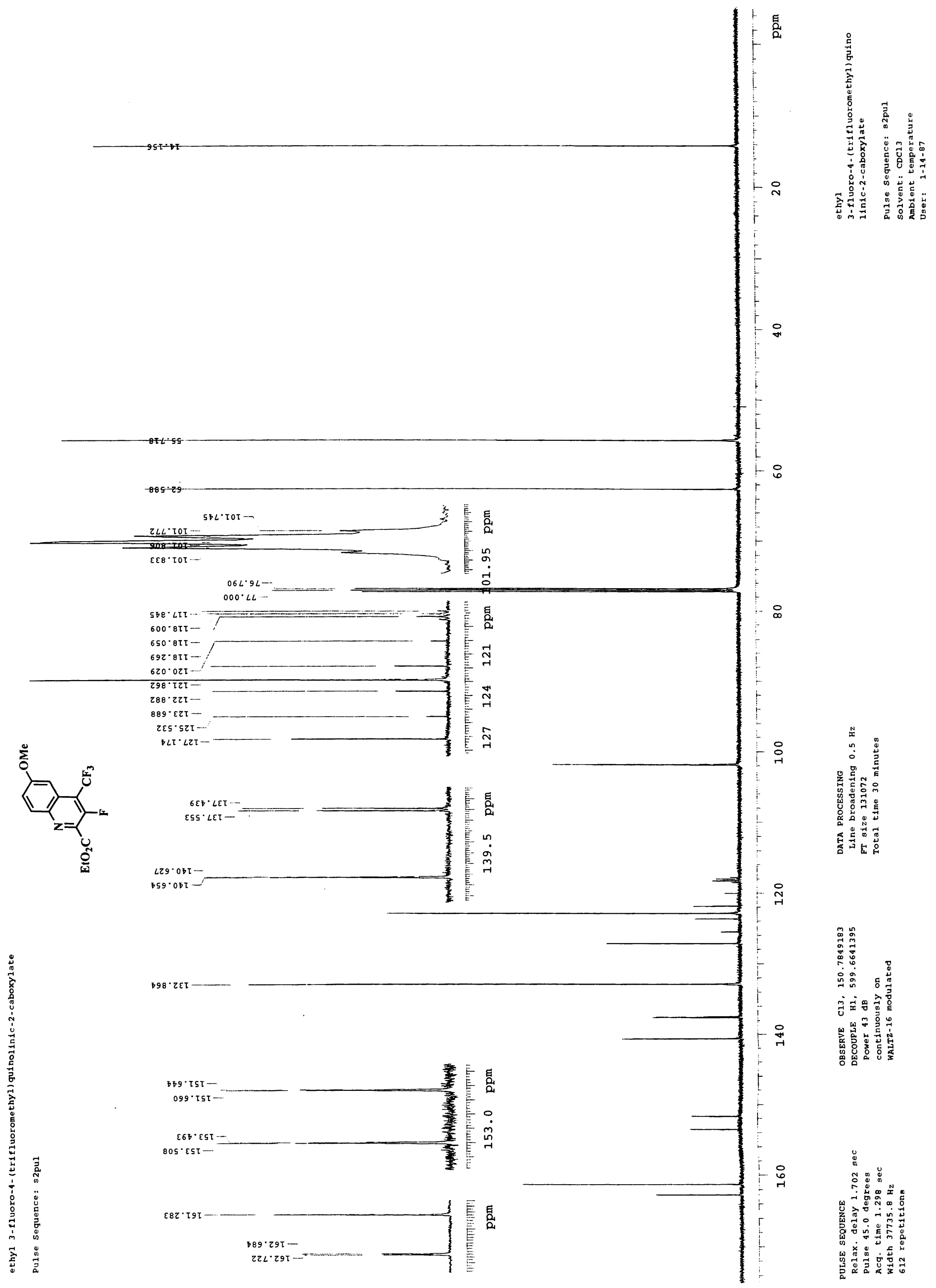




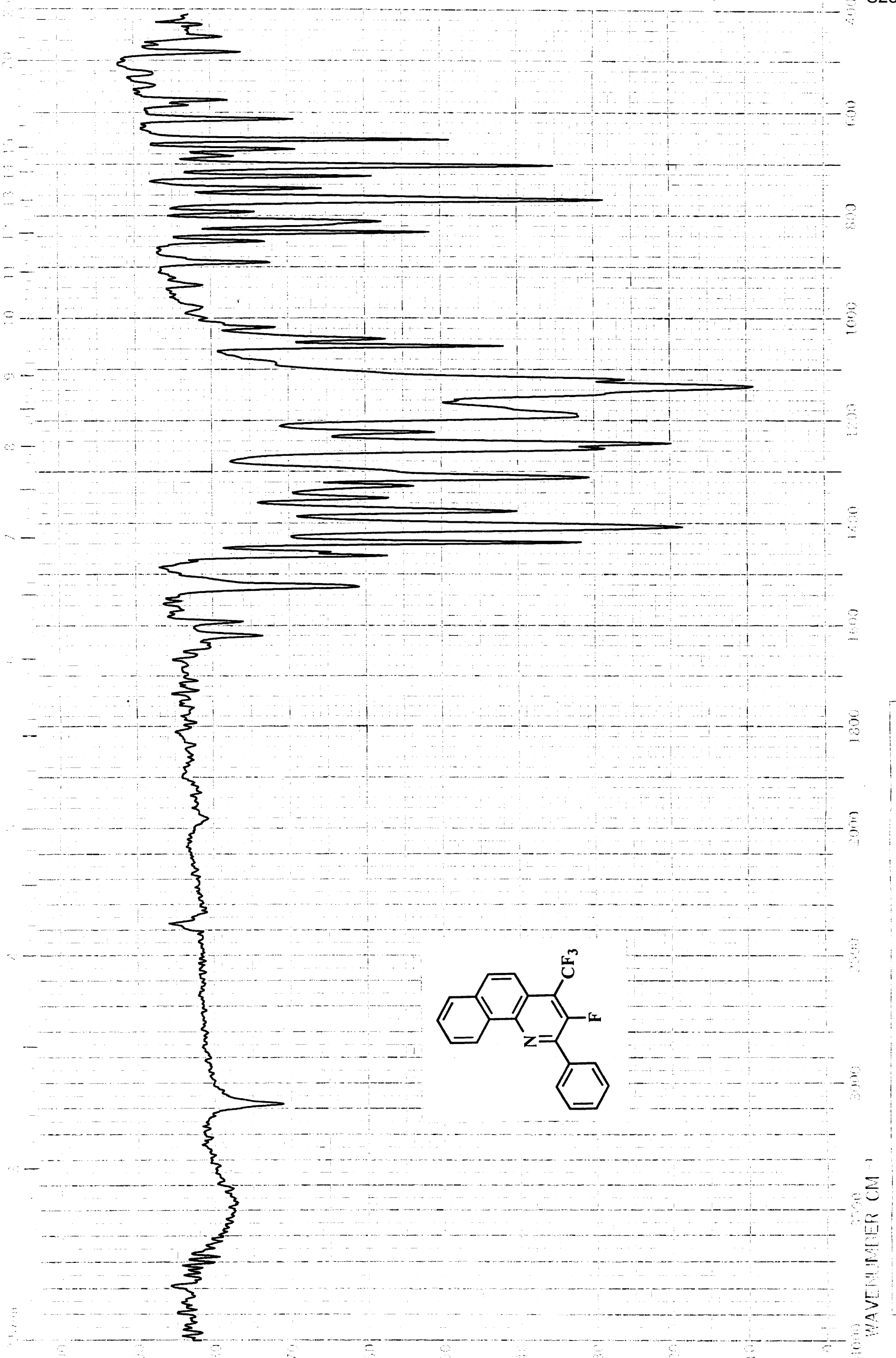




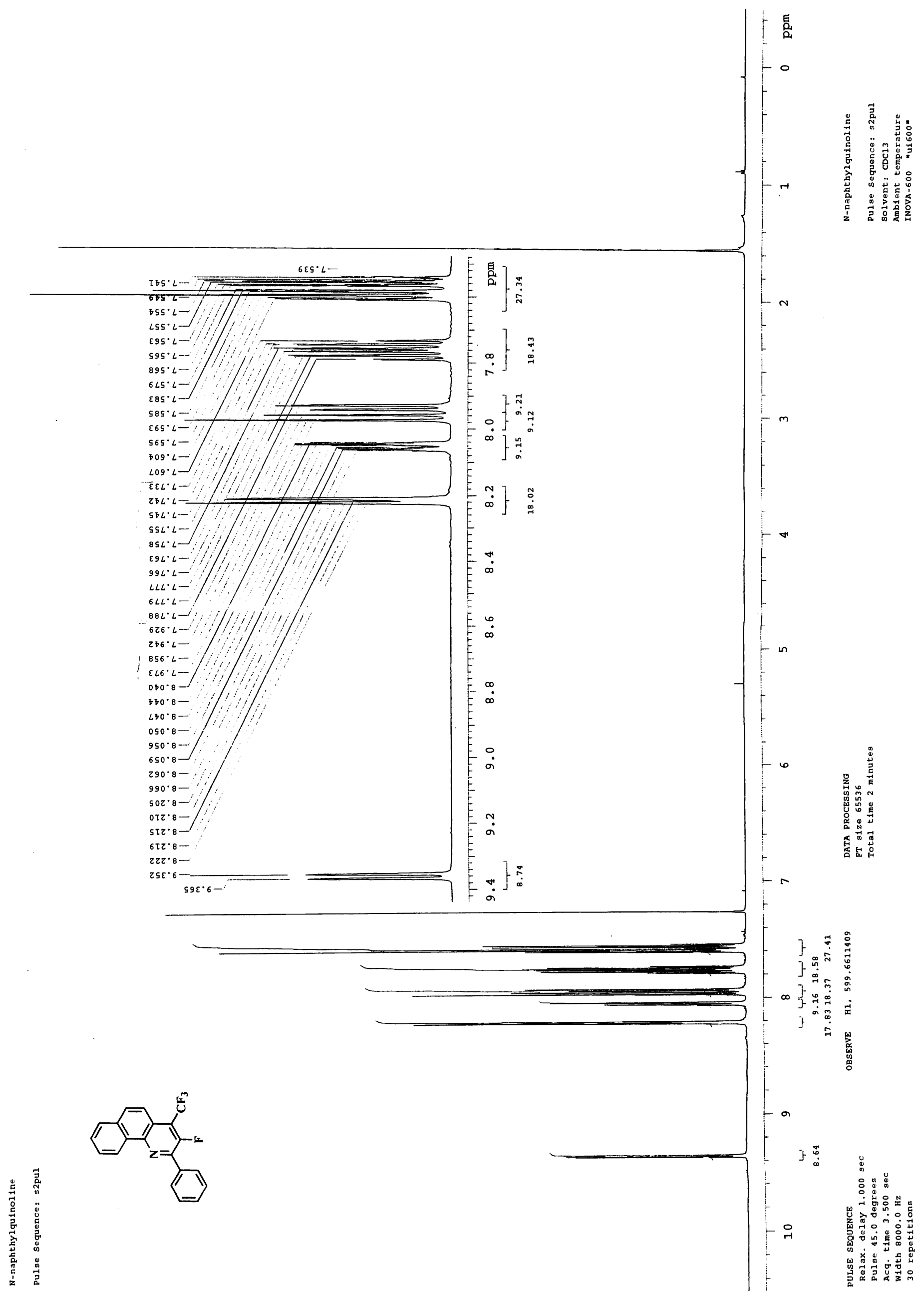




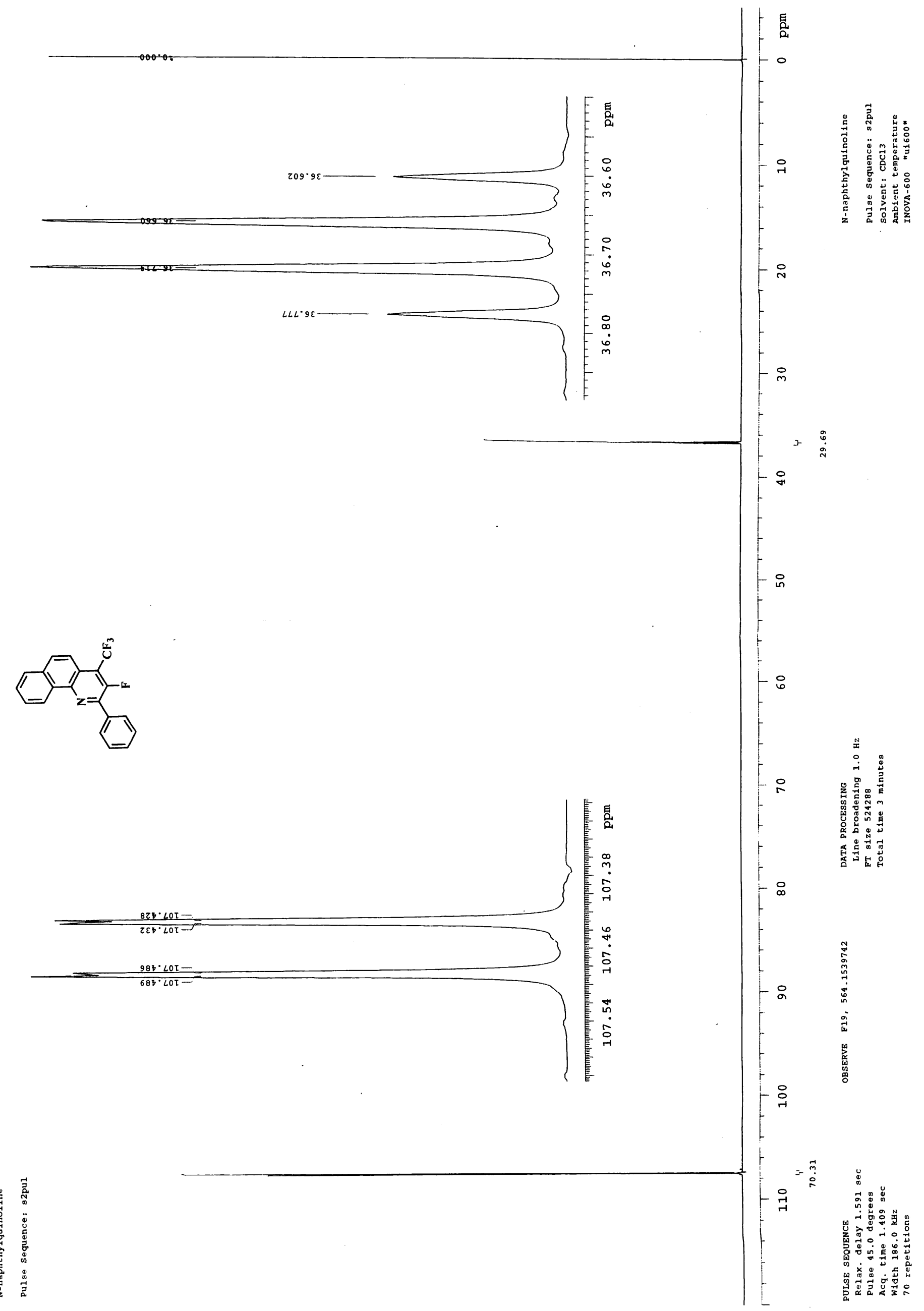




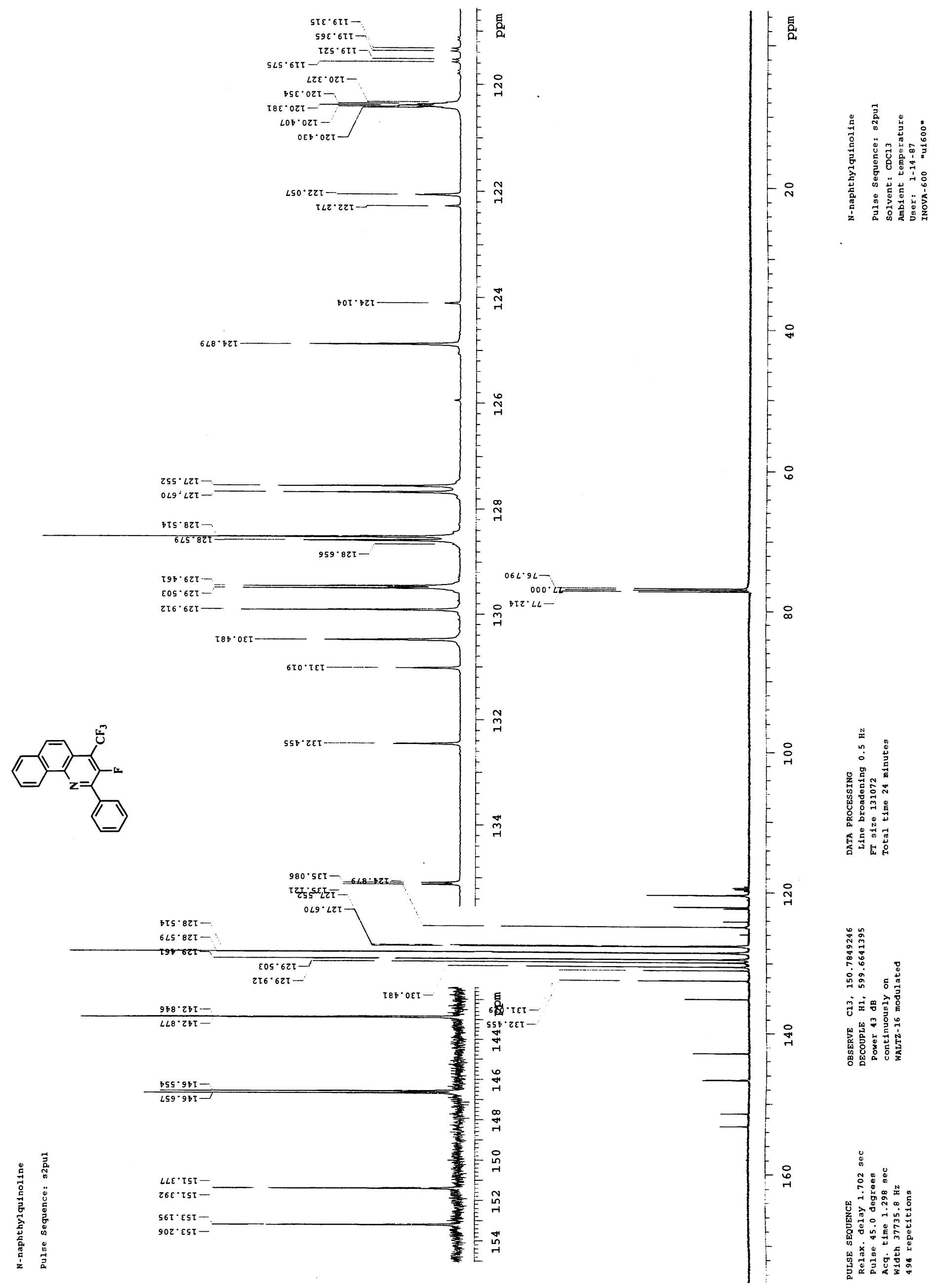



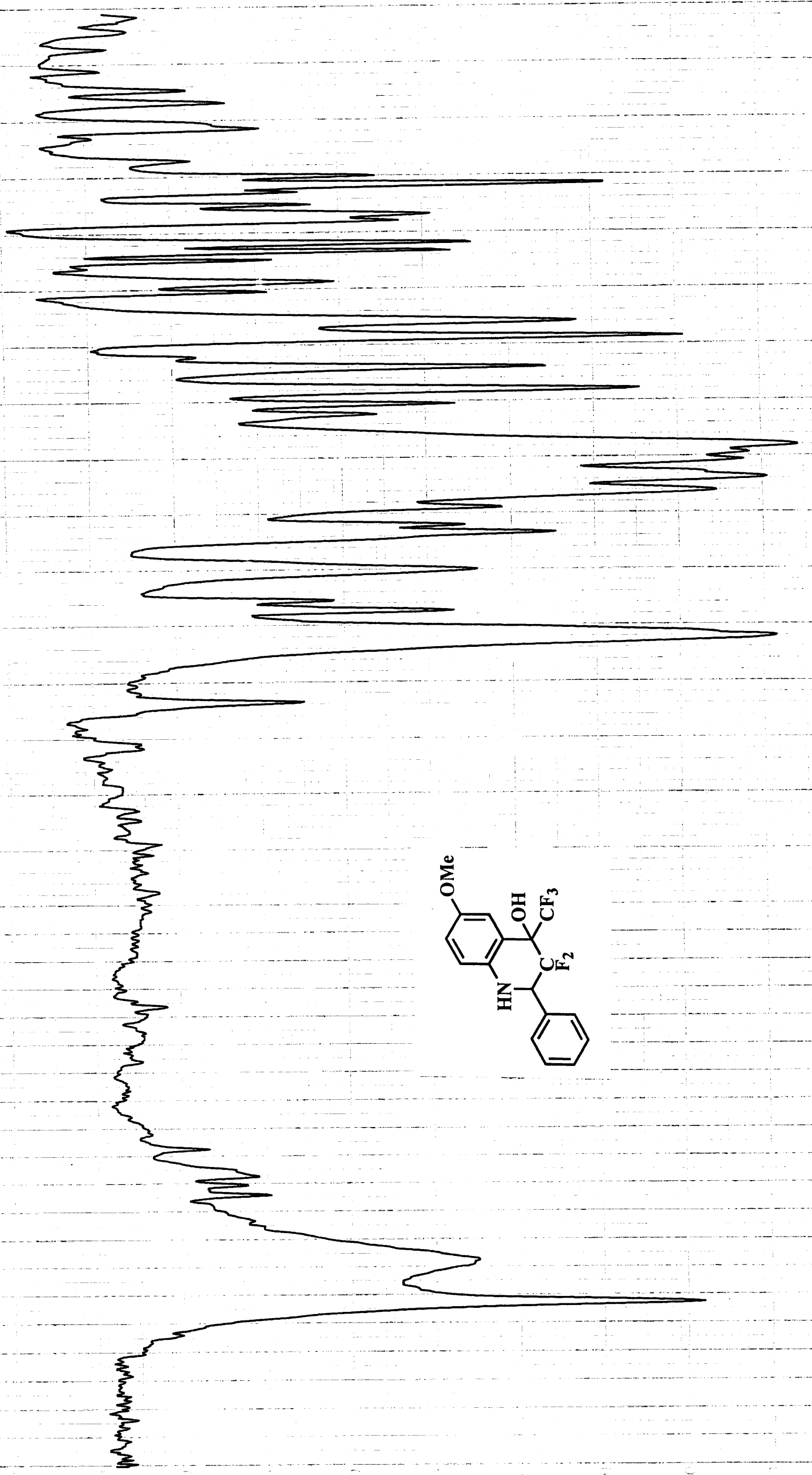


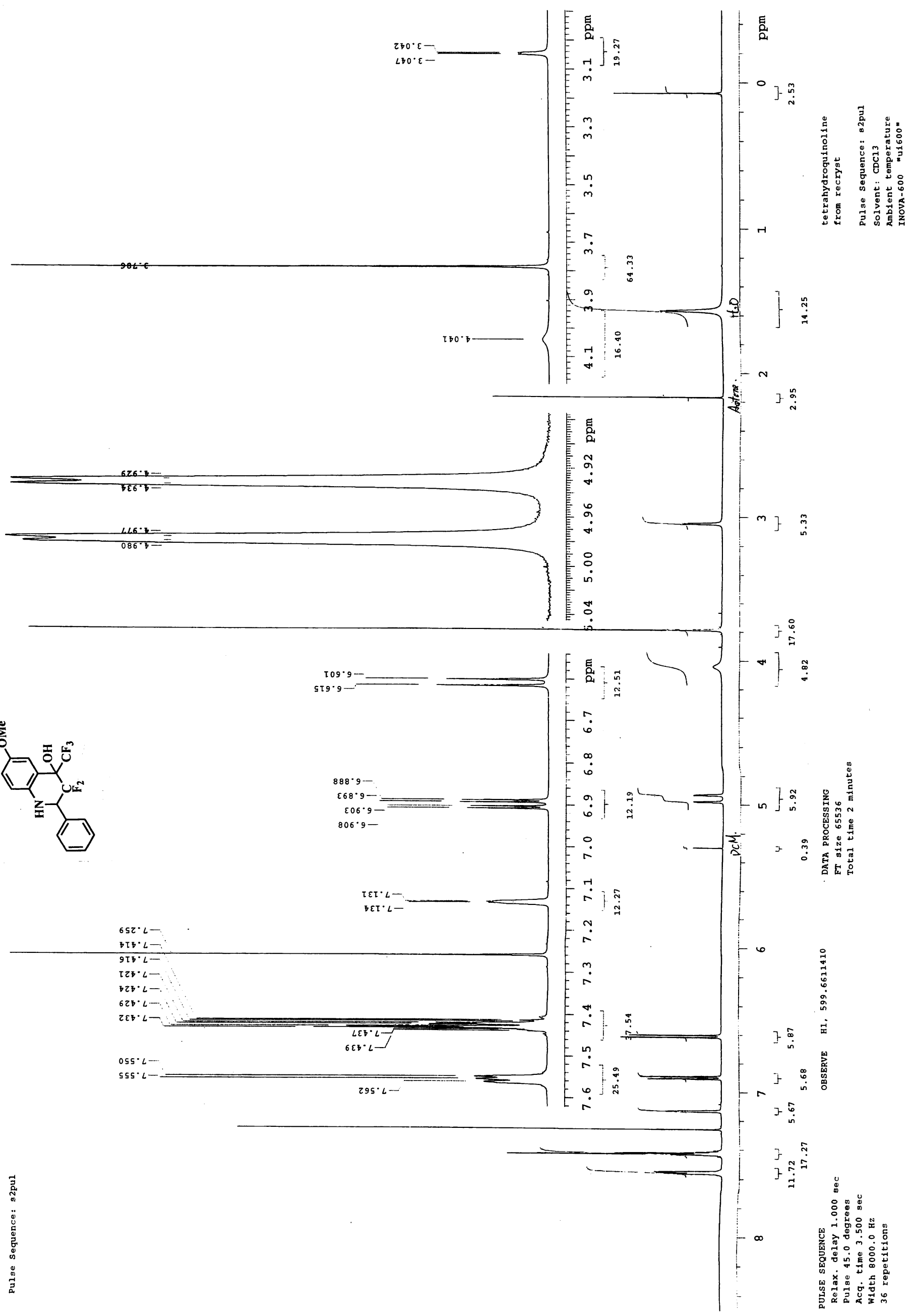




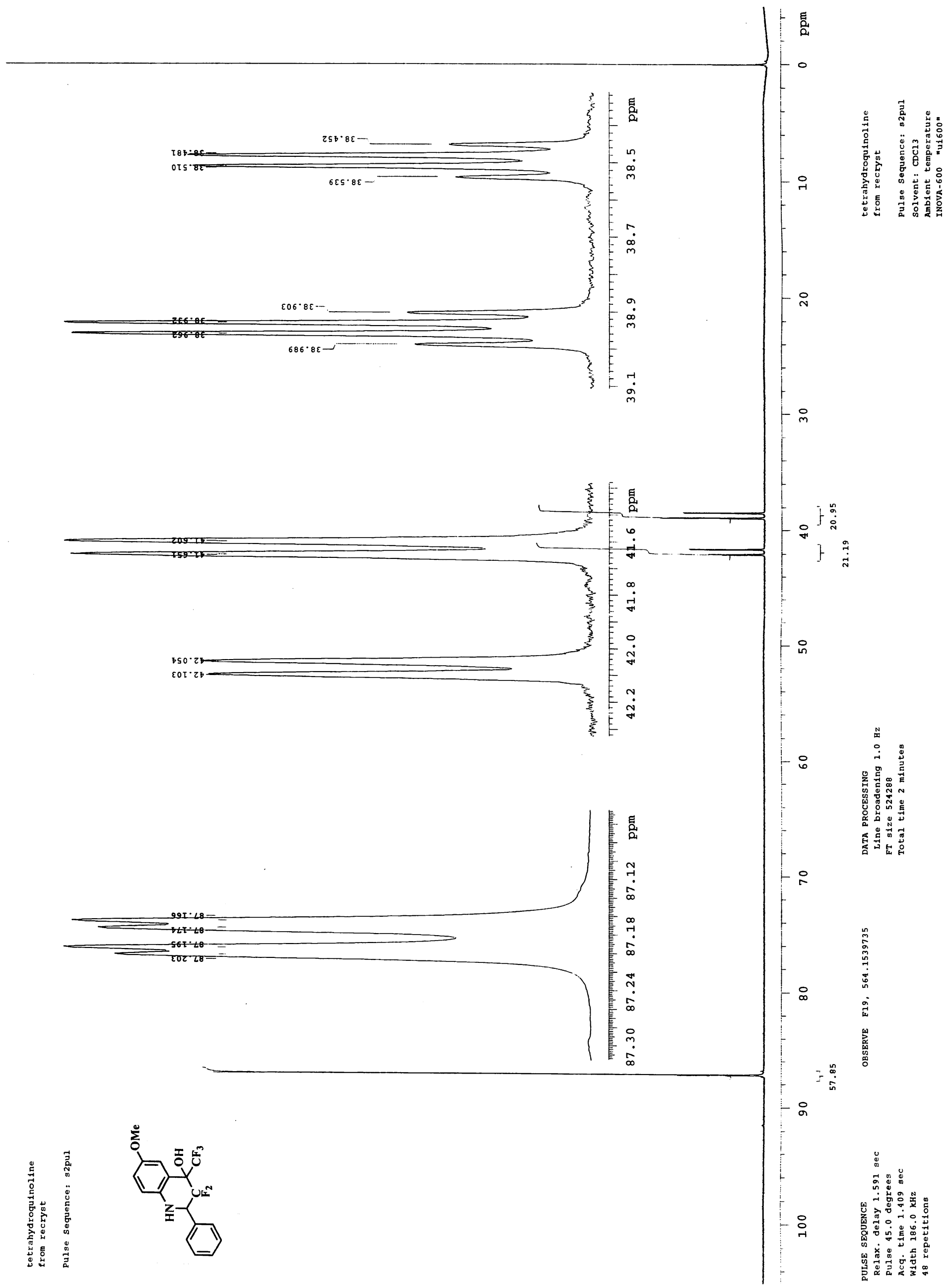




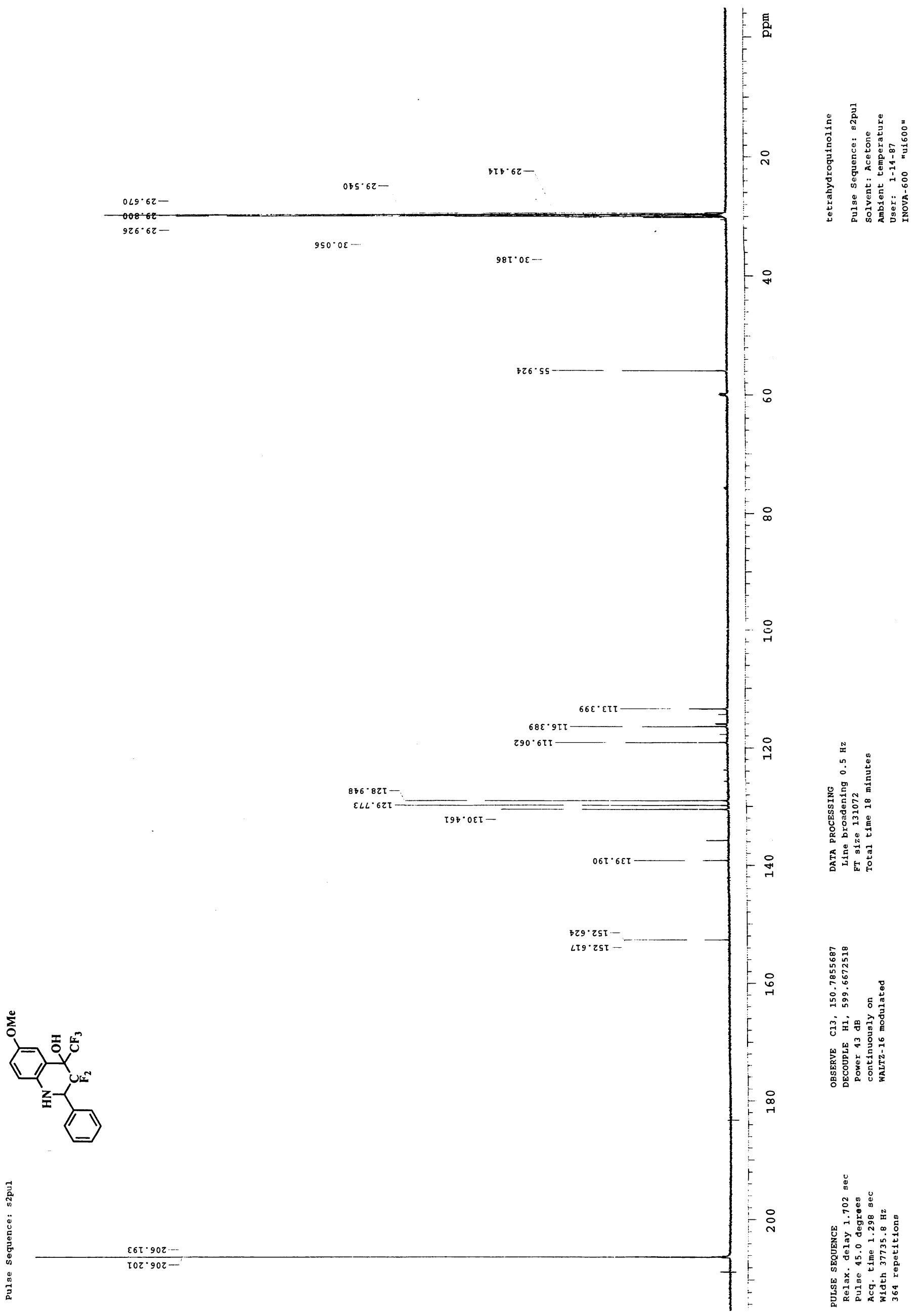




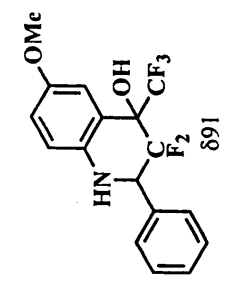

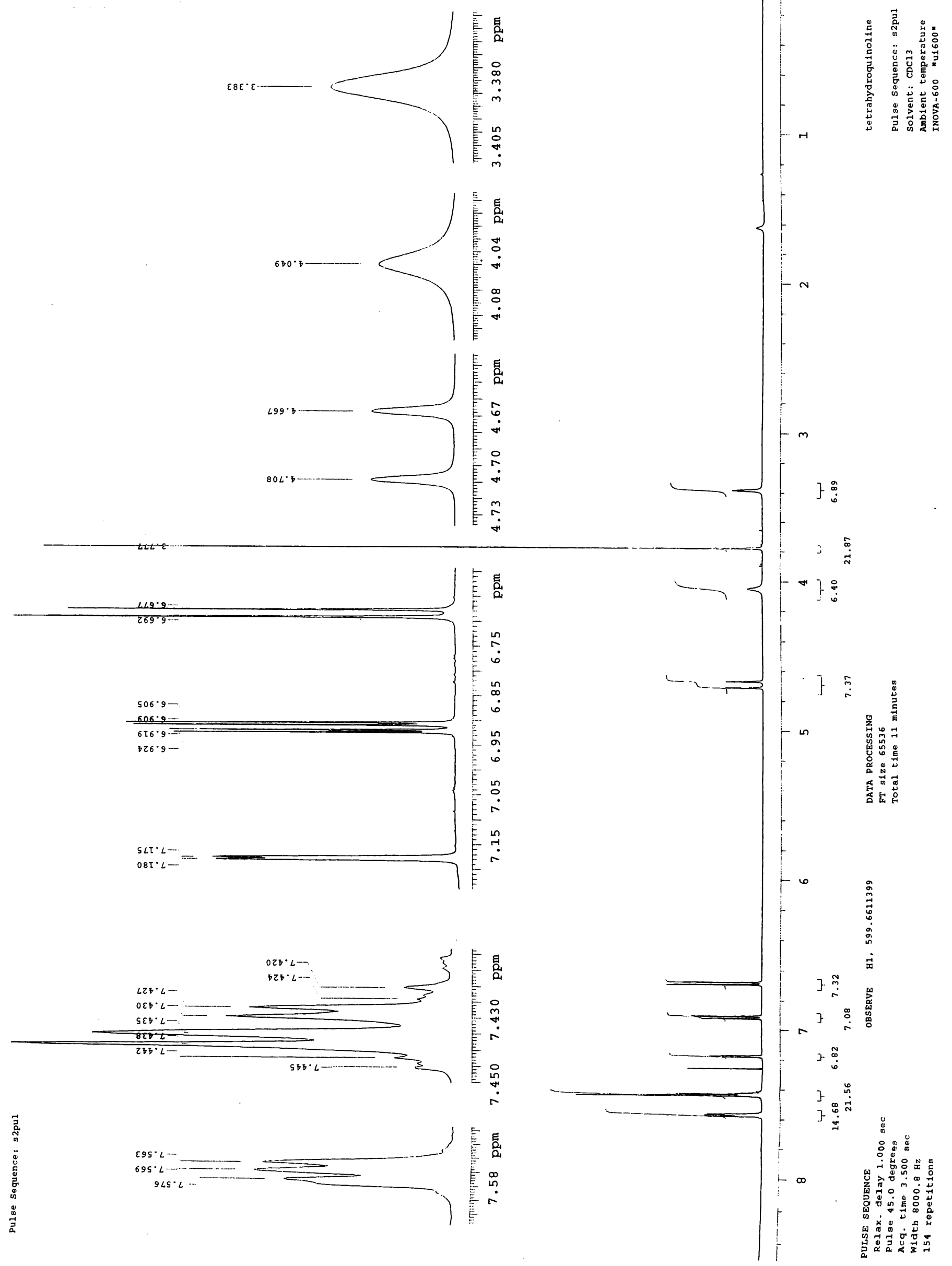




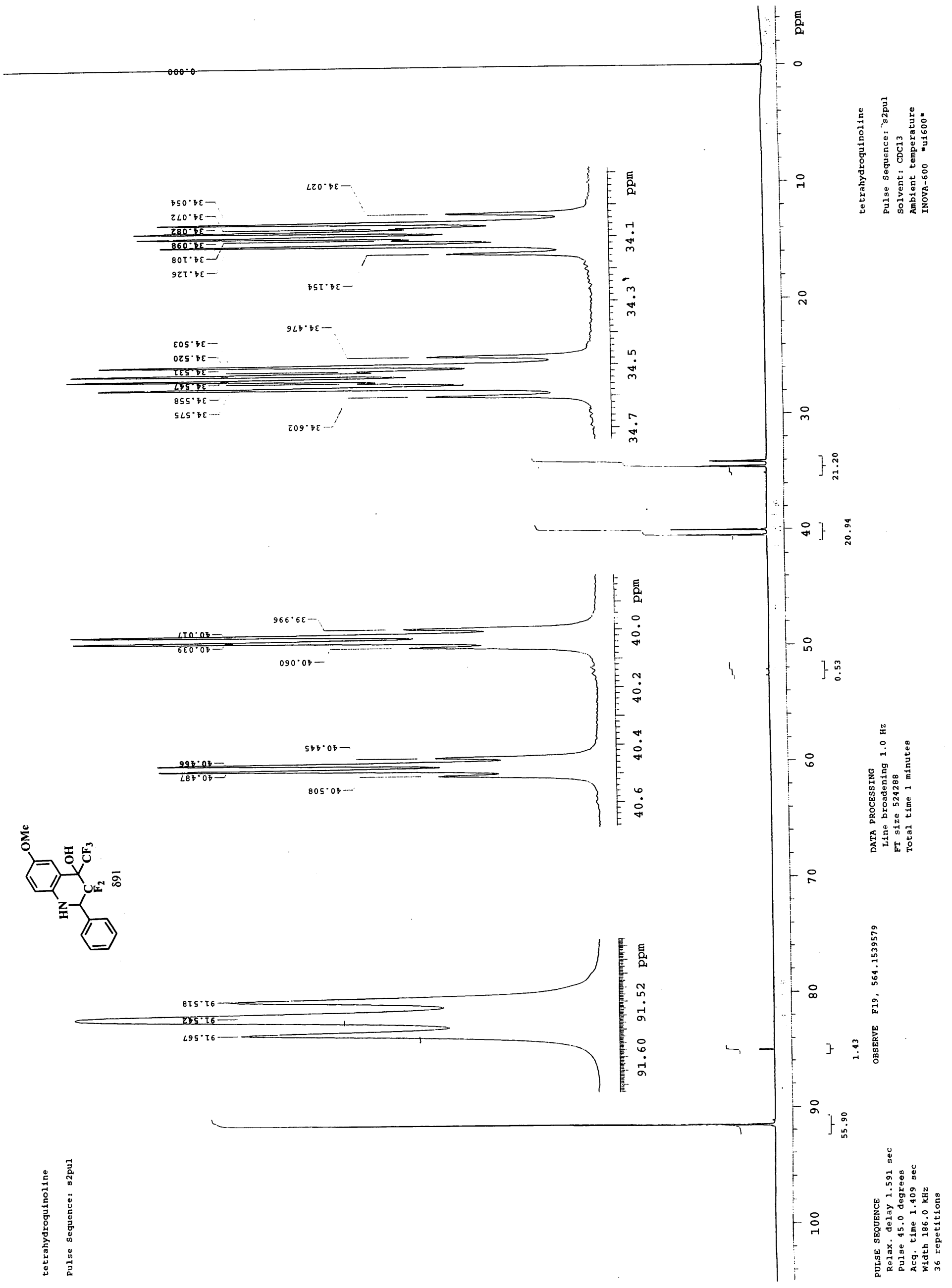




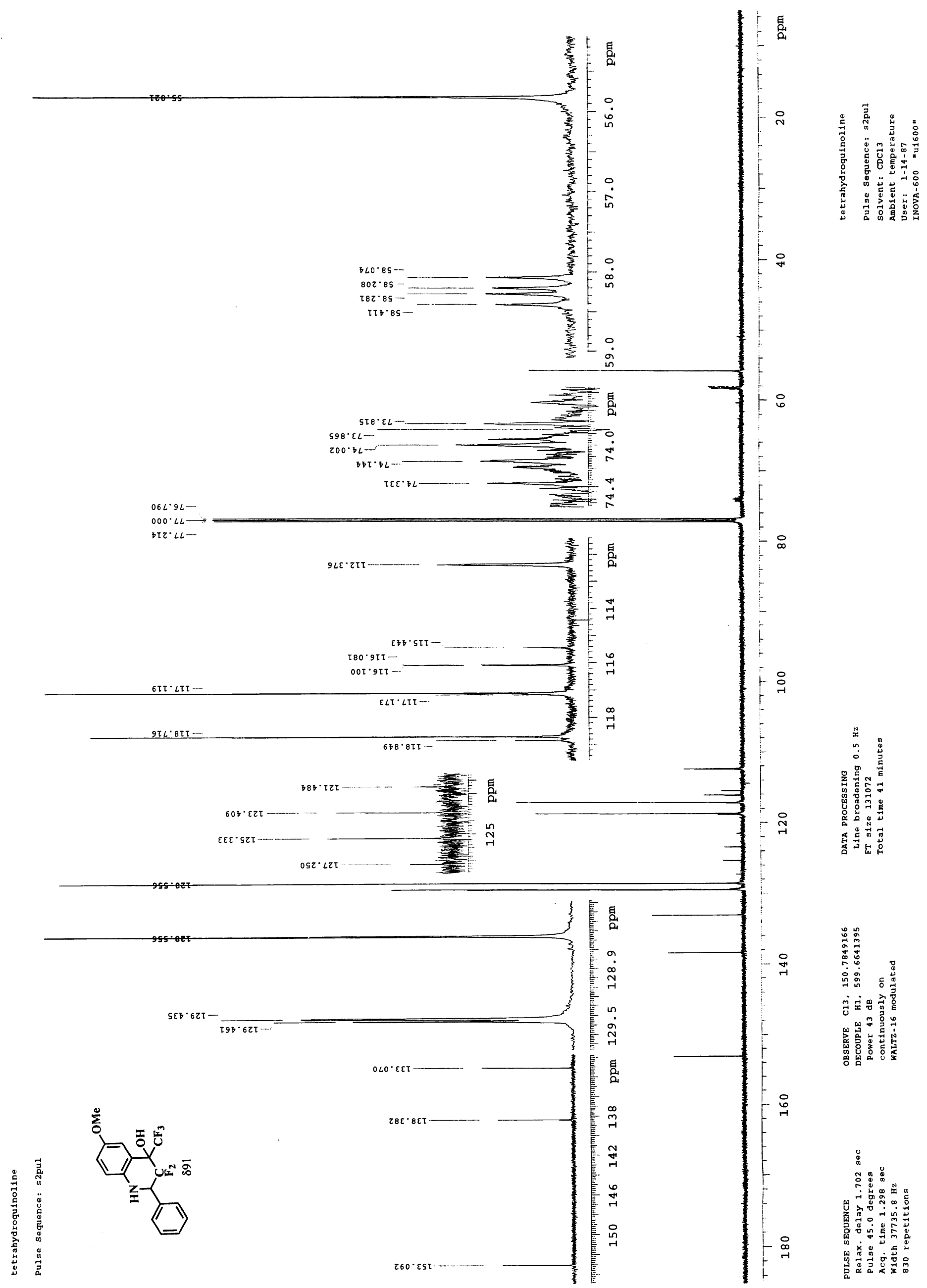



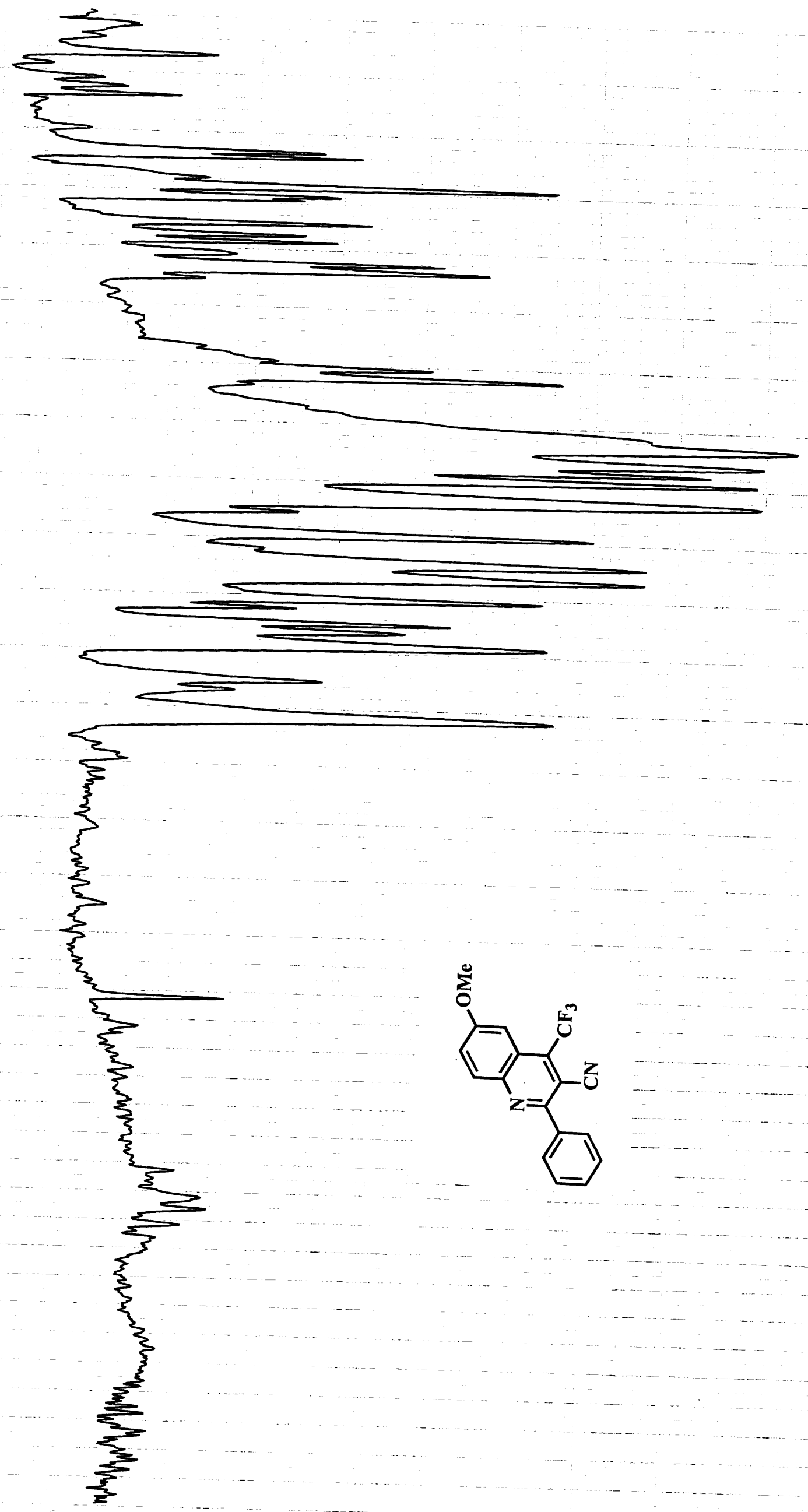


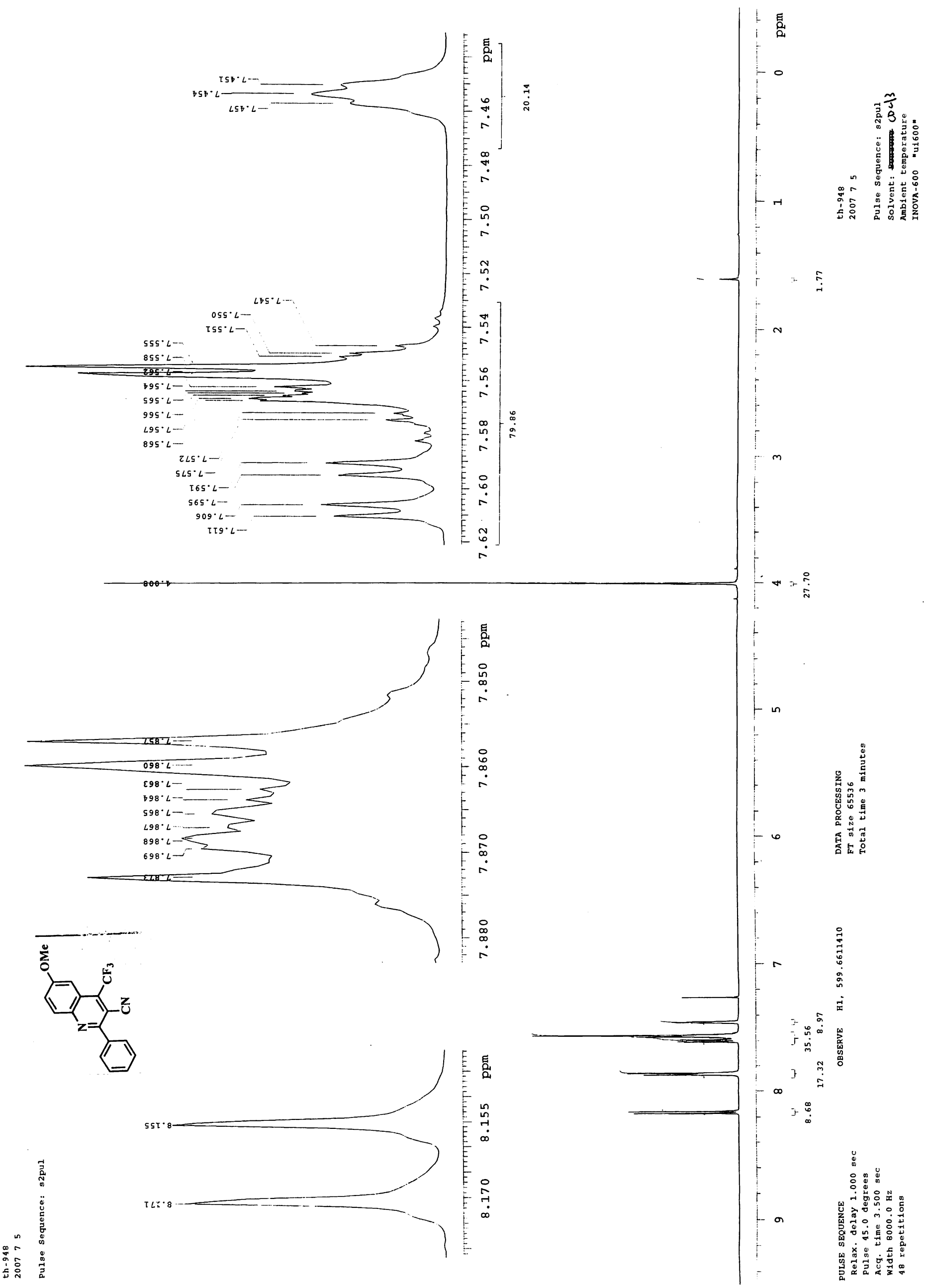




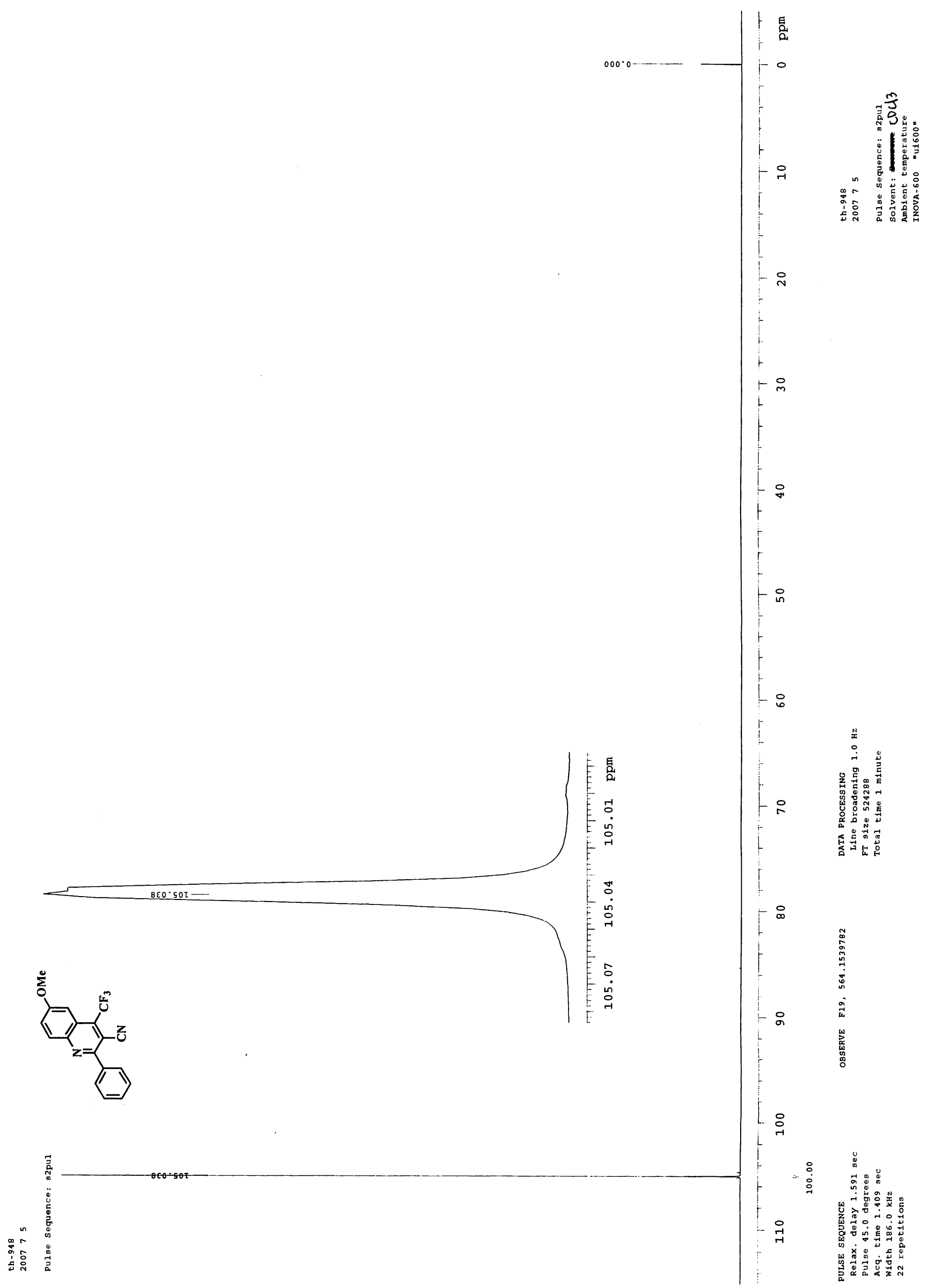




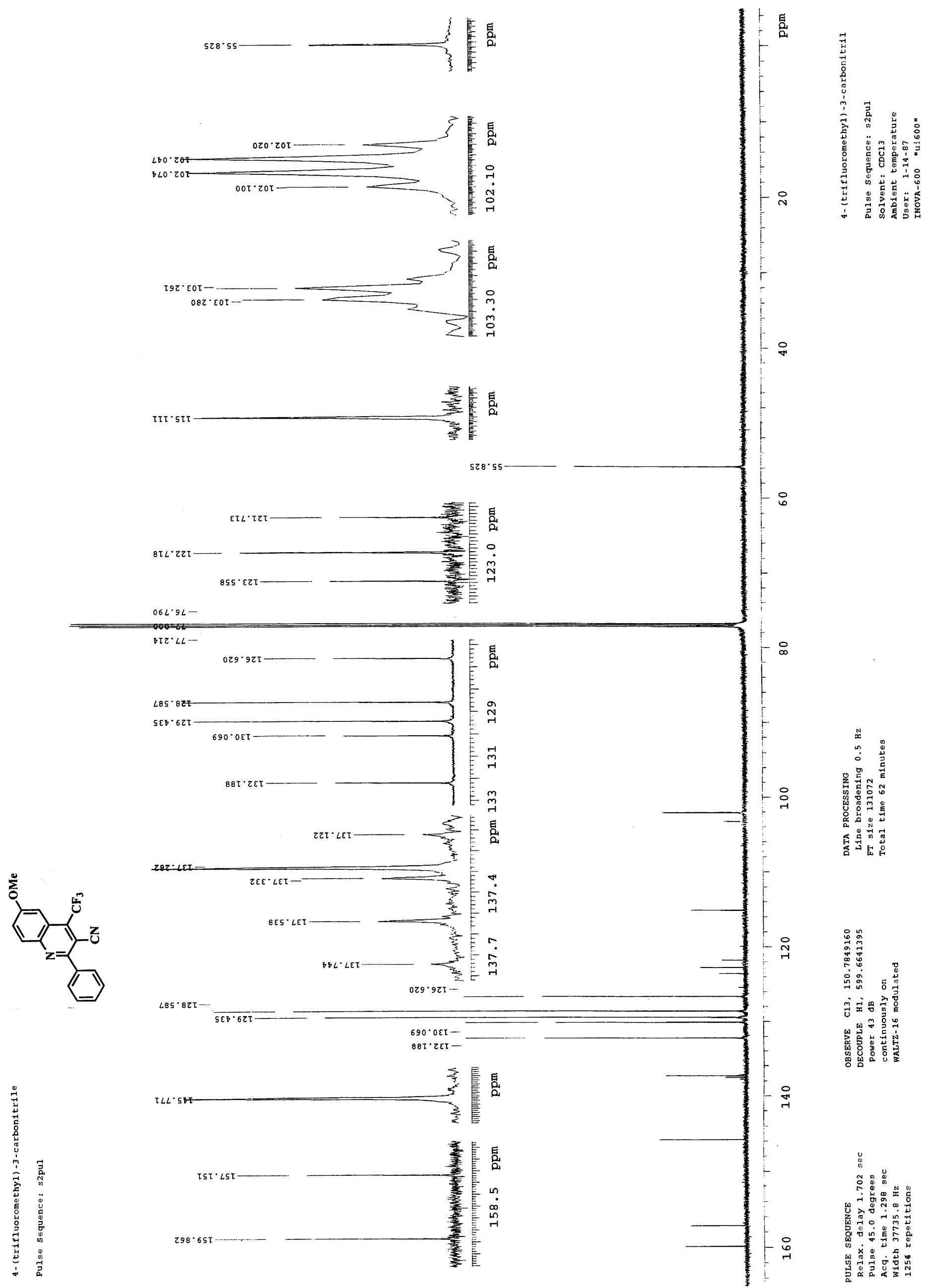



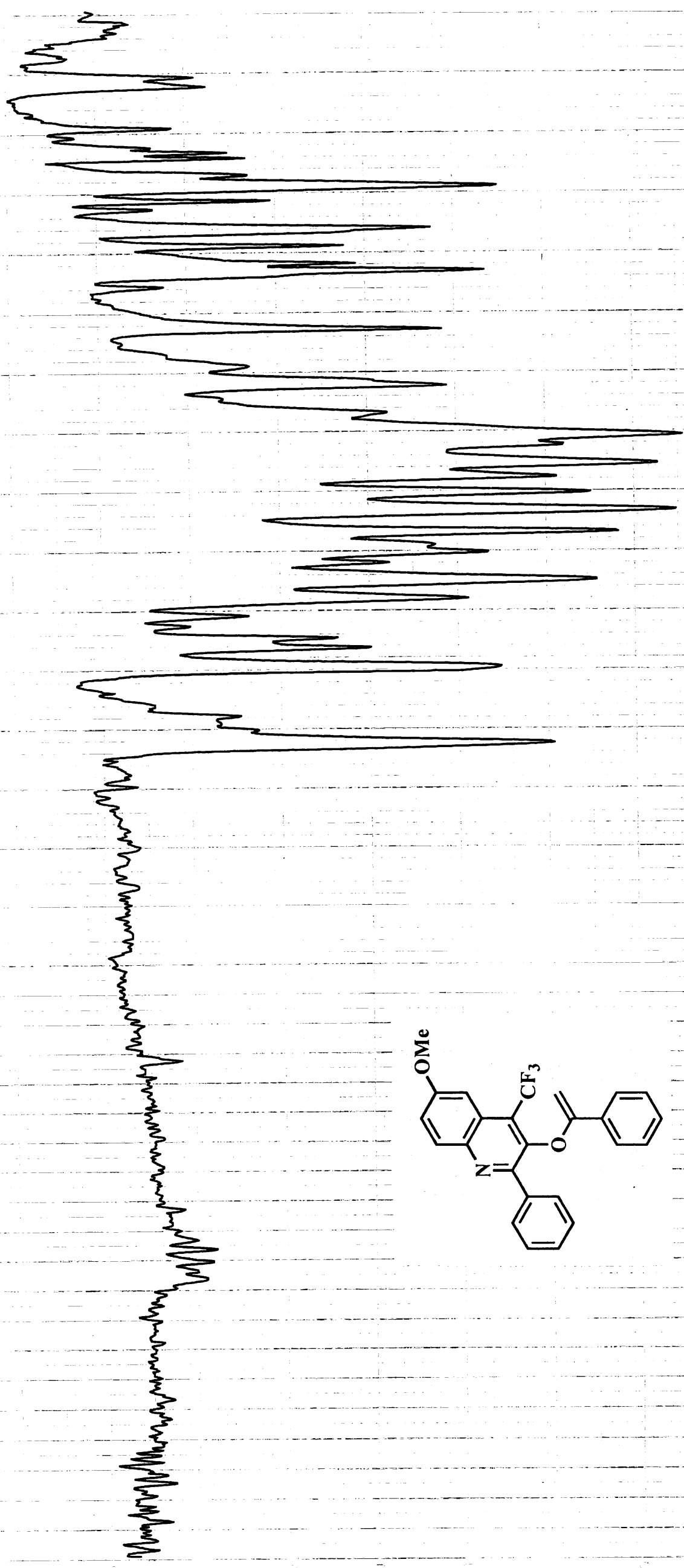


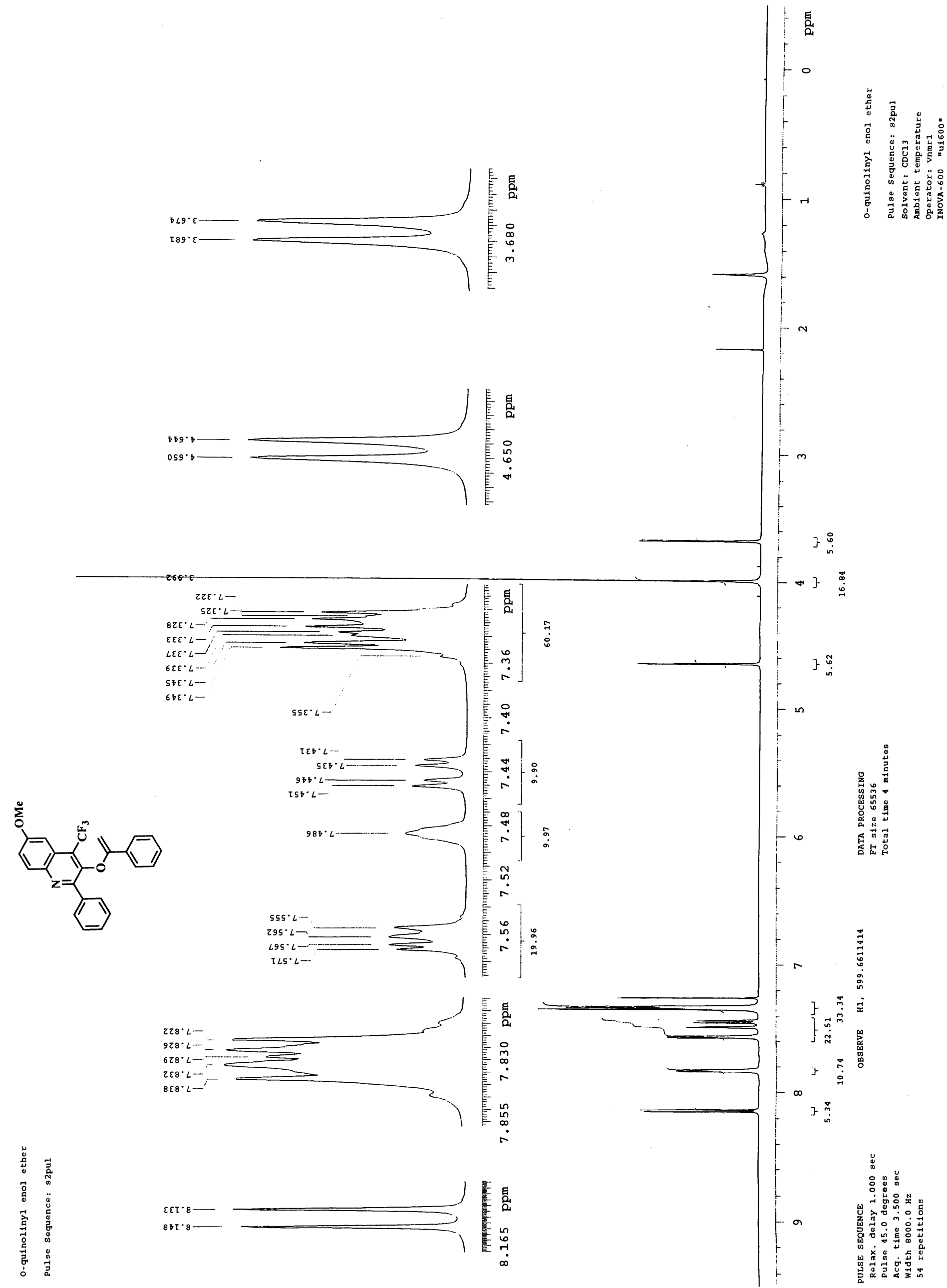




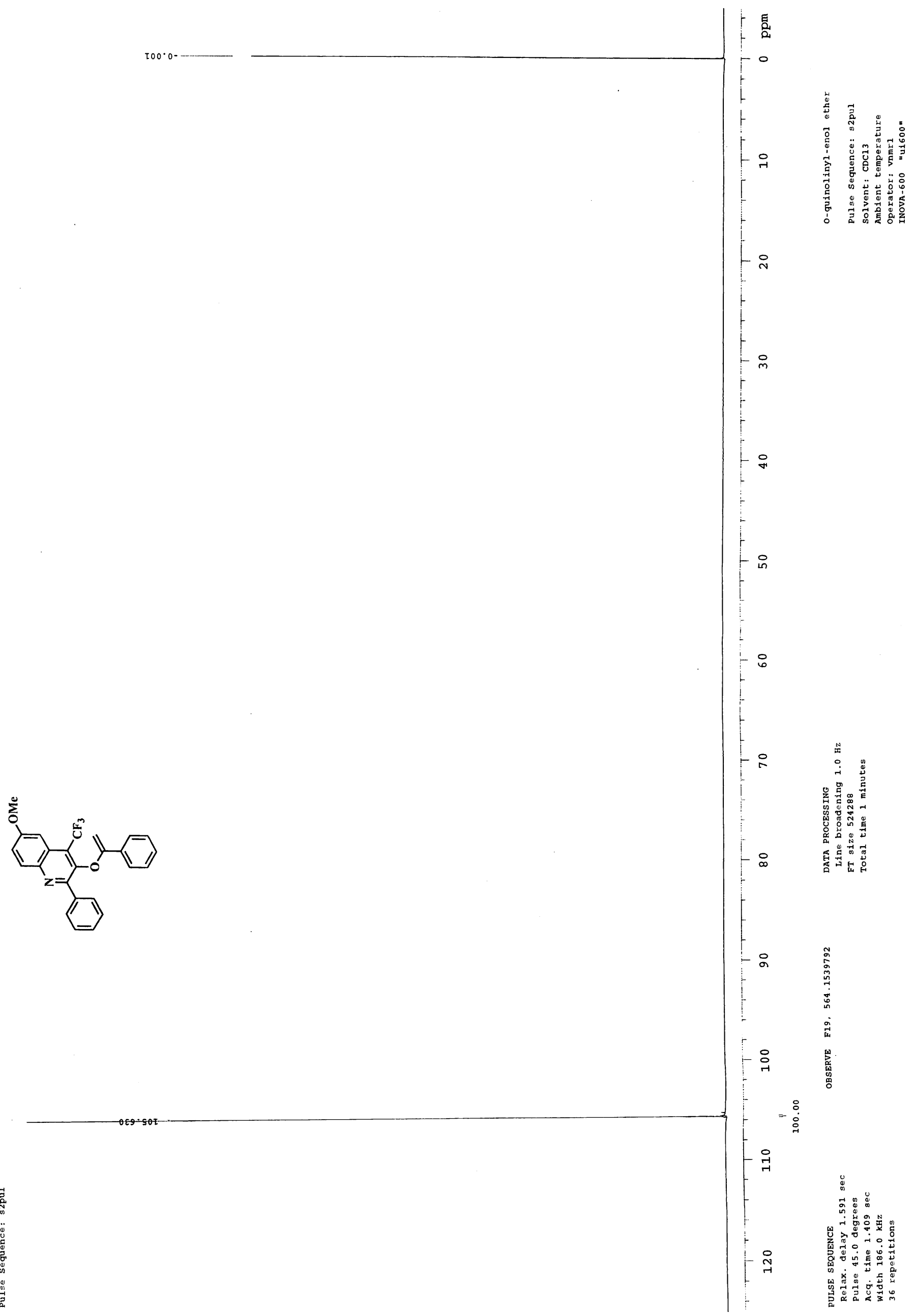




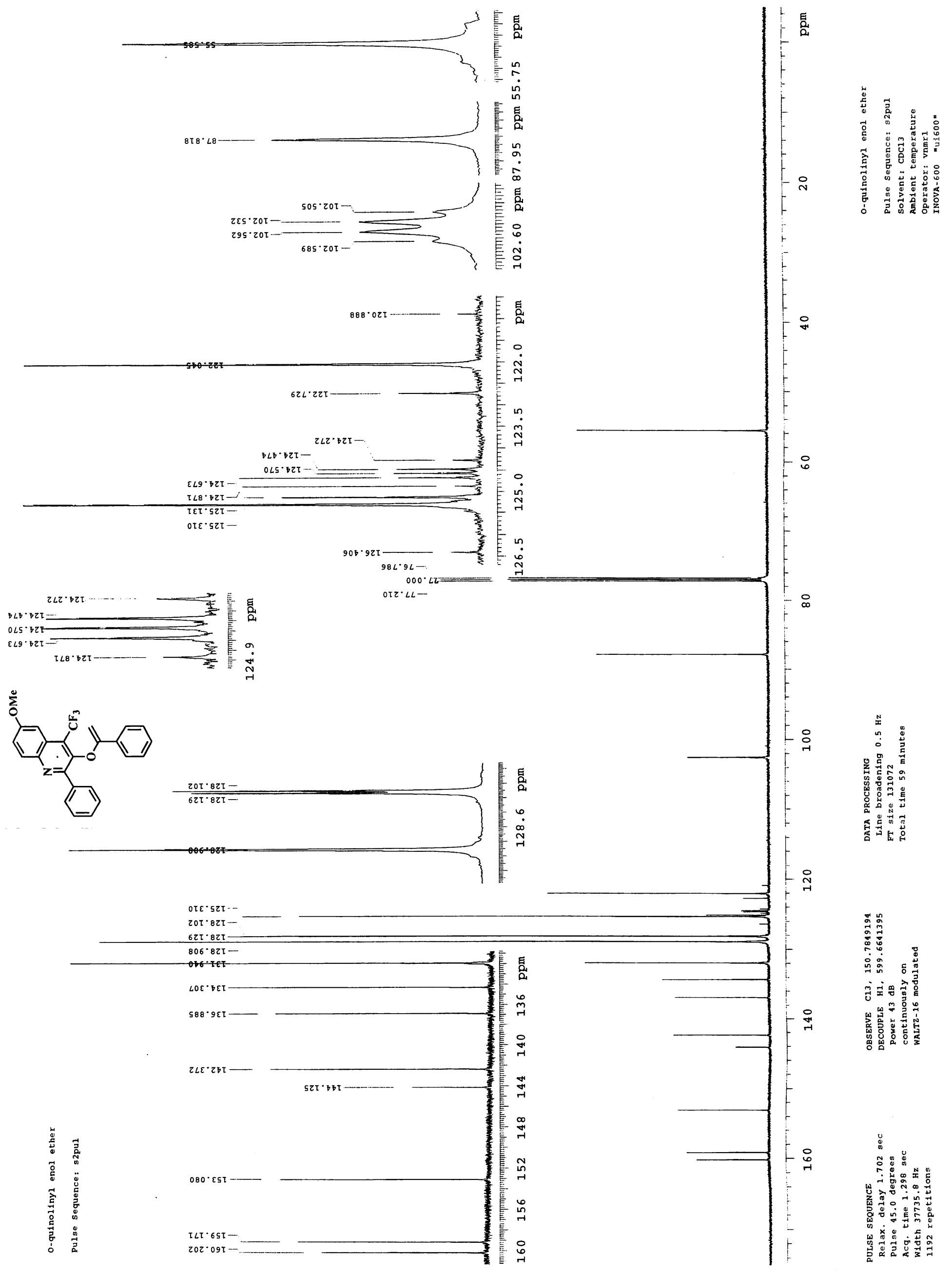



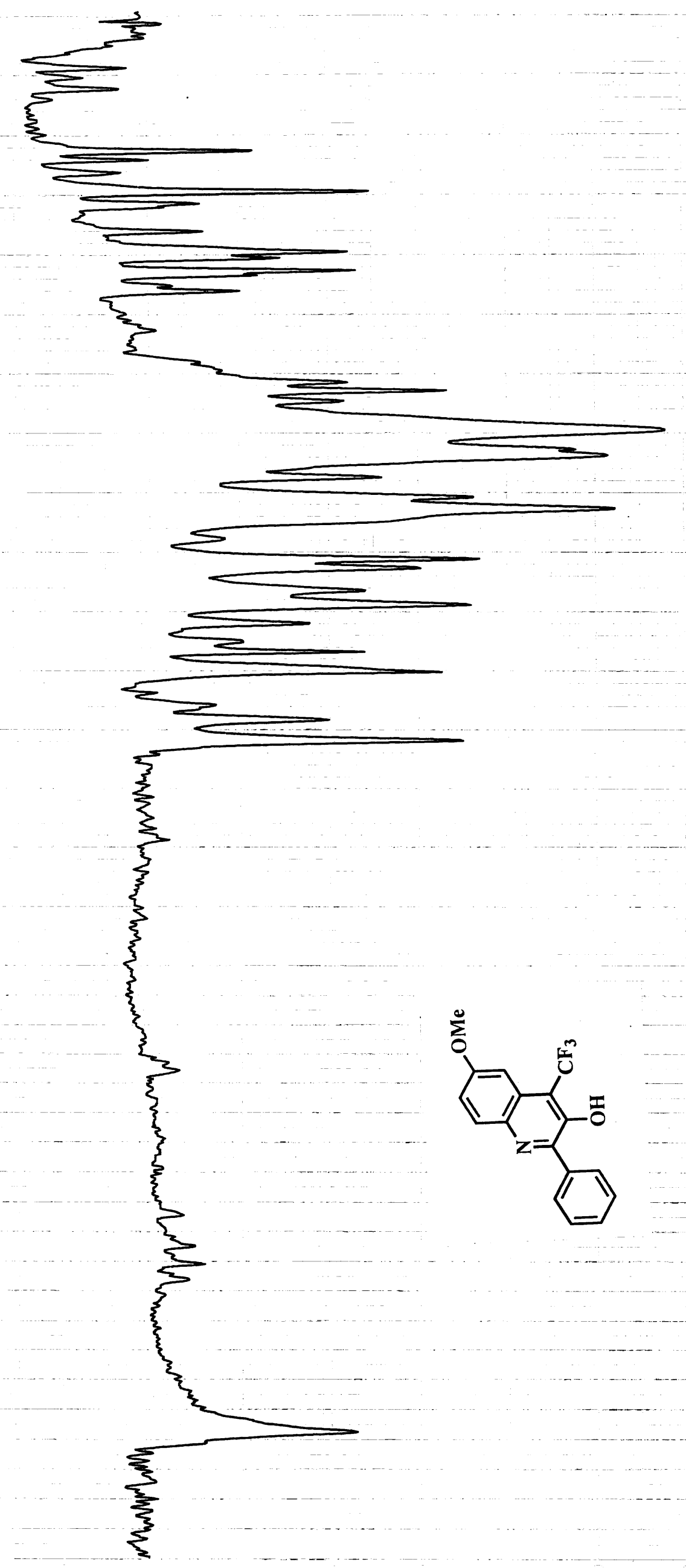
(1)
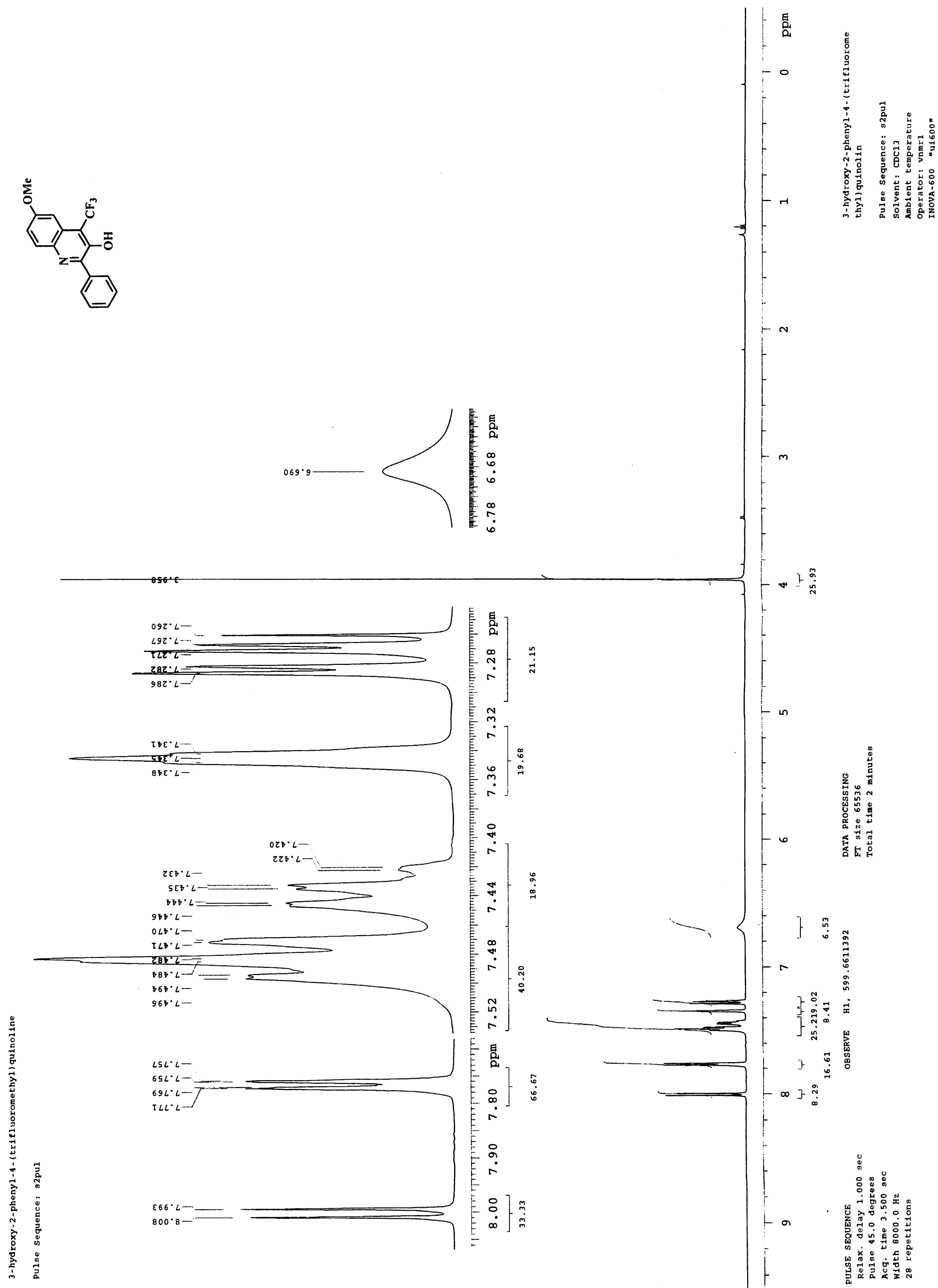
$9 c$

S49
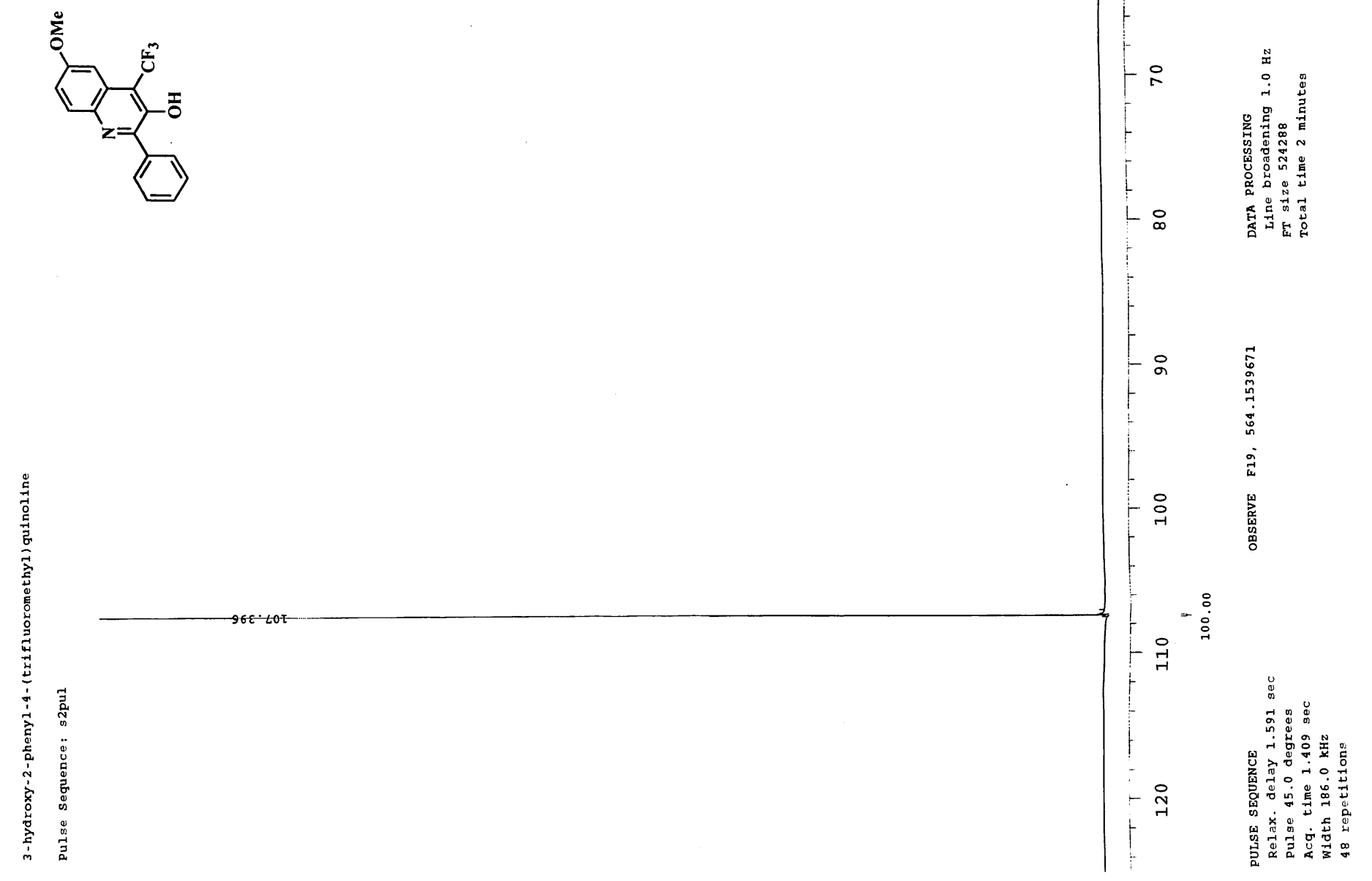

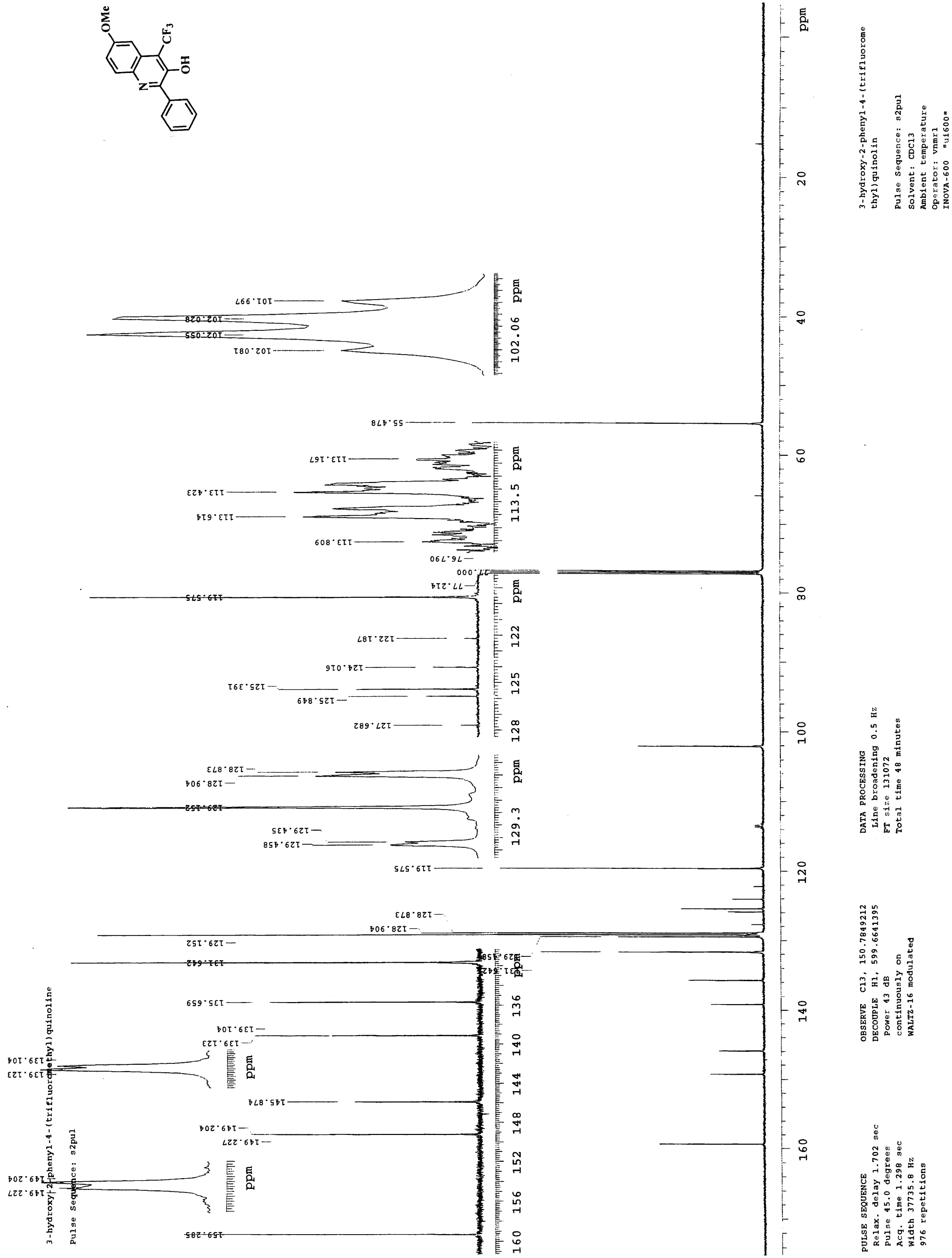

节 กั

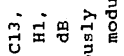

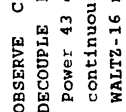

$-ㅇ ㅜ ㄱ$

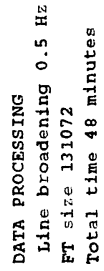

ัำ 

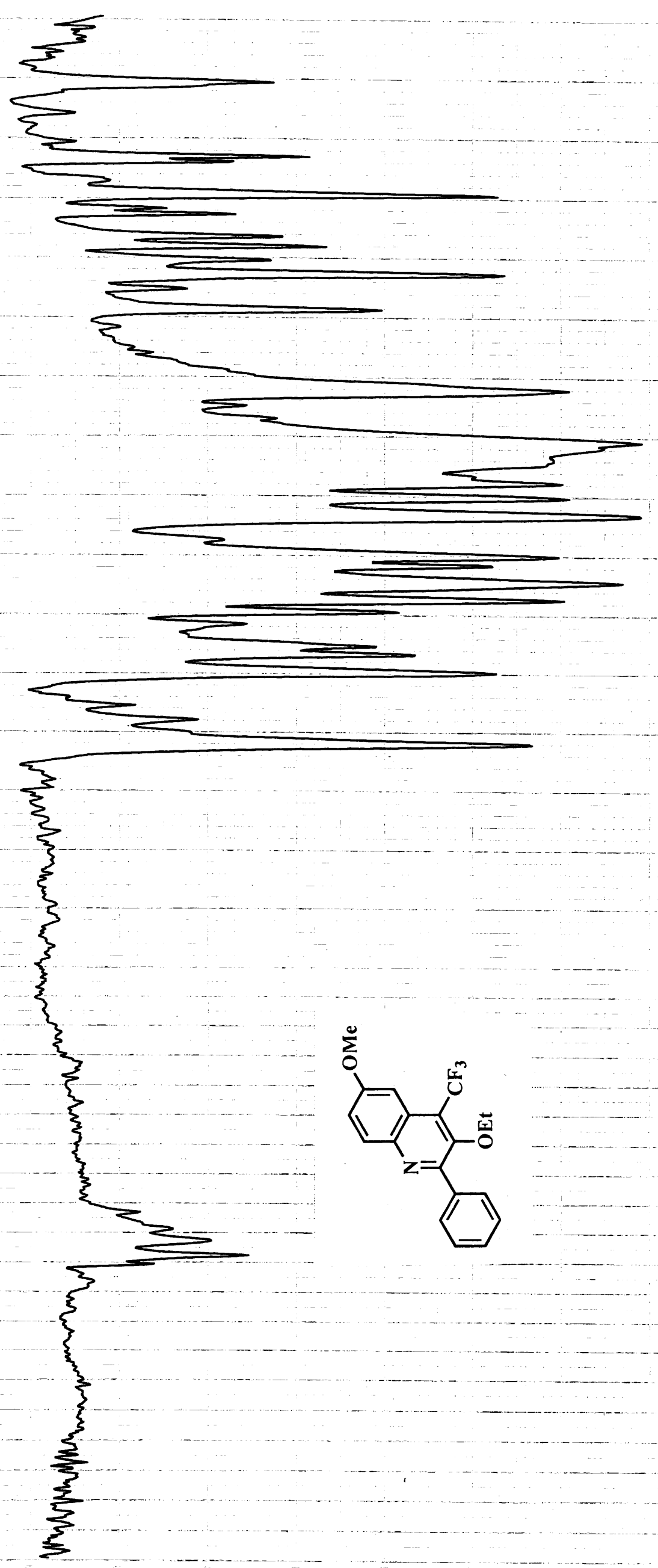


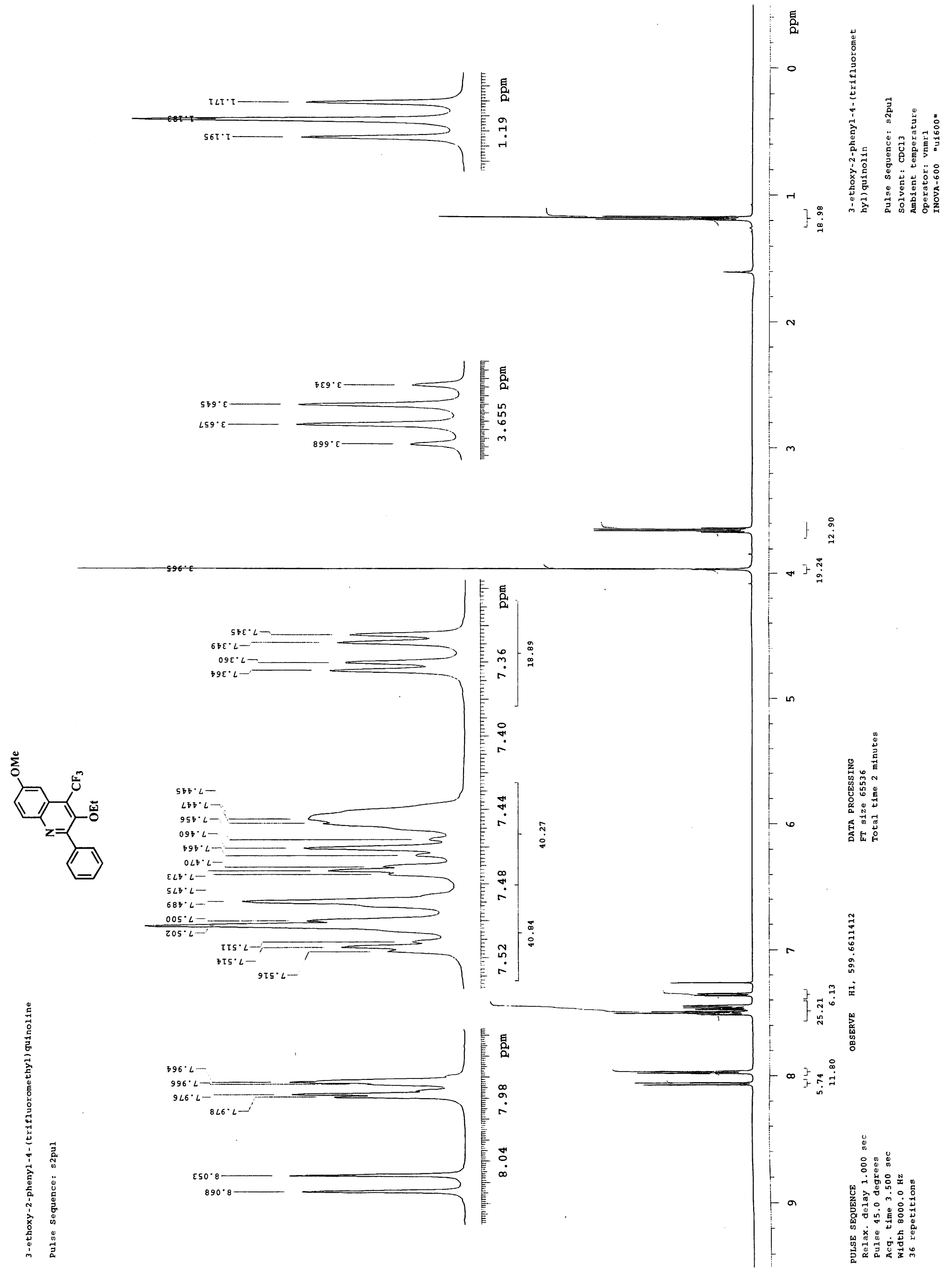




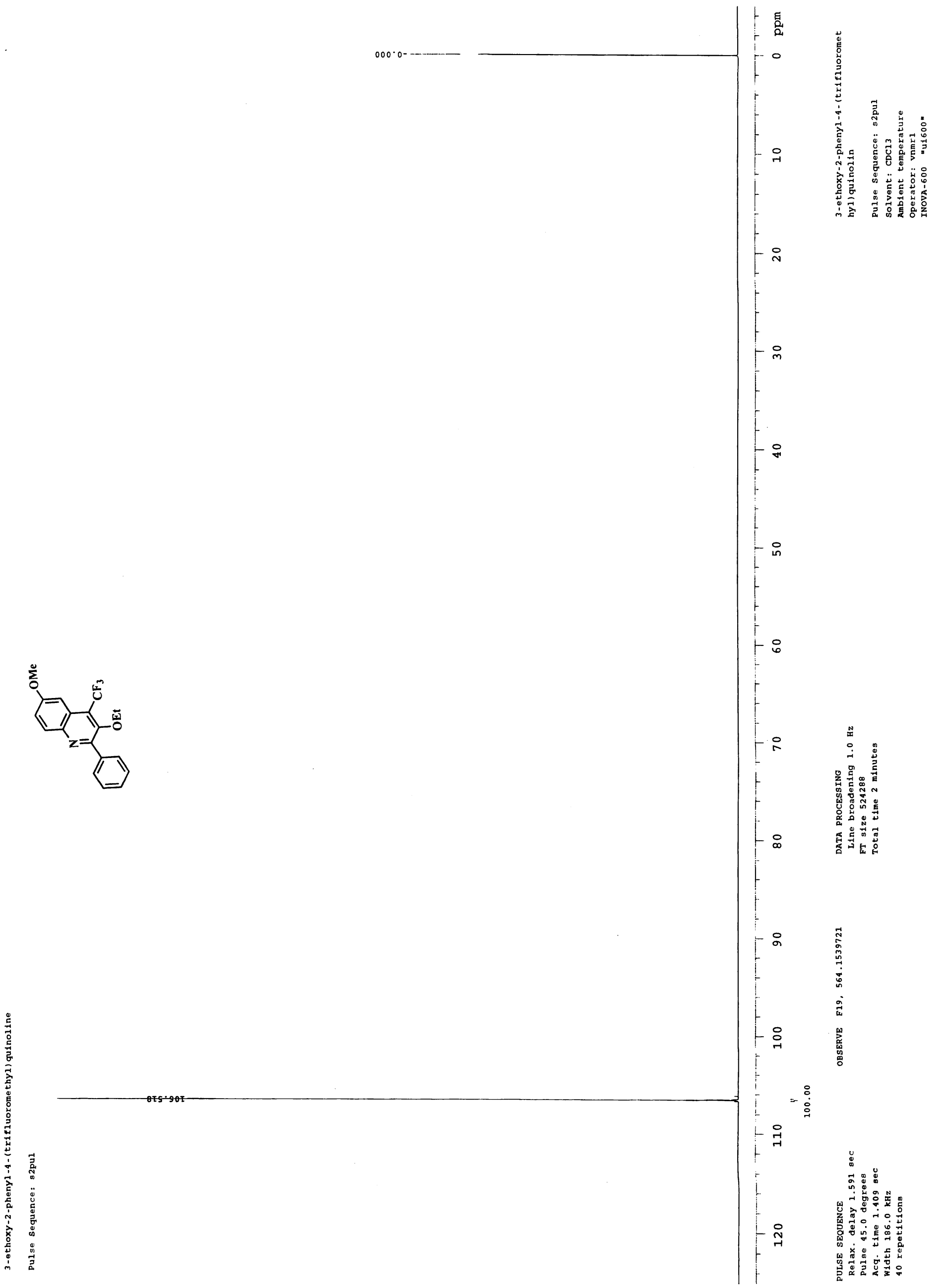




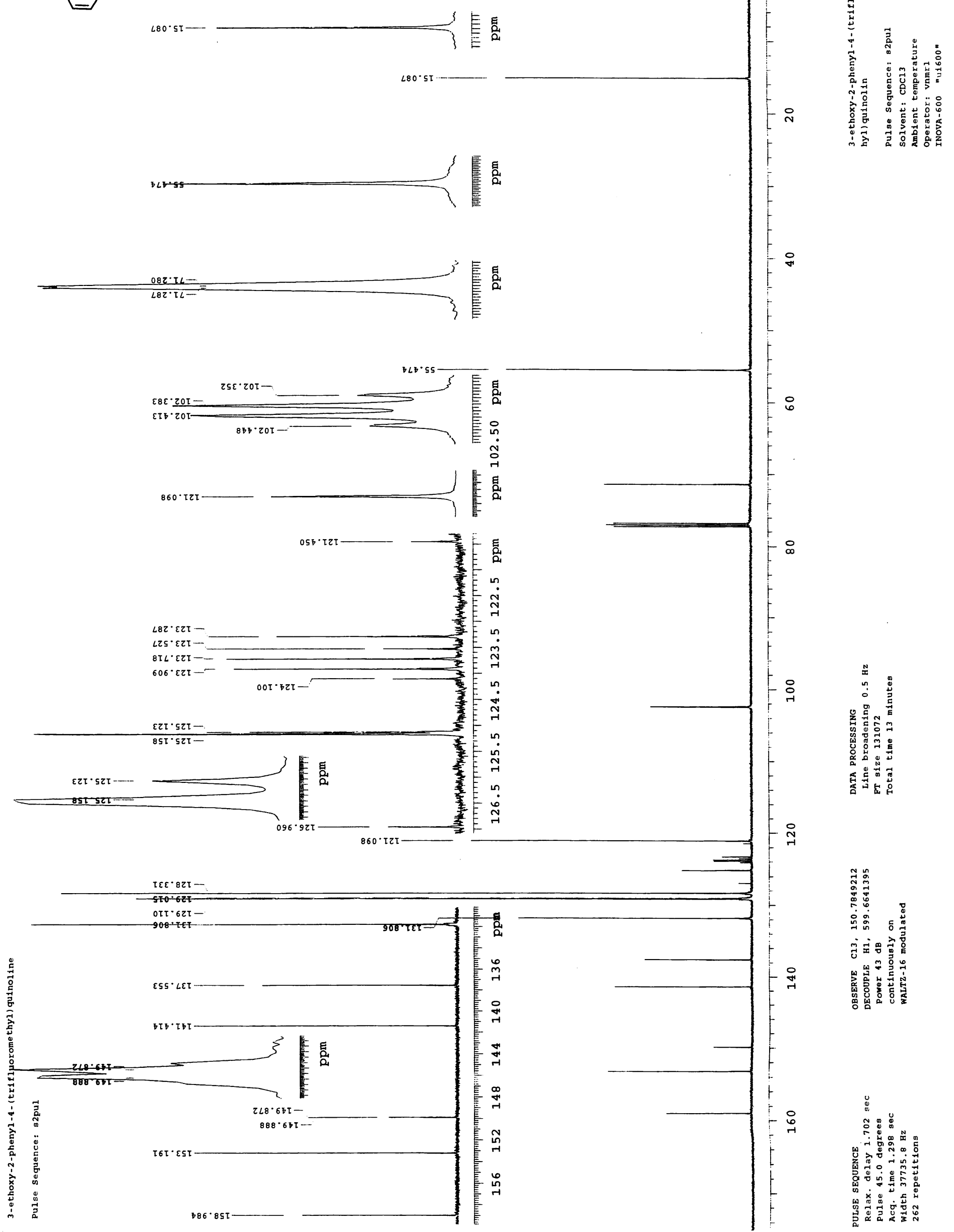




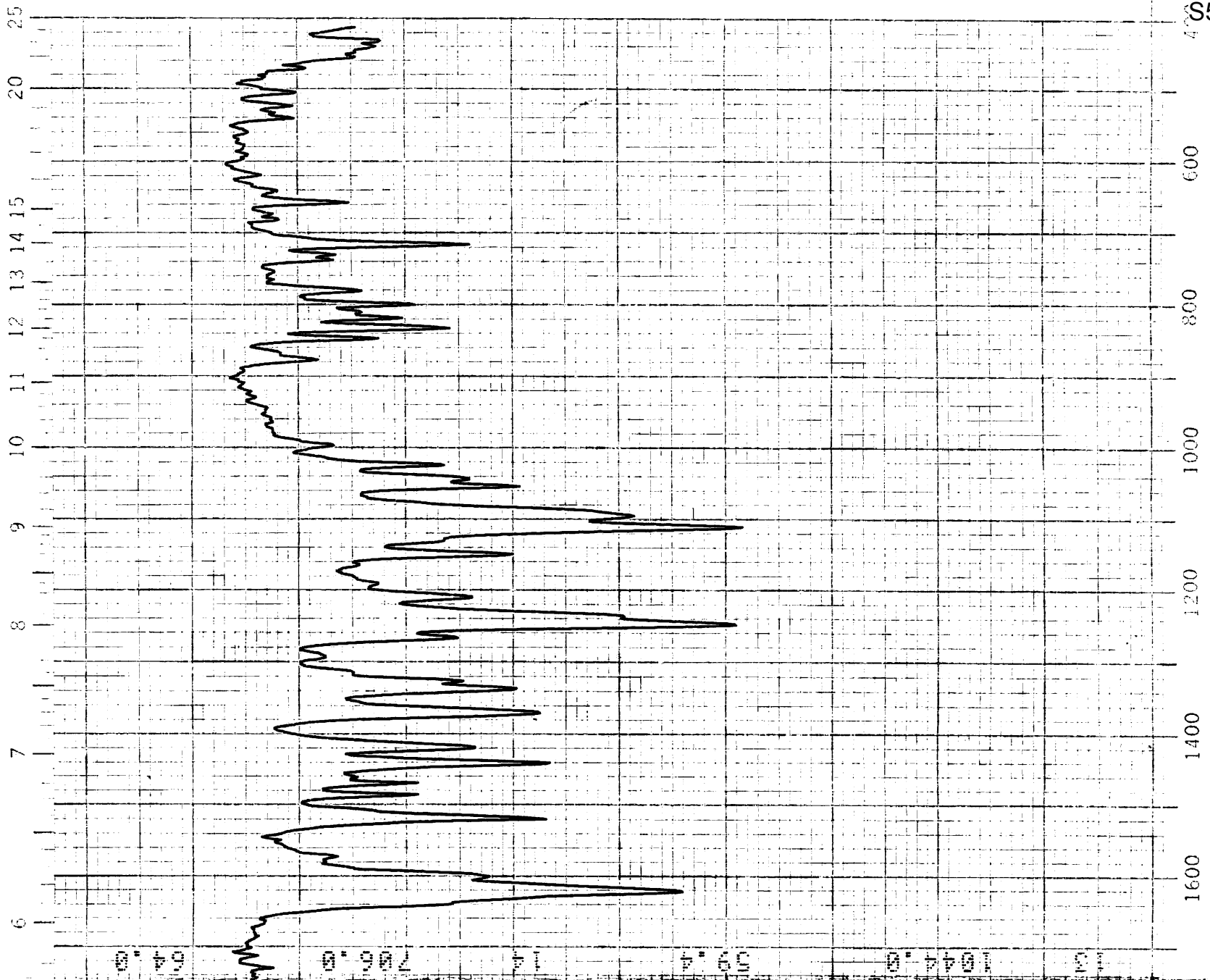

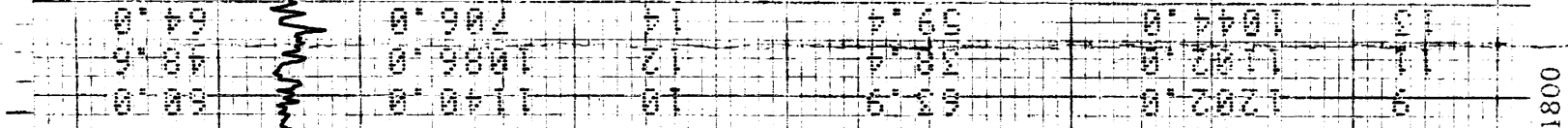

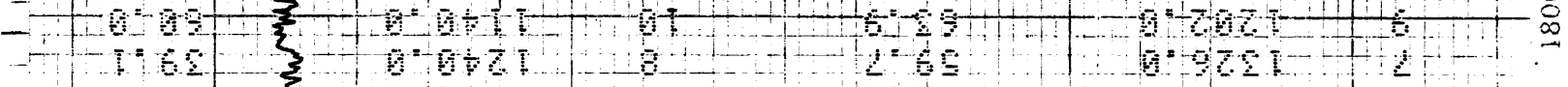

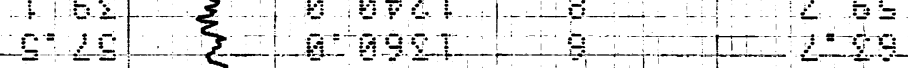

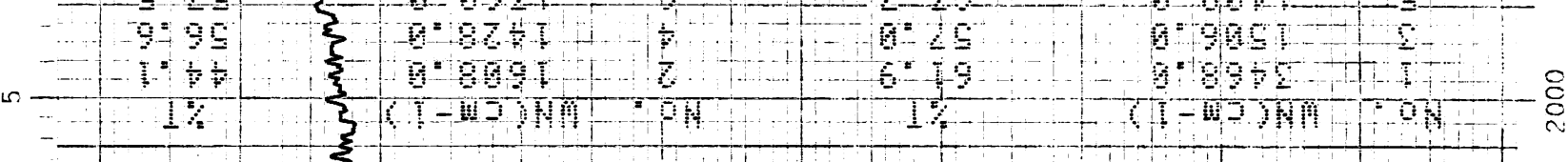

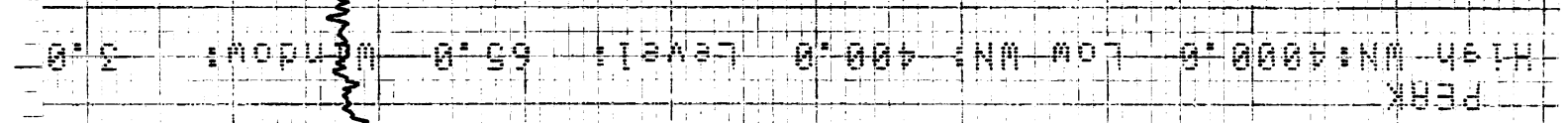
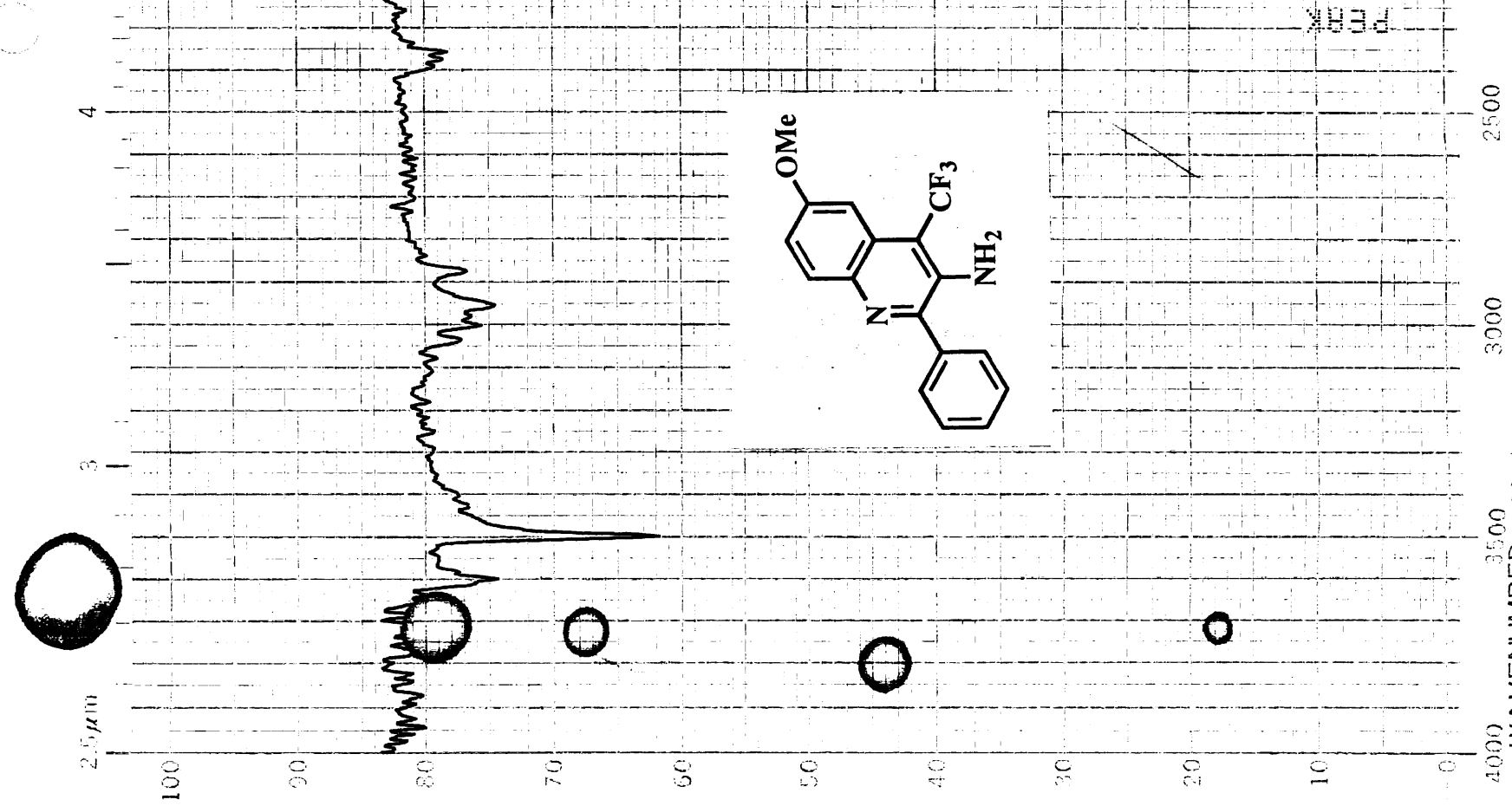


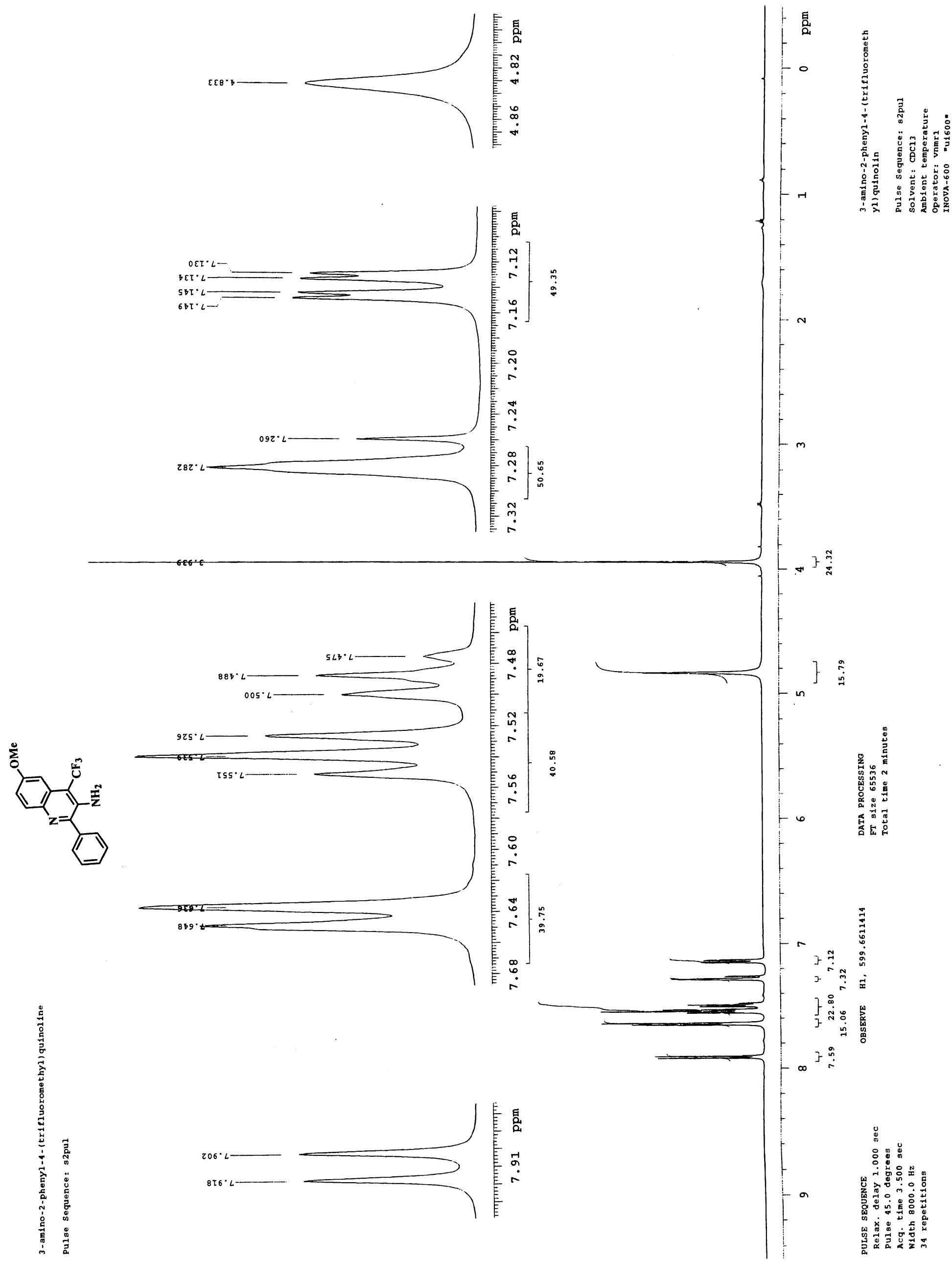




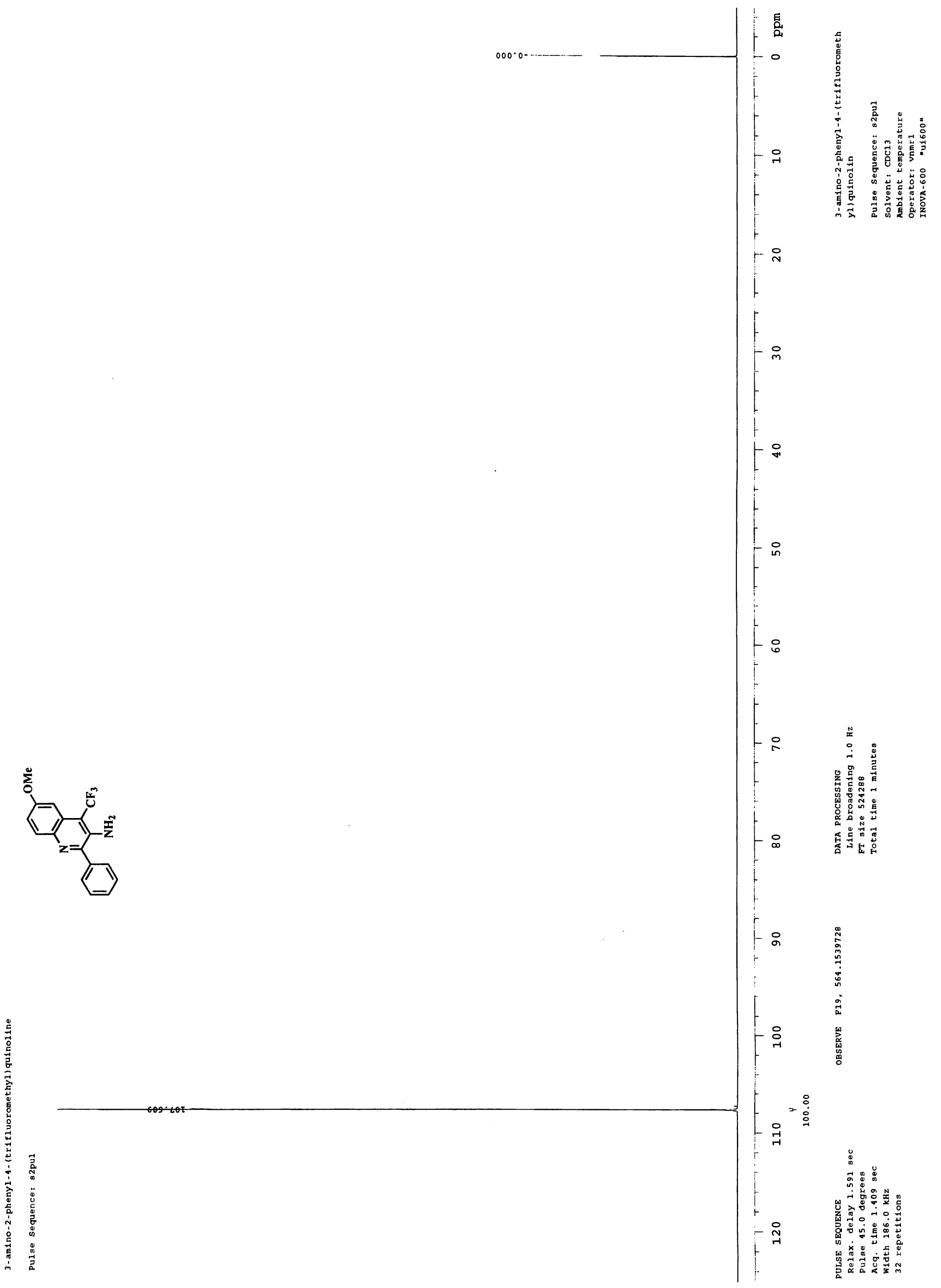




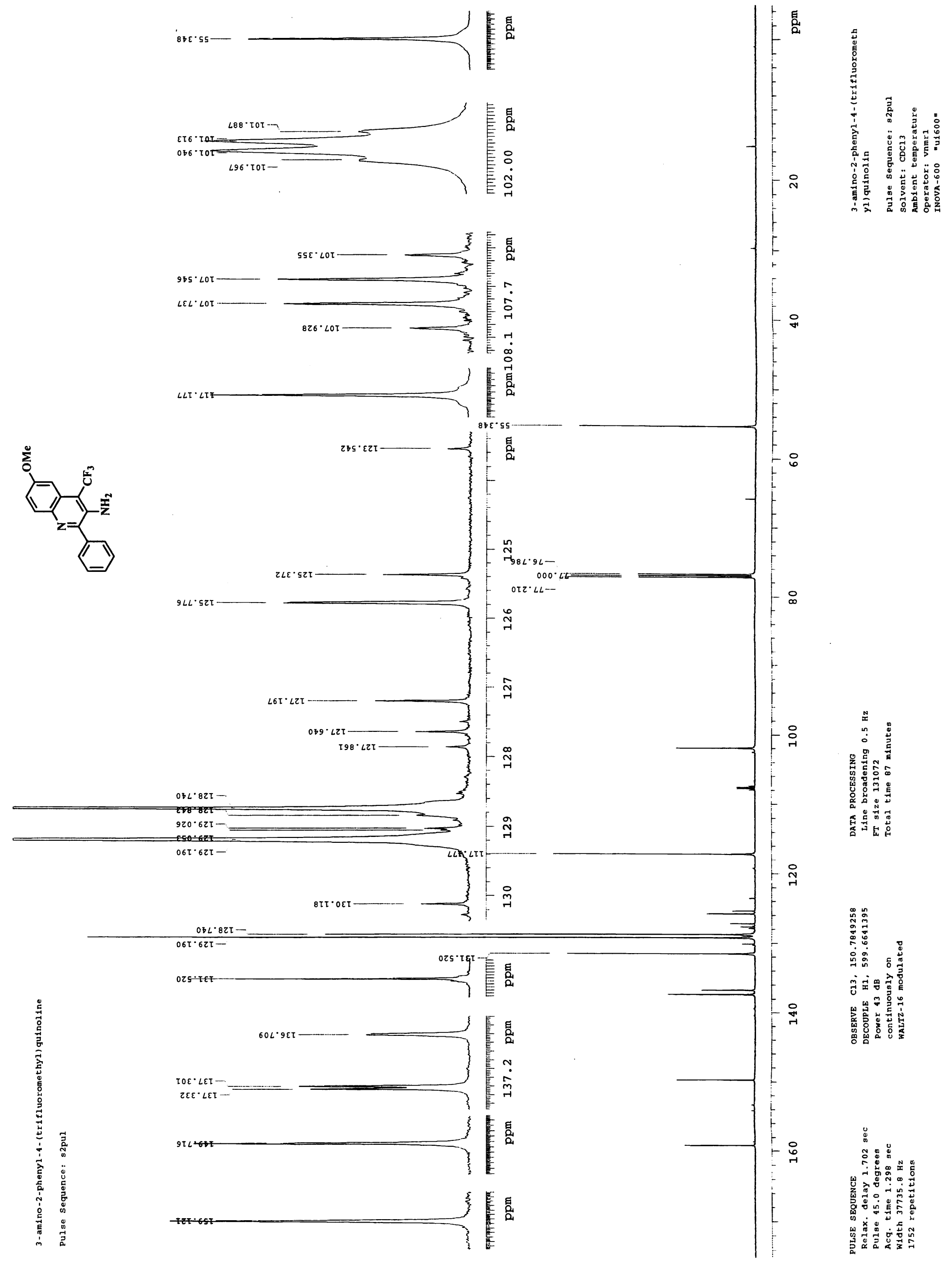



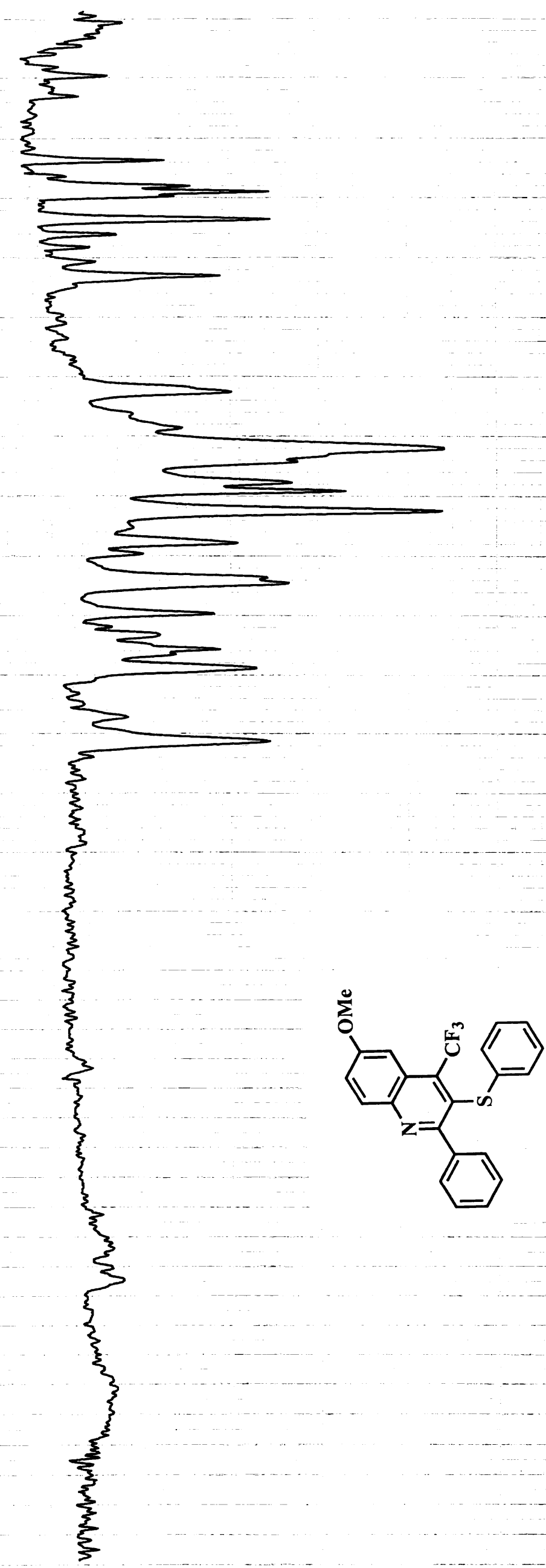

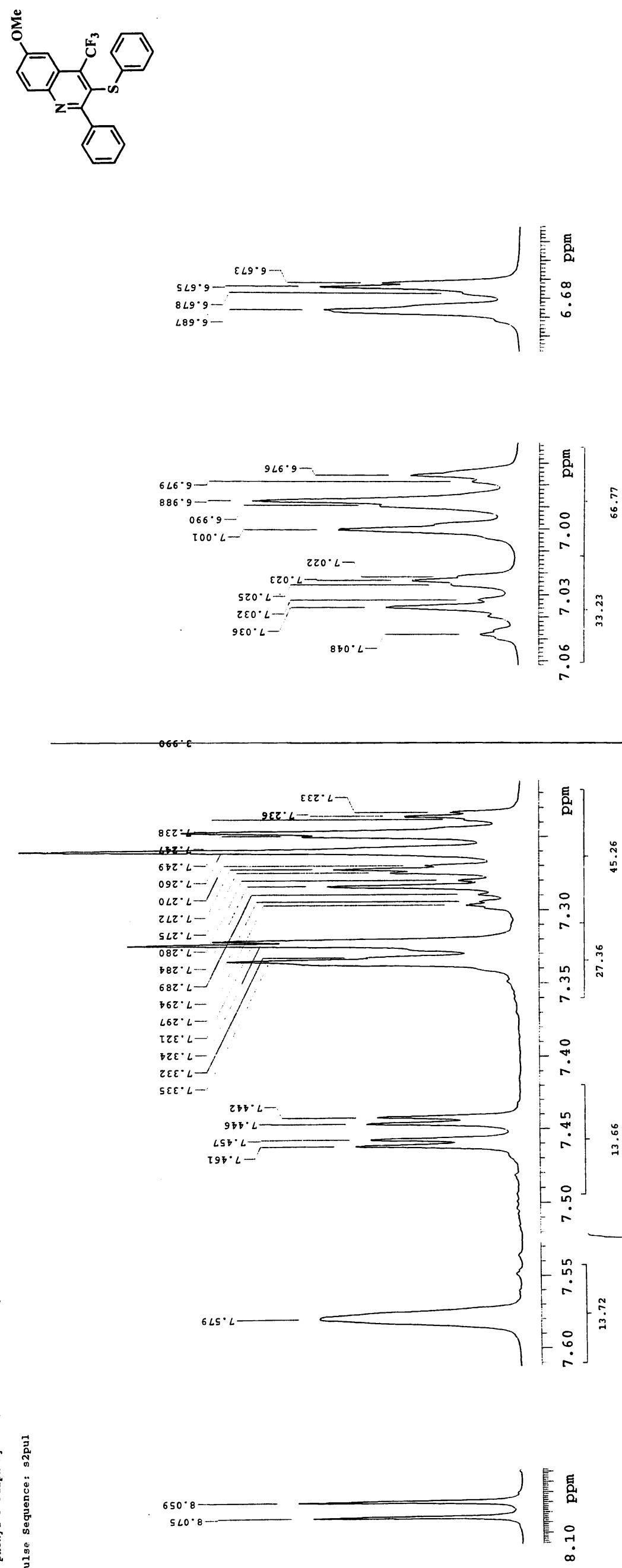


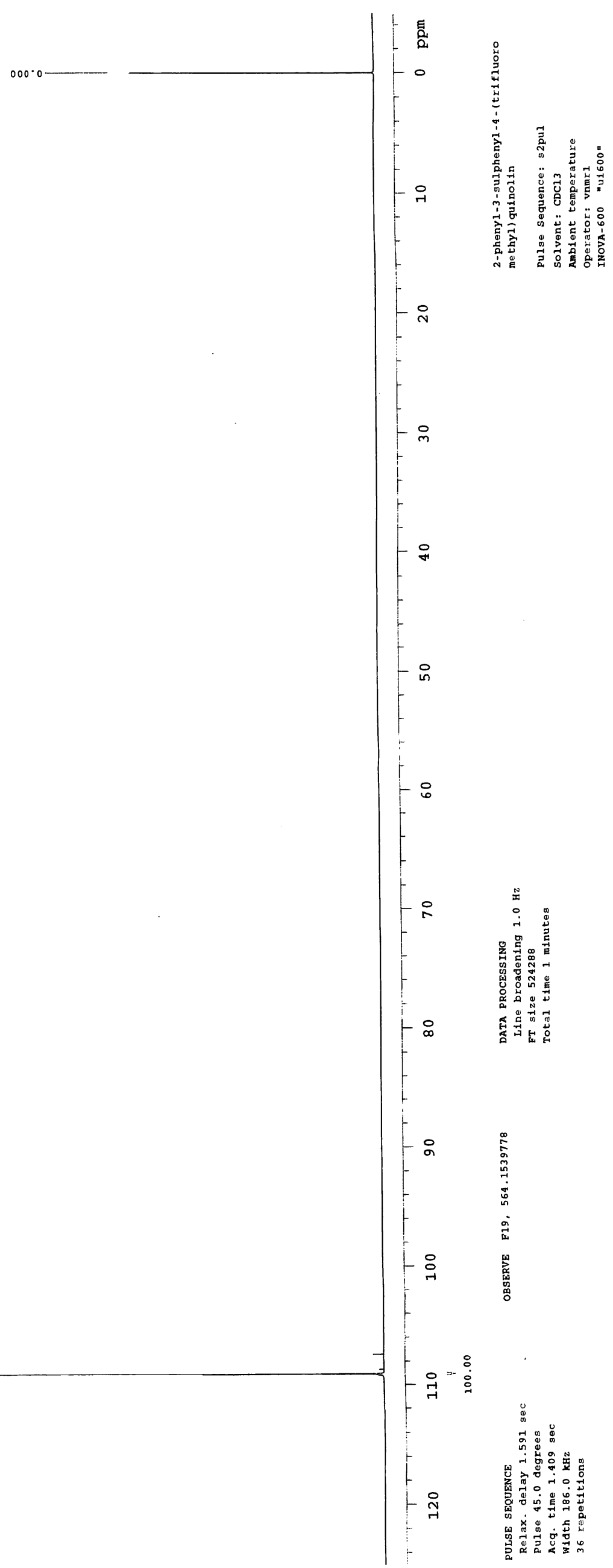


(1)
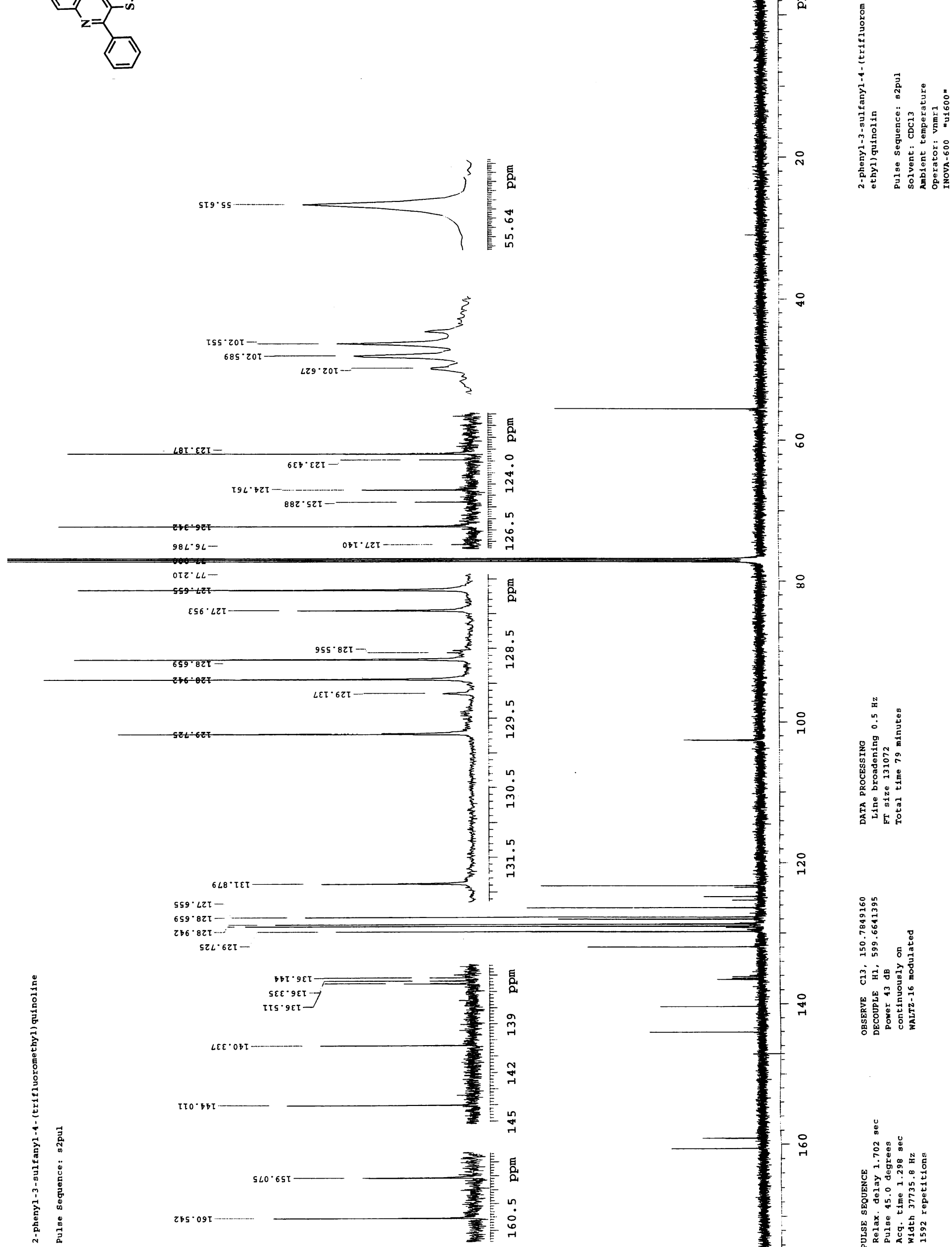

$5 Z L \cdot 6 Z \tau-$
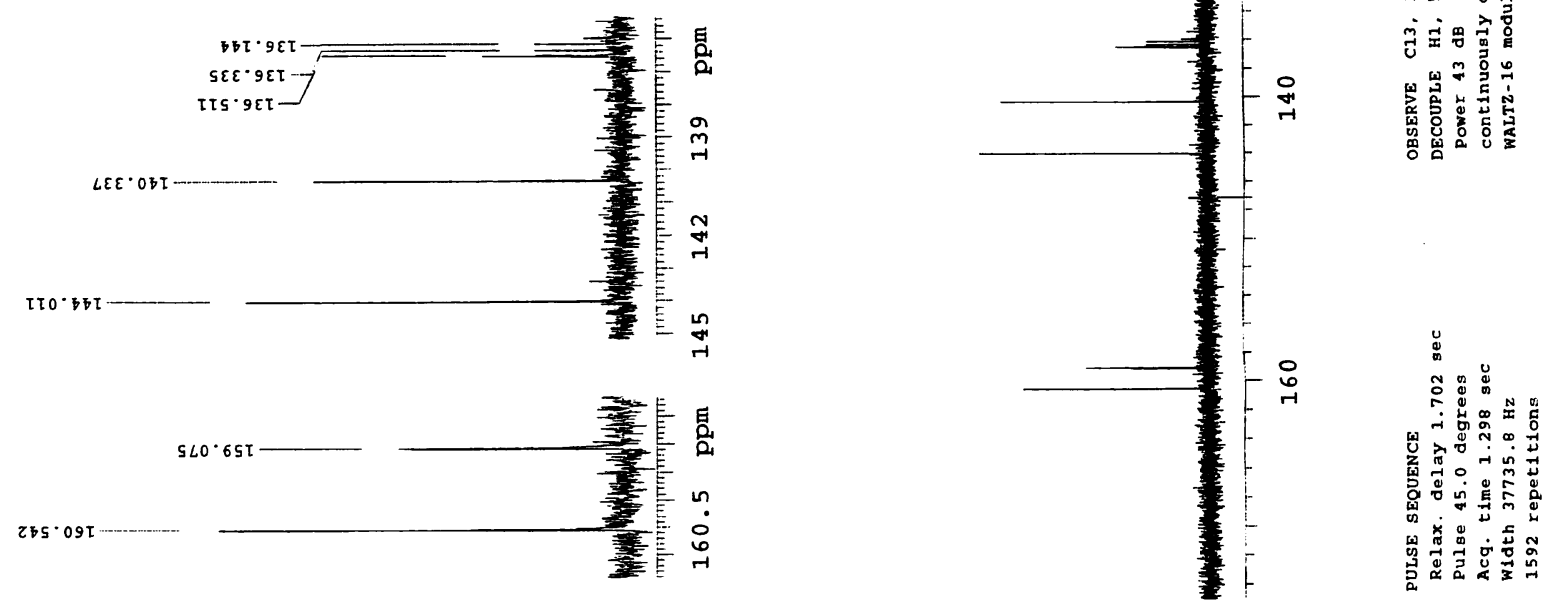

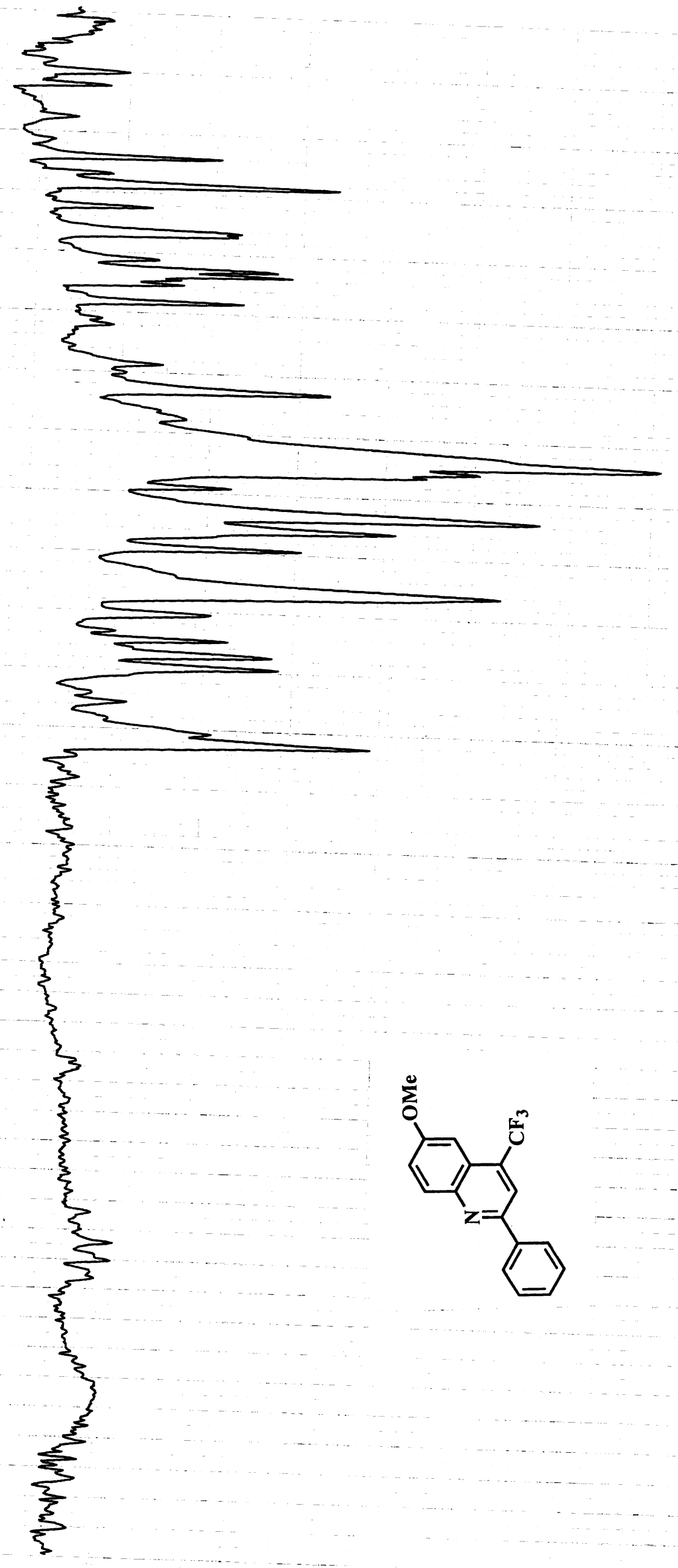


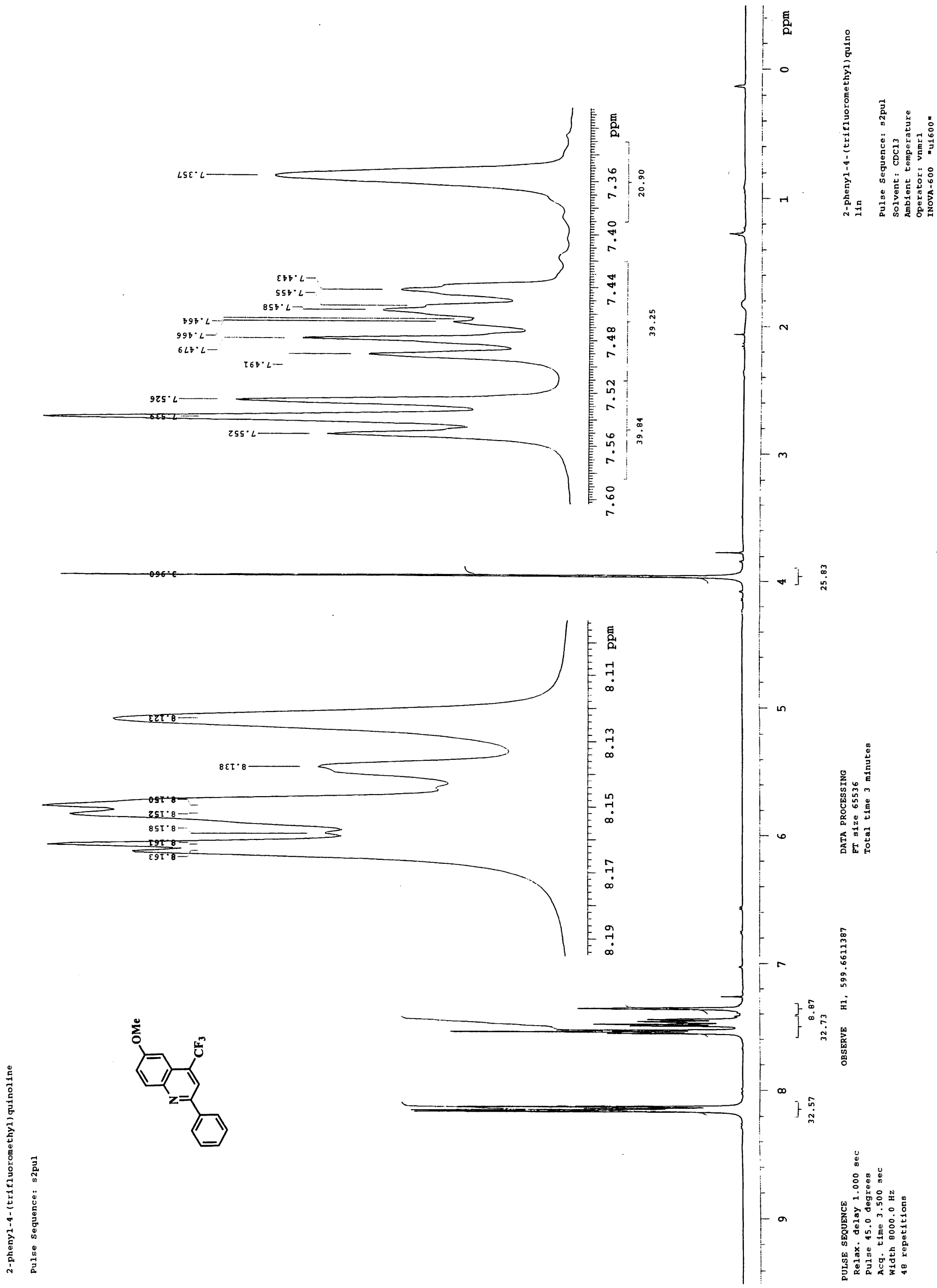


$9 g$

S65

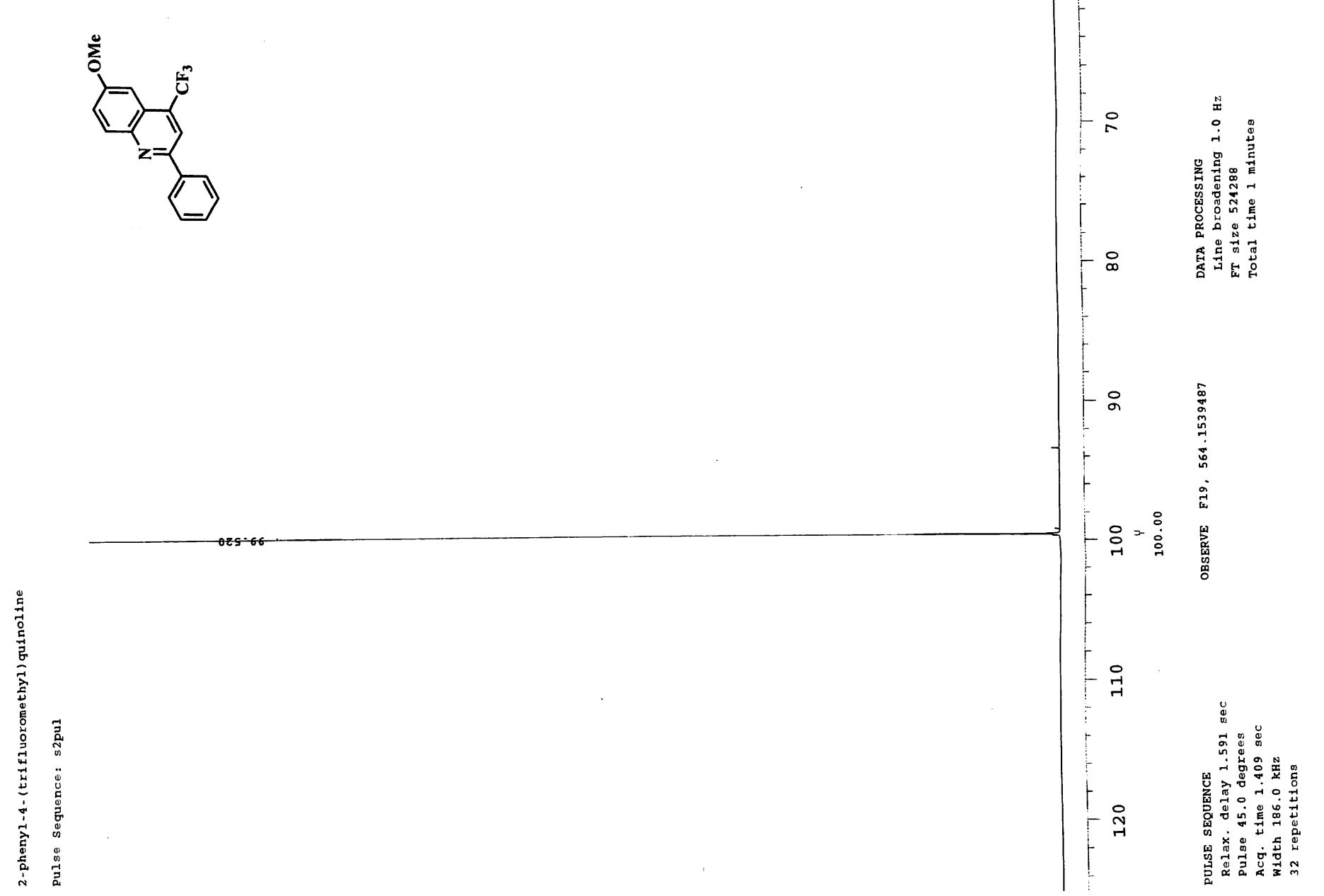


(2)
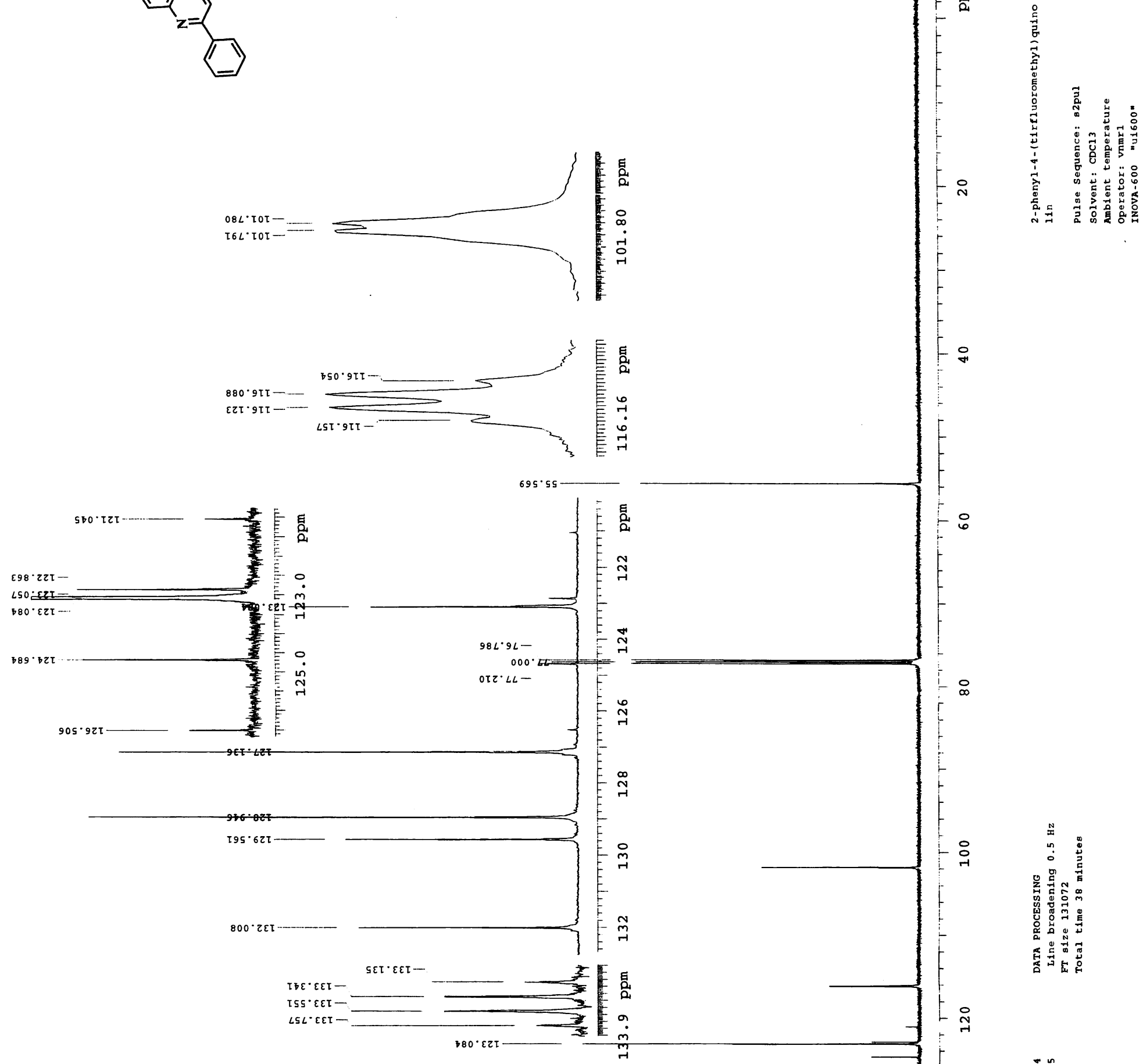

กิ

$\infty$

$\underset{7}{\sim}$

9ET. LZI -

โ95.62น-

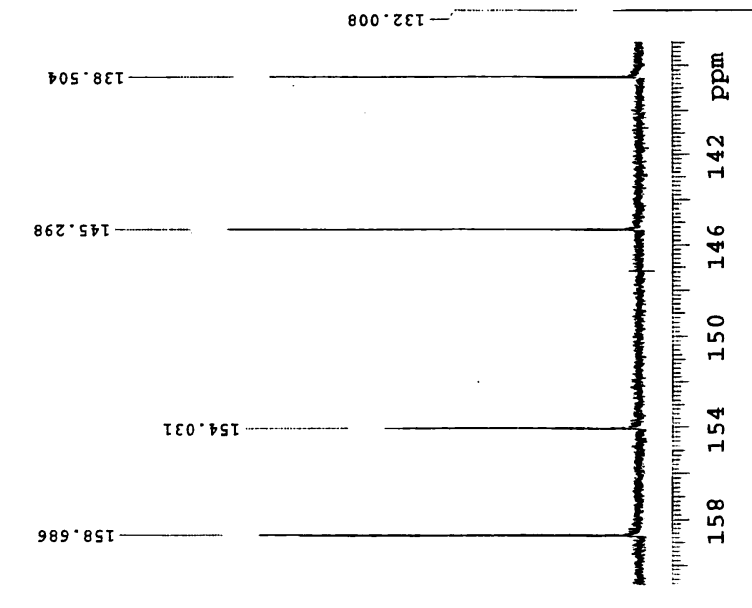

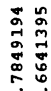

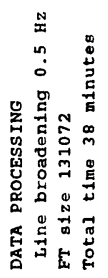

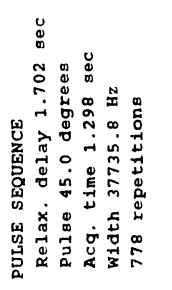



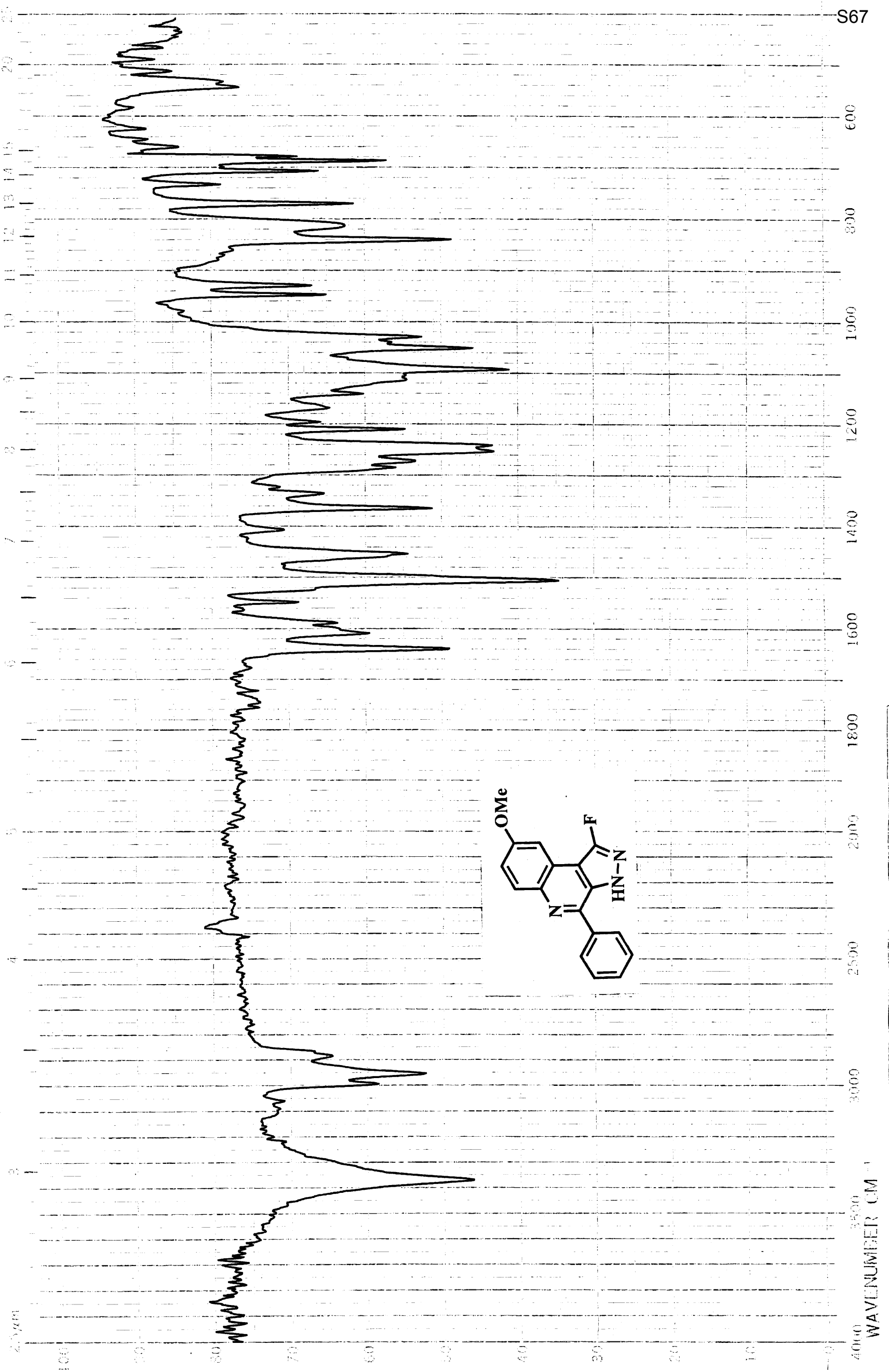


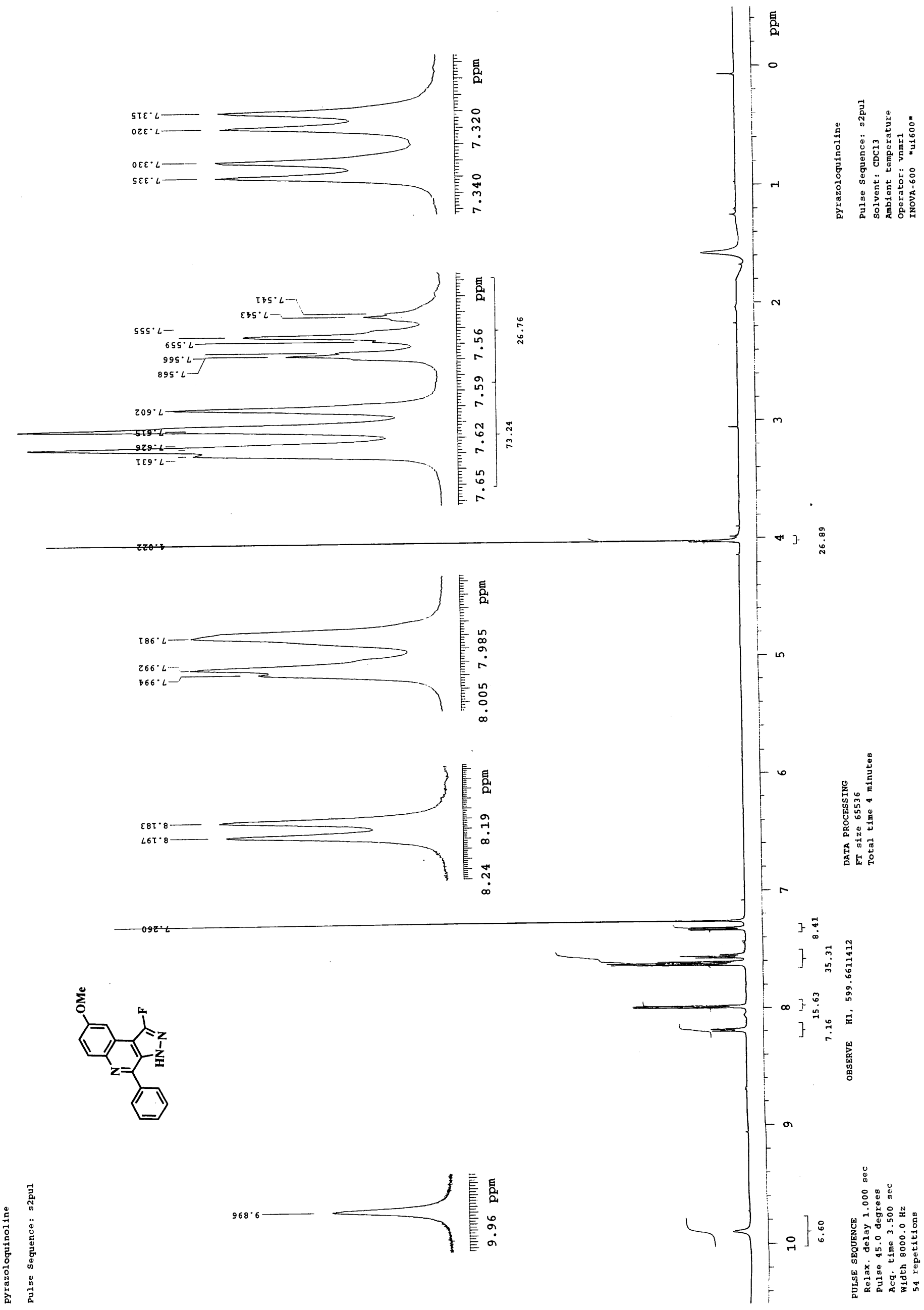




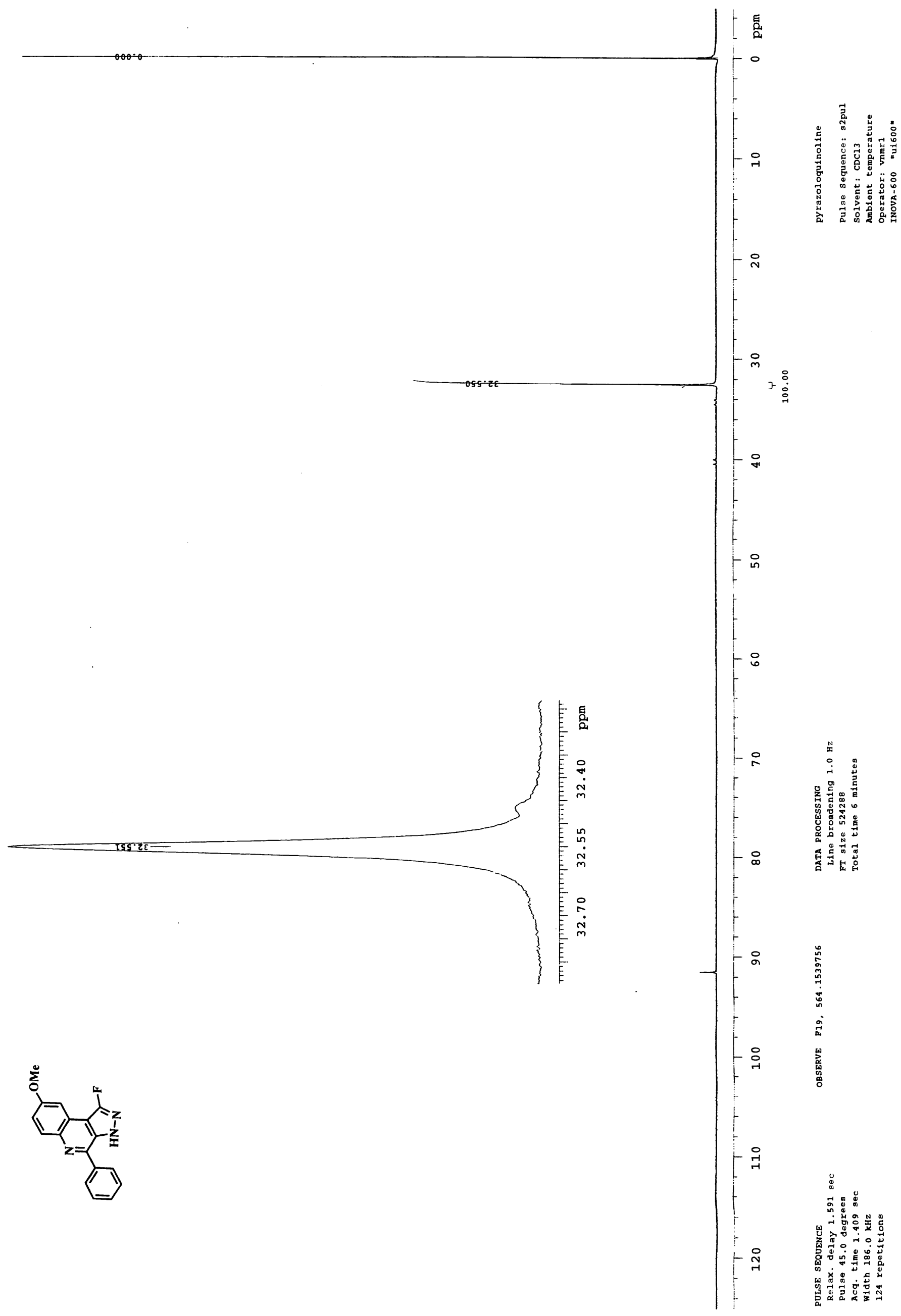




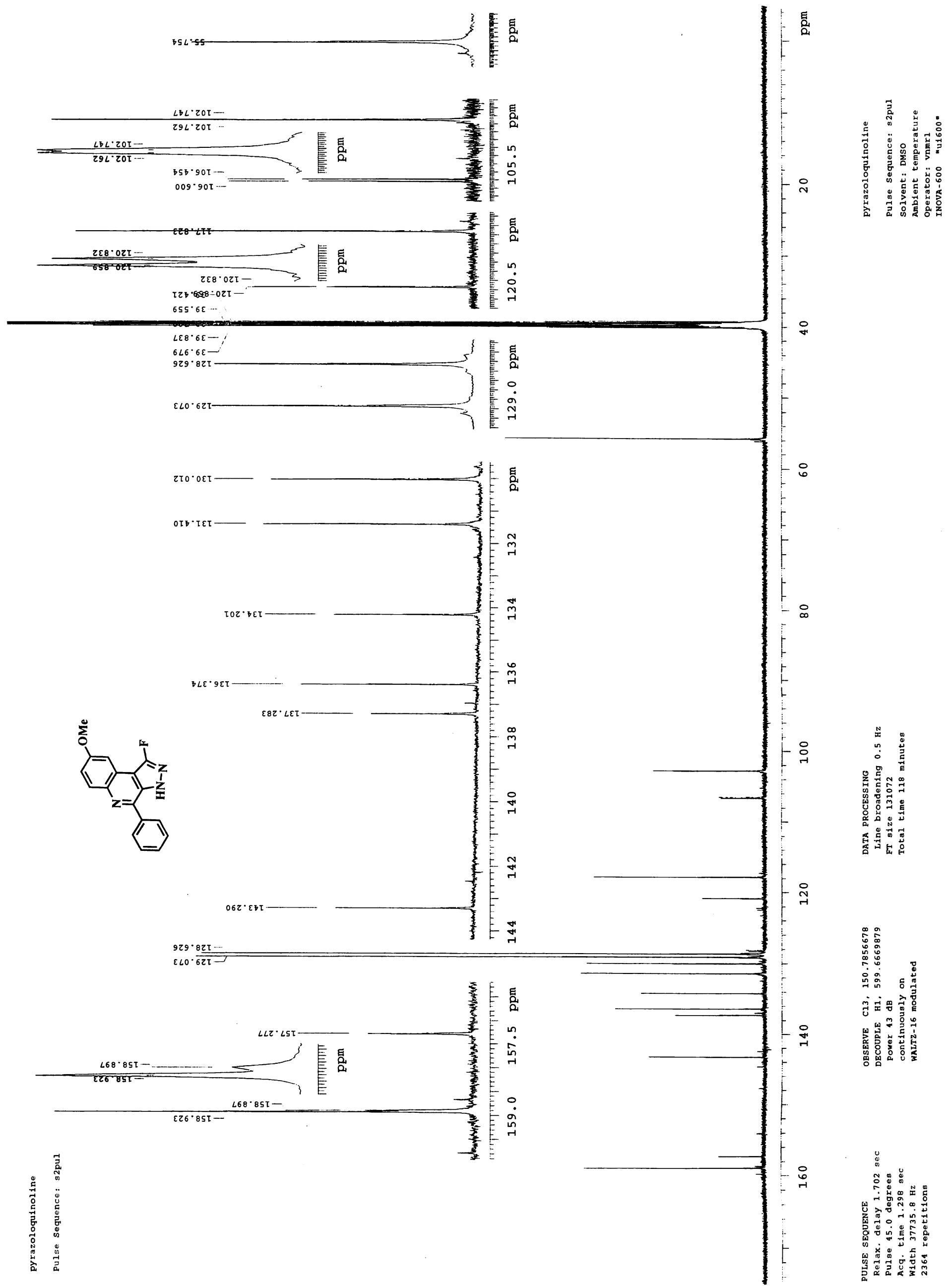




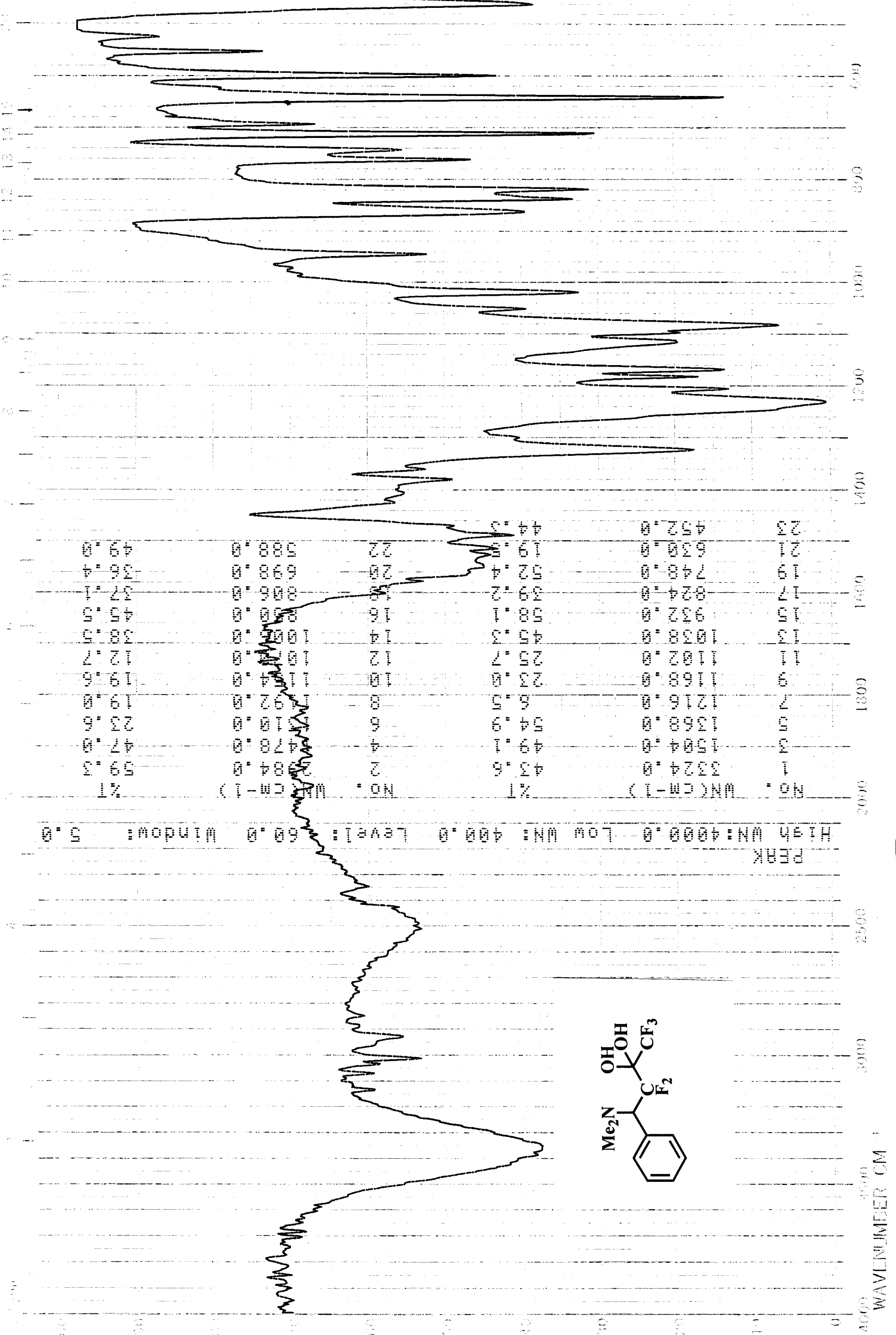


[(CD3)2C=0]

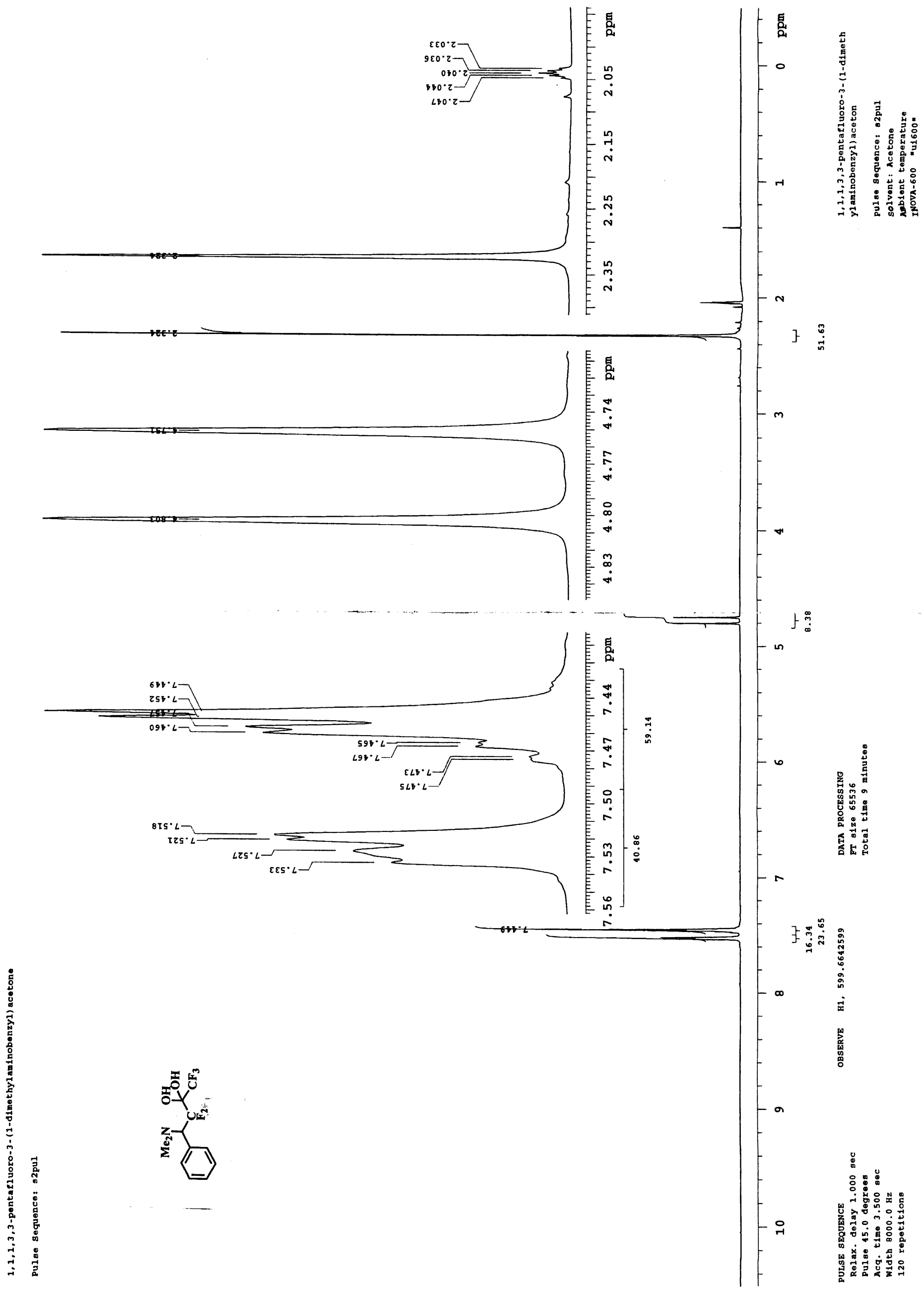


[(CD3)2C=0]

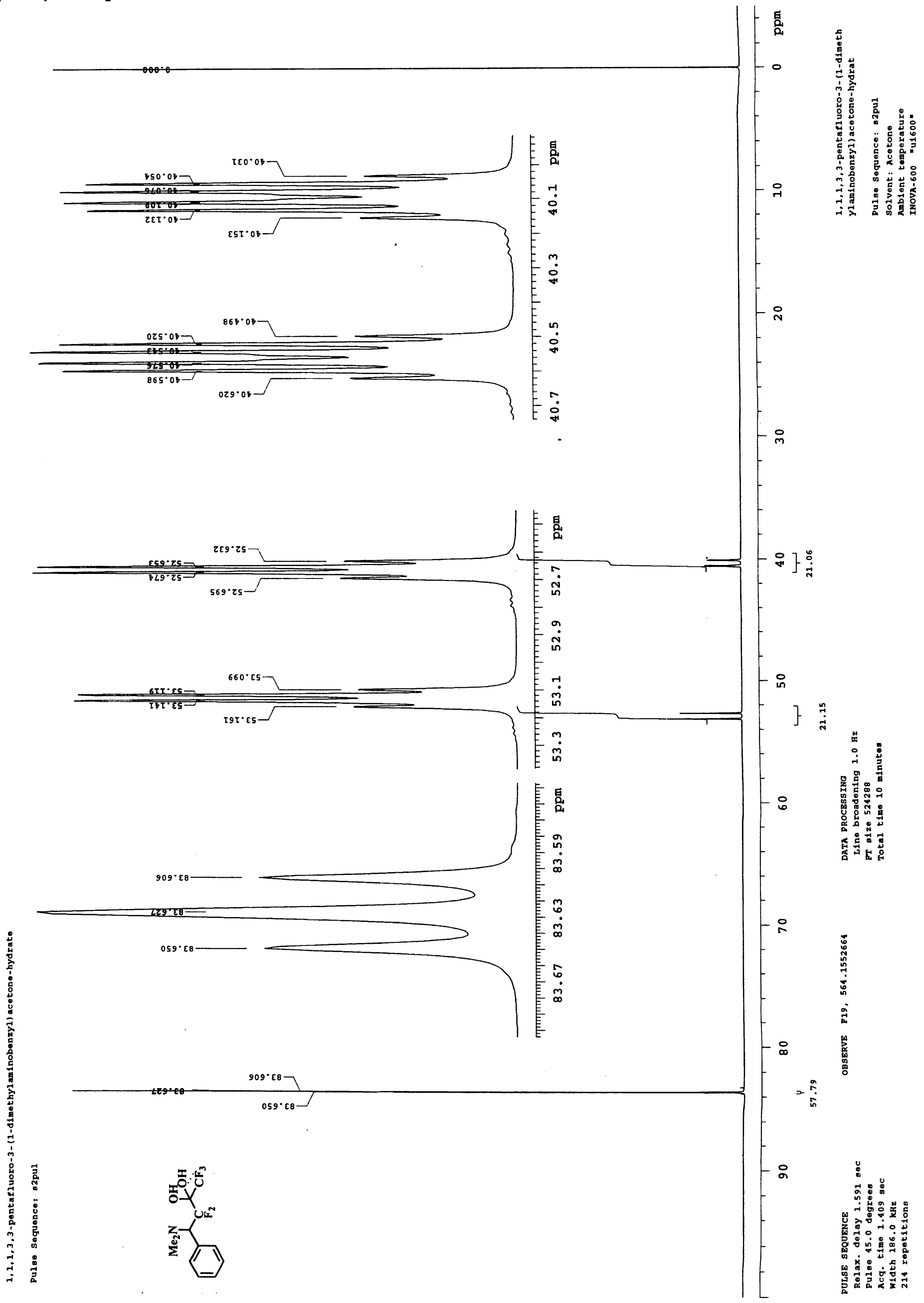


[(CD3)2C=0]

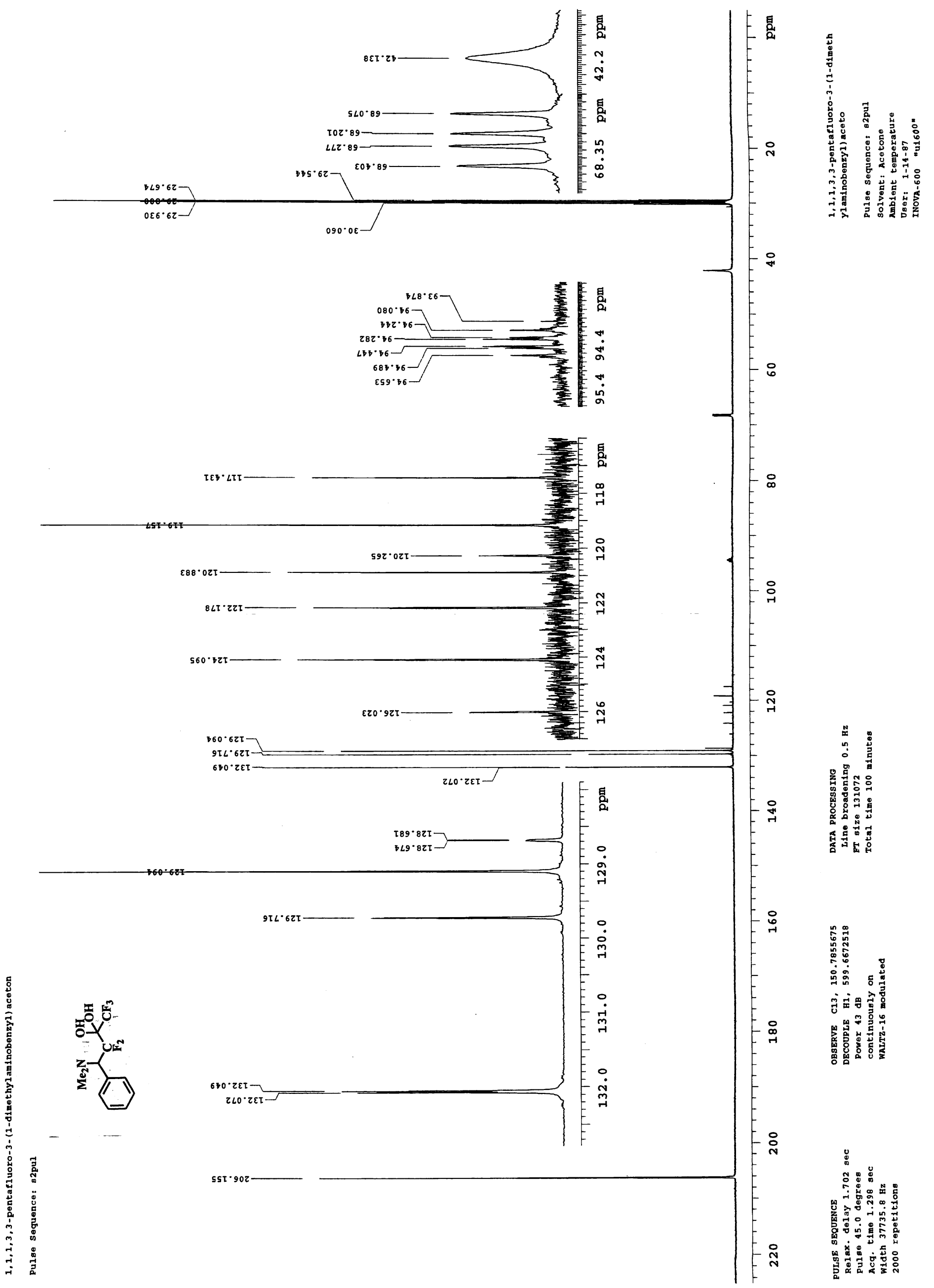


(CDCl3)

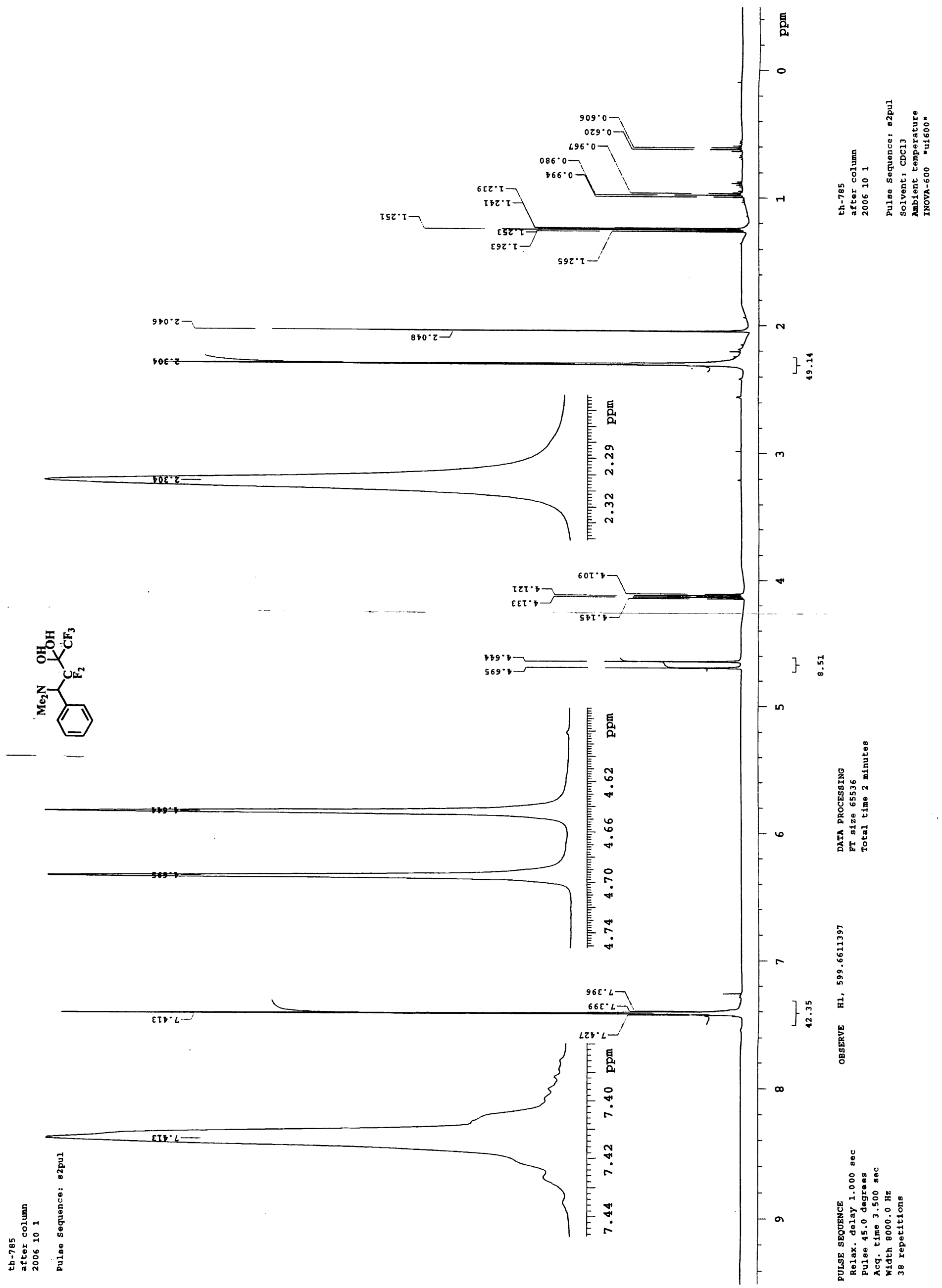


(CDCl3)

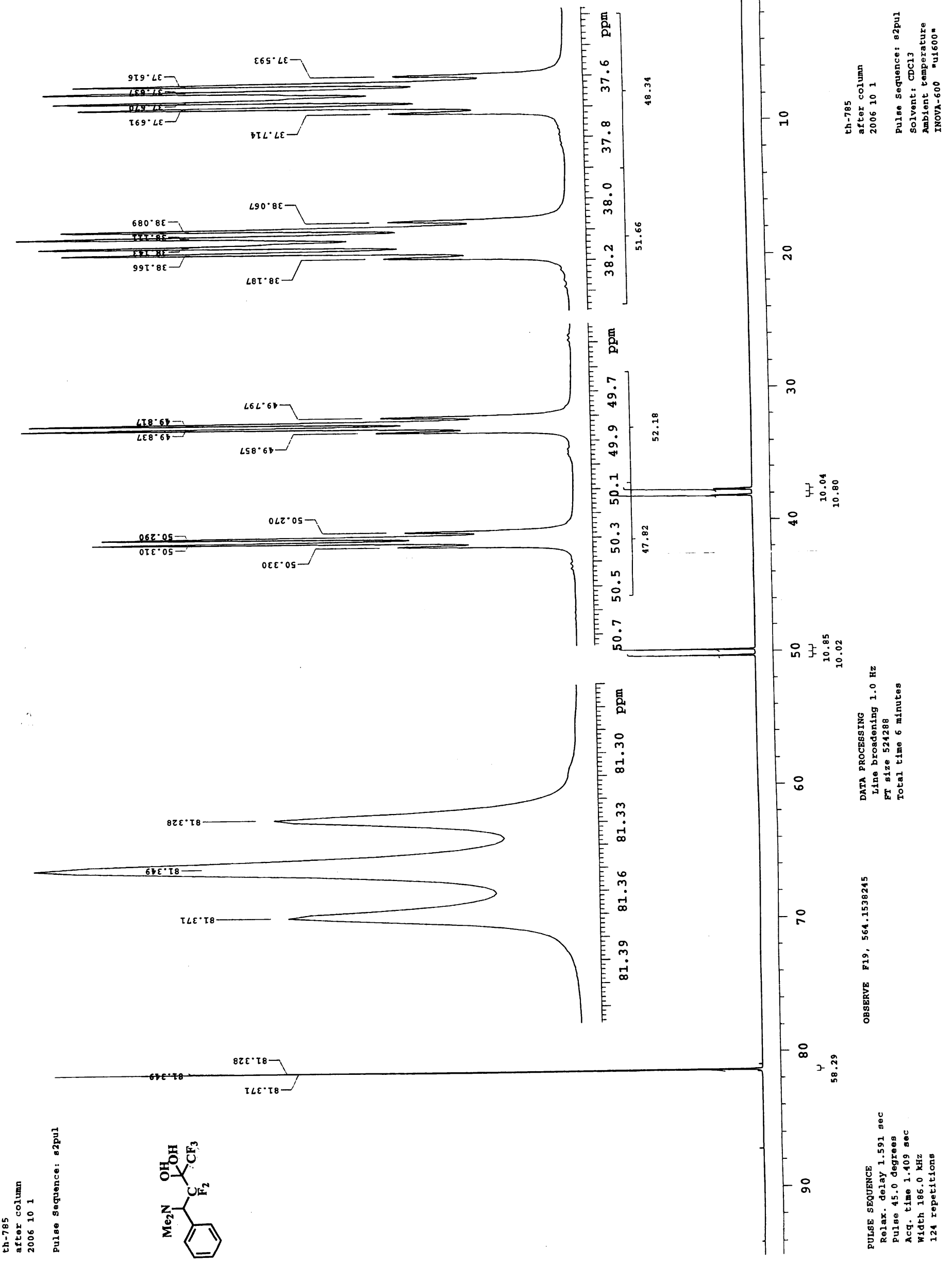




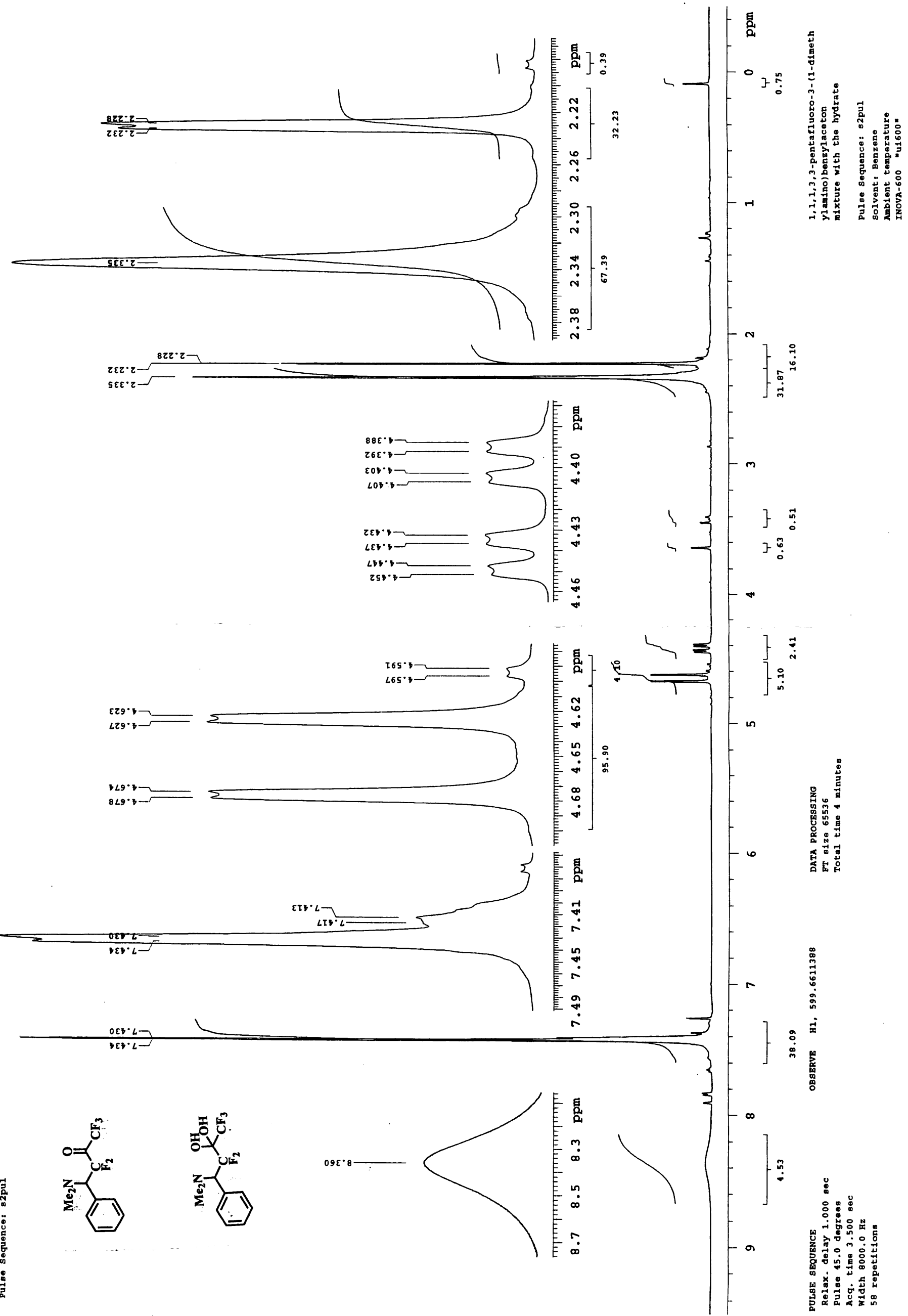




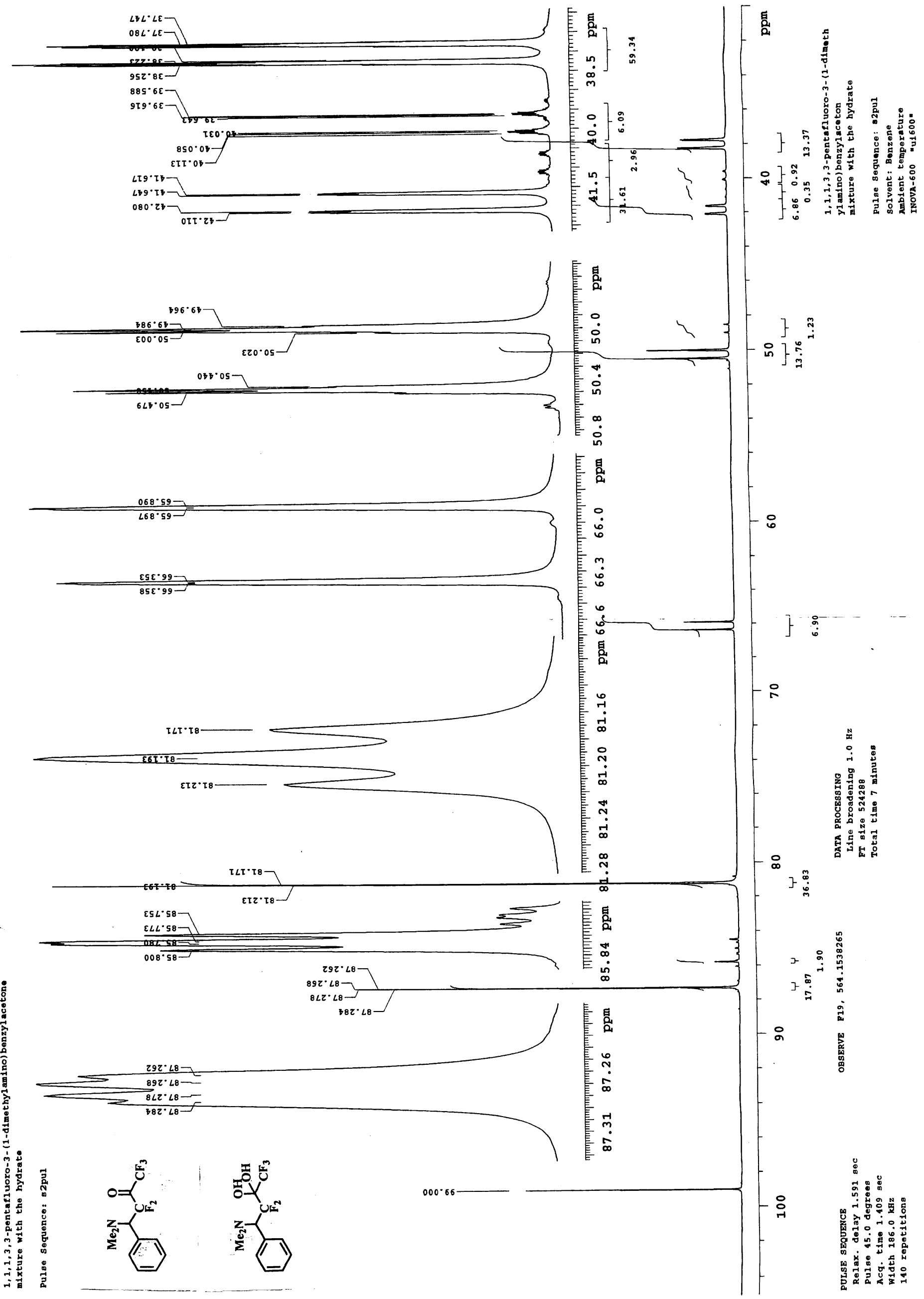

